\title{
DETAILED NUMERICAL STUDY OF SOOT SURFACE GROWTH AND OXIDATION IN LAMINAR DIFFUSION FLAMES
}

\author{
by \\ Ali Khosousi \\ Bachelor of Science, Sharif University of Technology, Tehran, Iran, 2007 \\ Master of Science, Sharif University of Technology, Tehran, Iran, 2009 \\ A dissertation presented to \\ Ryerson University \\ in partial fulfillment of the \\ requirements for the degree of \\ DOCTOR OF PHILOSOPHY \\ in the Program of \\ Mechanical and Industrial Engineering
}

Toronto, Ontario, Canada, 2016

(C)Ali Khosousi 2016 


\section{AUTHOR'S DECLARATION}

I hereby declare that I am the sole author of this dissertation. This is a true copy of the dissertation, including any required final revisions, as accepted by my examiners.

I authorize Ryerson University to lend this dissertation to other institutions or individuals for the purpose of scholarly research.

I further authorize Ryerson University to reproduce this dissertation by photocopying or by other means, in total or in part, at the request of other institutions or individuals for the purpose of scholarly research.

I understand that my dissertation may be made electronically available to the public. 


\begin{abstract}
DETAILED NUMERICAL STUDY OF SOOT SURFACE GROWTH AND OXIDATION IN LAMINAR DIFFUSION FLAMES
\end{abstract}

Doctor of Philosophy, 2016

Ali Khosousi

Mechanical and Industrial Engineering

Ryerson University

The focus of the present study is to obtain detailed knowledge of the soot formation and oxidation processes in laminar diffusion flames. The present work studies the effects of various flame properties on soot growth and oxidation, and how they affect a flame's sooting behaviour.

Numerically modelling of soot formation in laminar coflow diffusion flames of vaporized gasoline/ethanol blends at atmospheric pressure is performed. The numerical results are compared with experimental data to gain improved understanding of ethanol addition to gasoline on soot formation. Four gasoline/ethanol blends are investigated to quantify how soot loading varies with the amount of ethanol blending in the fuel. The results of experimental and numerical modelling agree relatively well in terms of the levels of soot volume fraction. Both results show a decrease in soot loading as more ethanol is added in the fuel stream.

The work continues by numerically studying the oxidation of soot in laminar ethylene/air coflow diffusion flames. A new model for soot oxidation, a complex process in numerical soot modelling, is developed based on the observation that soot ageing reduces surface reactivity. 
Using this new model, it is possible to capture the correct behaviour of both smoking and nonsmoking flames in various flame configurations. Along with a detailed soot sectional model, the new model predicts the correct soot volume fractions, smoke emission characteristics, and primary particle diameters for different flames without any variation in model parameters.

The work extends to study soot surface reactivity in the growth and oxidation regions. Laminar ethylene/air and methane/air coflow diffusion flames are numerically studied to develop a unique soot surface reactivity model. A newly developed surface character model simultaneously accounts for soot surface reactivity in surface growth and oxidation by considering soot ageing and its effects on the particle surface. The new model, which eliminates tuning of one modelling parameter, reconciles the quantification of the evolving soot surface character for both growth and oxidation. The model is shown to be uniquely capable of predicting soot concentrations and smoke emissions within experimental uncertainty in a wide range of laminar diffusion sooting flames. 


\section{Acknowledgements}

I would like to express my deepest gratitude to my supervisor, Professor Seth B. Dworkin, who has been extremely helpful throughout my Ph.D. studies. As an active member of Combustion Institute, Professor Dworkin provided me with several opportunities to participate in national and international conferences to present my work, from which I benefitted enormously. I am grateful to him not just for introducing me to the field of Combustion, but for his constant support, care, and sympathy when was needed most. Professor Dworkin has always encouraged me to take up teaching activities by introducing me to various professors to be their teaching assistant. I express my sincere appreciation of all he has done.

I would like to acknowledge members of my dissertation Committee, especially Professor Jacob Friedman and Professor David Naylor for their constructive suggestions in my candidacy exam and Ph.D. preliminary defence. I would also like to acknowledge the external committee members of my defence, Prof. Jeffrey Yokota from the Department of Aerospace Engineering at Ryerson University and Dr. Nabiha Chaumeix at Centre National de la Recherche Scientique (CNRS), France.

I would like to thank those with whom I had the fortune to collaborate during my Ph.D. research, especially Armin Veshkini and Nick Eaves, at the University of Toronto. I also had the

opportunity to work with Dr. Fengshan Liu from National Research Council of Canada. I learned immensely from Dr. Fengshan Liu during our collaboration, and I would like to express my acknowledgement here. 
I would like to thank Dr. Nadezhda Slavinskaya and Prof. Uwe Riedel of the German Aerospace Center (DLR) for providing the chemical reaction mechanism, thermodynamic data, and transport data for ethylene combustion and PAH formation.

Computations were performed on the Ryerson University Sandybridge (Sandy) computing cluster and the GPC supercomputer at the SciNet HPC Consortium. SciNet is funded by: the Canada Foundation for Innovation under the auspices of Compute Canada; the Government of Ontario; Ontario Research Fund-Research Excellence; and the University of Toronto. Further, I would like to acknowledge The Natural Sciences and Engineering Research Council of Canada (NSERC) for financial support. 


\section{Dedication}

I would like to dedicate my dissertation to my lovely wife, Mrs. Maryam L Kassaei, whose constant support and encouragement made this work possible.

I would also like to dedicate this work to my compassionate parents, Gholamreze and Fatemeh, especially my departed father whom I missed every day and will always be in my heart.

My dedications also go to my brother, Amir, and my sister, Azar, for their continual inspiration. 


\section{Table of Contents}

AUTHOR'S DECLARATION .......................................................................................... ii

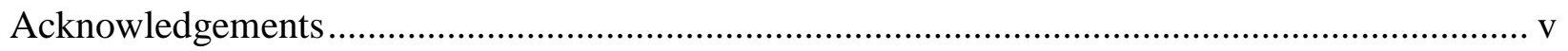

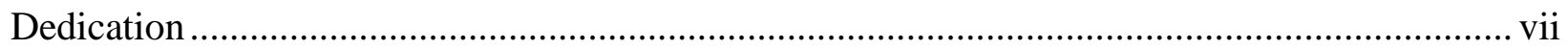

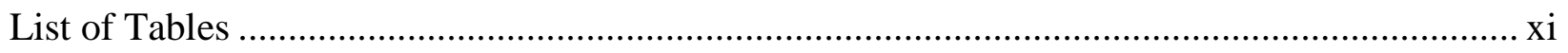

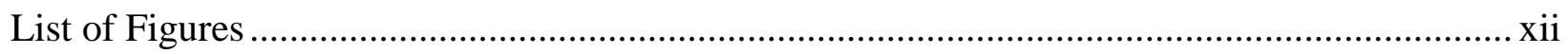

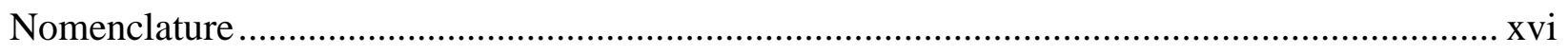

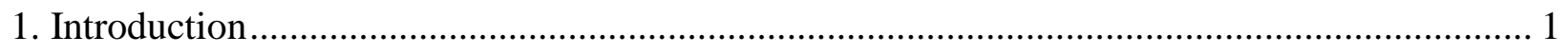

1.1. Gasoline/Ethanol Flame Simulations ............................................................... 4

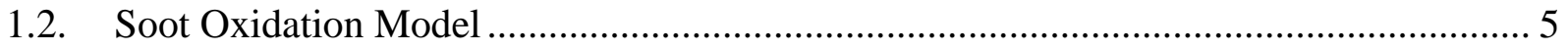

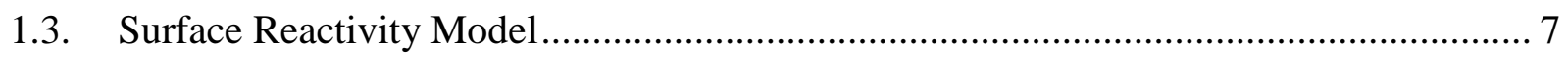

1.4. Relationships between the Journal Papers ..................................................... 9

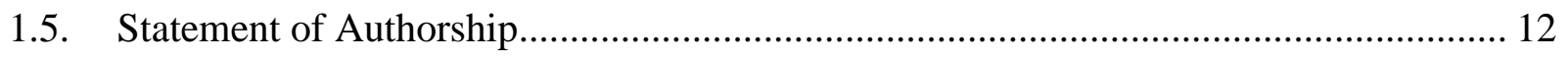

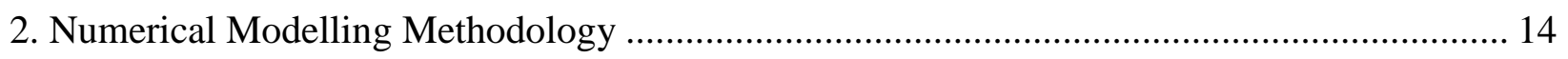

2.1. Burner Configurations and Flames ..................................................................... 14

2.2. Governing Equations and Boundary Conditions................................................ 16

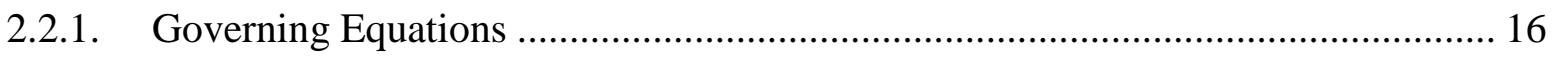

viii 


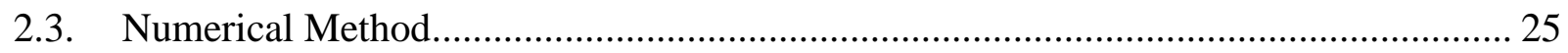

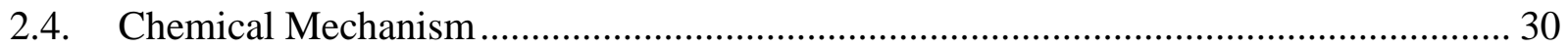

3. Experimental and Numerical Study of Soot Formation in Laminar Coflow Diffusion Flames of

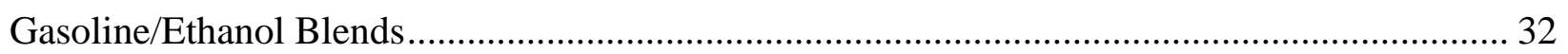

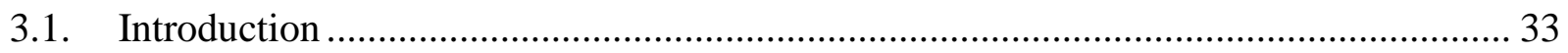

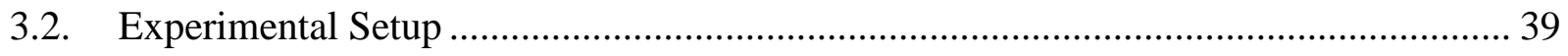

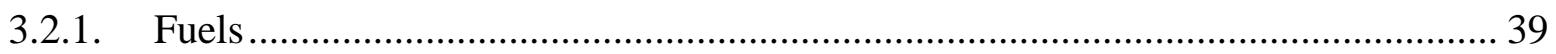

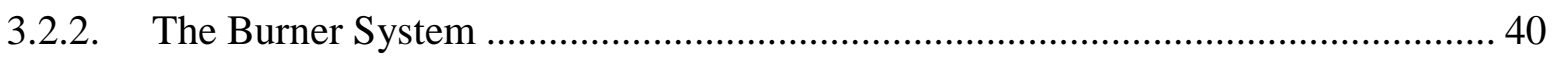

3.2.3. Soot Volume Fraction Measurement ................................................................... 42

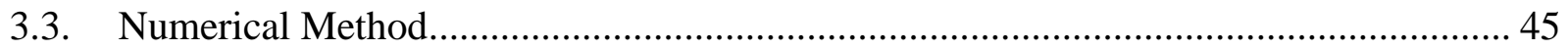

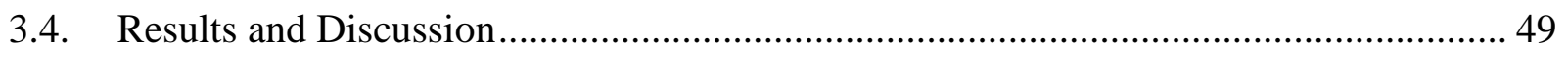

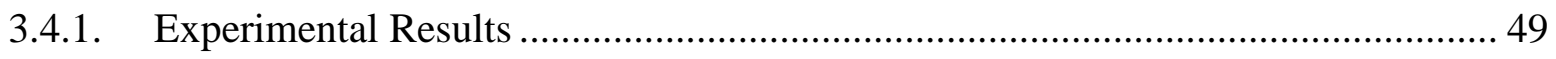

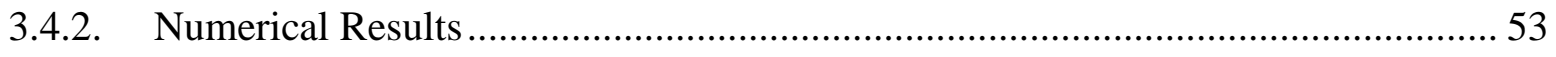

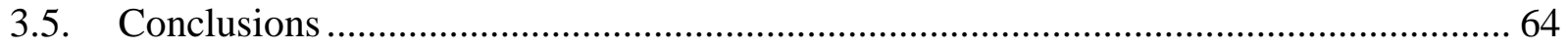

4. Detailed Modelling of Soot Oxidation by $\mathrm{O}_{2}$ and $\mathrm{OH}$ in Laminar Diffusion Flames ............... 66

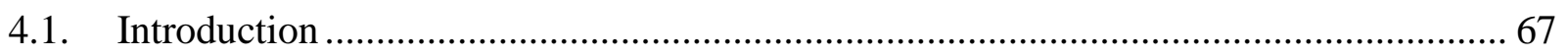

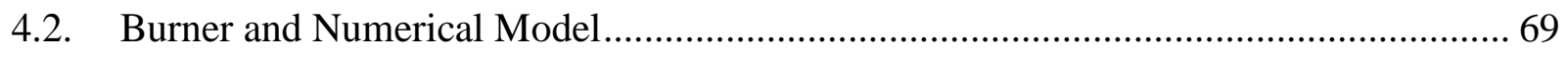

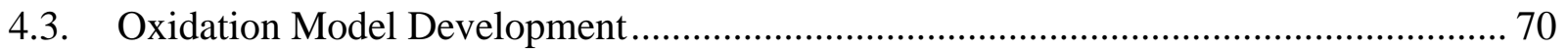




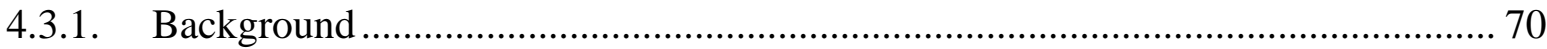

4.3.2. Determination of Model Parameters ..................................................................... 73

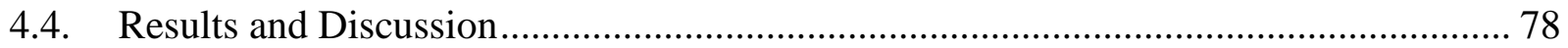

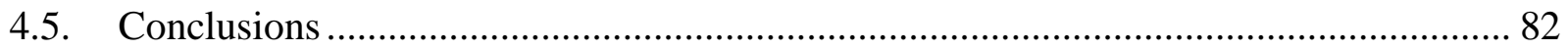

5. Soot Surface Reactivity during Surface Growth and Oxidation in Laminar Diffusion Flames 84

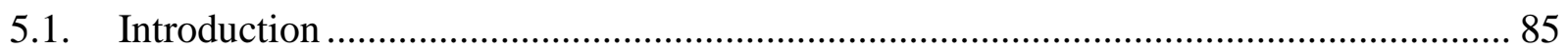

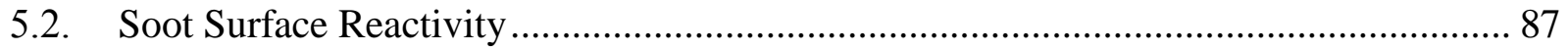

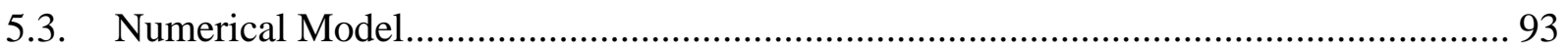

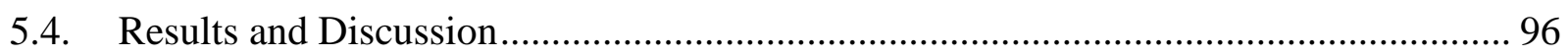

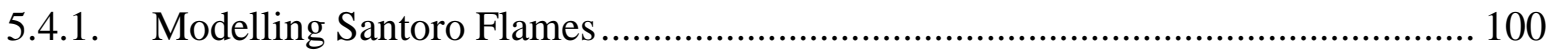

5.4.2. Modelling Diluted Smooke Flames ................................................................... 106

5.4.3. Modelling Methane/Air Flame ……………................................................... 110

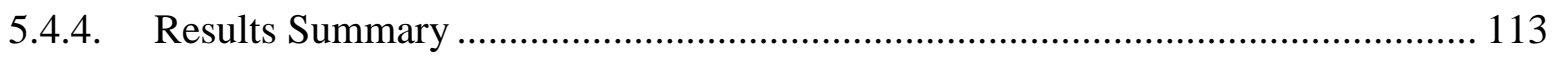

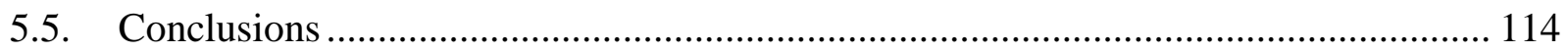

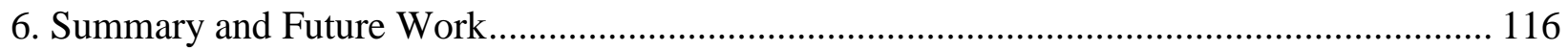

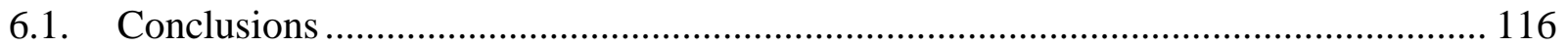

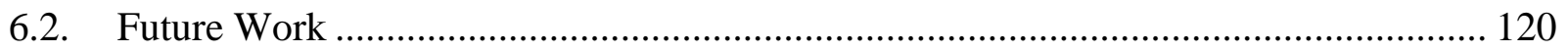

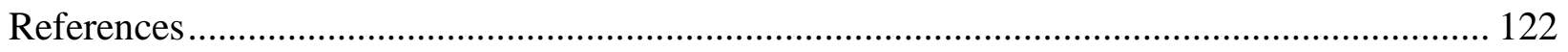




\section{List of Tables}

Table 2.1. Flames investigated in the present study......................................................... 16

Table 2.2. Solution domain for the flames studied......................................................... 26

Table 3.1. Gasoline and ethanol volume percentages in the four liquid fuel blends, ................. 39

Table 3.2. The mean velocities, temperatures, and mole fractions of ...................................... 48

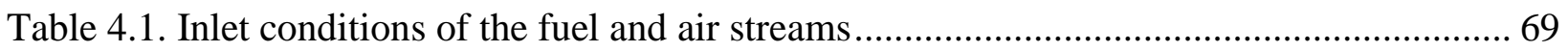

Table 4.2. Comparison of the model predictions with experiments ....................................... 81

Table 5.1. HACA-based soot surface growth and oxidation reactions [21], $k=A T b e-E a / R T$.

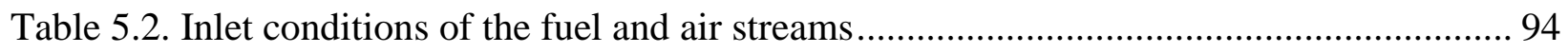

Table 5.3. Different models and their surface reactivity models used in the present work....... 102

Table 5.4. Comparison of the model predictions for the nine flames studied with experiments 114 


\section{List of Figures}

Fig. 1.1. Soot formation processes in different flame regions.

Fig. 2.1. Schematic of the burner showing the flame configuration, boundary conditions, grid distribution, and domain decomposition. 15

Fig. 2.2. Numerical Procedure 28

Fig. 3.1. The liquid fuel laminar diffusion flame burner system. 40

Fig. 3.2. A schematic of the 2D-LOSA setup for soot volume fraction measurements. 43

Fig. 3.3. Photographs of the visible appearance of the E0, E20, E50, and E85 flames. 49

Fig. 3.4. Measured soot volume fraction distributions in the E0, E20, E50, and E85 flames. The peak soot volume fraction in each flame is indicated. 50

Fig. 3.5. Experimental radial soot volume fraction profiles in the four flames at fours heights above the burner: (a) $10 \mathrm{~mm}$, (b) $20 \mathrm{~mm}$, (c) $30 \mathrm{~mm}$, and (d) $40 \mathrm{~mm}$. 52

Fig. 3.6. The calculated temperature distributions in the four flames. The peak temperature is indicated for each flame.

Fig. 3.7. The calculated soot volume fraction distributions in the four flames. The peak soot volume fraction is indicated for each flame. 55

Fig. 3.8. Computed radial soot volume fraction profiles in the four flames at fours heights above the burner: (a) $10 \mathrm{~mm}$, (b) $20 \mathrm{~mm}$, (c) $30 \mathrm{~mm}$, and (d) $40 \mathrm{~mm}$. 57 
Fig. 3.9. Comparison between the measured and the calculated peak soot volume fractions in the four flames. 59

Fig. 3.10. (a) The cumulative contributions of soot oxidation by $\mathrm{O}_{2}$ and $\mathrm{OH}$ to soot mass reduction, and (b) cumulative contributions of inception, surface growth by HACA, and PAH condensation to soot mass increase, along the pathline of the maximum soot between soot inception and the peak soot in the four flames studied. 61

Fig. 3.11. Distributions of the calculated A4 mole fraction along the pathline of the maximum soot in the E0, E20, E50, and E85 flames against the vertical distance above the burner exit. ... 63

Fig. 4.1. Variation of soot volume fraction along the streak line exhibiting maximum soot in response to varied $\mathrm{O}_{2}$ oxidation, as a percentage of the rate in [21] (left) and $\mathrm{OH}$-soot collision efficiency, $\gamma_{\mathrm{OH}}$ (right) for Flame 4.

Fig. 4.2. The function proposed for $\alpha_{o x}$ as a function of thermal age, normalized by the thermal age at the point of maximum soot denoted by $T_{a, \max }$ in the equation. 77

Fig. 4.3. Soot volume fraction along the streak line exhibiting maximum soot with the experimental results [13] for Flames 2 and 4 using a constant $\alpha(0.3)$ for oxidation. 79

Fig. 4.4. Soot volume fraction along the streak line exhibiting maximum soot with the experimental results [13] for Flames 1 through 4 using the $\alpha_{o x}$ function for oxidation (Experimental results of soot volume fraction along the wings for Flame 3 were not available). 80

Fig. 4.5. Primary particle size as a function of height above the burner for soot particles traveling along the particle path exhibiting maximum soot for Flames 2 and 4. The experimental data is from [71]. 82

Fig. 5.1. Proposed function for soot surface reactivity to employ in both growth and oxidation regions 98 
Fig. 5.2. Surface reactivity $(\alpha)$ determined by Eq. 3.3 for the NSII, S, SM32, and SM80 flames versus the height above the burner. 99

Fig. 5.3. Comparison of numerical predictions of the present model and experimental data for (a) temperature (measurements from [114]), (b) acetylene mole fraction (measurements from [71]), (c) $\mathrm{OH}$ mole fraction (measurements from [114]), and (d) soot volume fraction (measurements from [13]) at the axial heights indicated as functions of radial distance from the centerline..... 101

Fig. 5.4. Comparison of numerical predictions of the present model, Veshkini model [11], Khosousi model [113], and constant- $\alpha$ model for soot volume fraction along the streak line exhibiting maximum soot with the experimental results from [13] for the (a) NSII and (b) S flames. 104

Fig. 5.5. Comparison of numerical predictions of the present model, Veshkini model [11], Khosousi model [113], and constant- $\alpha$ model for primary particle size along the streak line exhibiting maximum soot, with the experimental results from [71] for the (a) NSII and (b) S flames. 105

Fig. 5.6. Soot volume fraction along the pathline exhibiting maximum soot as a function of fluid parcel residence time for the NSI, NSII, IS, and S flames 106

Fig. 5.7. Contours of soot volume fraction for the (a) SM32, (b) SM40, (c) SM60, and (d) SM80 flames. The predictions of the present model are shown on the right side and the experimental measurements from [14] are shown on the left side of each panel. 108

Fig. 5.8. Soot volume fraction along the pathline exhibiting maximum soot as a function of fluid parcel residence time for the SM32, SM40, SM60, and SM80 flames. 110

Fig. 5.9. Comparison of the profiles of soot volume fraction as a function of radial distance predicted by (a) the present model and (b) the constant- $\alpha$ model, with the experimental results 
from [15] for the M/A flame. The left side shows the experimental measurements and the right

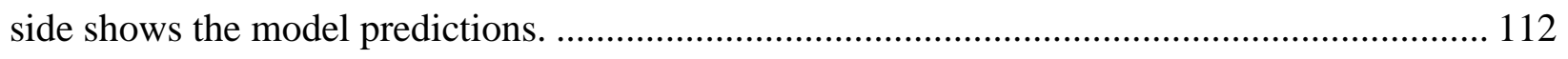




\section{Nomenclature}

$A_{s, i}\left[\frac{1}{c m}\right]$

$C_{p}\left[\frac{c a l}{g \cdot K}\right]$

$C_{p, k}\left[\frac{c a l}{g \cdot K}\right]$

$C_{p, s}\left[\frac{c a l}{g \cdot K}\right]$

$C_{S G}\left[\frac{m o l}{c m^{2}}\right]$

$\left[\mathrm{C}_{2} \mathrm{H}_{2}\right]\left[\frac{\mathrm{mol}}{\mathrm{cm}^{3}}\right]$

$D_{i}^{a}\left[\frac{c m^{2}}{s}\right]$

$E(m)$

$K_{a}$

$K K$

$N_{i}\left[\frac{1}{c m^{3}}\right]$
Surface density of the $i^{\text {th }}$ soot particle

The specific heat of the mixture at constant pressure

The specific heat of the $k^{\text {th }}$ species at constant pressure

The specific heat of soot at constant pressure

A constant parameter accounting for Avogadro's number and the mass of a carbon atom

$\mathrm{C}_{2} \mathrm{H}_{2}$ concentration

Diffusion coefficient of the $i^{\text {th }}$ sectional aggregates

Soot absorption function

Soot absorption coefficient reconstructed from the Abel inversion

The number of species in the gas phase

Number density of the $i^{\text {th }}$ particle

xvi 
$N_{i}^{a}\left[\frac{1}{\mathrm{~cm}^{3}}\right] \quad$ Number of $i^{t h}$ sectional soot aggregates per unit mass of the gaseous
mixture

$N_{i}^{p}\left[\frac{1}{\mathrm{~cm}^{3}}\right] \quad$ Number of $i^{t h}$ sectional primary soot particles per unit mass of the gaseous mixture

$Q_{r}\left[\frac{c a l}{c m^{3} . s}\right]$

The radiative heat transfer rate from soot and gaseous species $\left(\mathrm{CO}, \mathrm{CO}_{2}\right.$, and $\mathrm{H}_{2} \mathrm{O}$ )

$R_{S G}\left[\frac{m o l}{c m^{3} \cdot s}\right] \quad$ Rate of HACA surface growth

$T[K] \quad$ Temperature

$T_{a}[K . s] \quad$ Thermal age

$T_{a, \max }[K . s] \quad$ Thermal age at the point of maximum soot

$V_{k, r}\left[\frac{c m}{s}\right] \quad$ The $k^{\text {th }}$ species radial diffusion velocity

$V_{k, z}\left[\frac{c m}{s}\right] \quad$ The $k^{\text {th }}$ species axial diffusion velocity

$V_{T_{s, r}}\left[\frac{\mathrm{cm}}{\mathrm{s}}\right] \quad$ The thermophoretic velocity of soot particles in the radial direction

$V_{T_{S, Z}}\left[\frac{\mathrm{cm}}{\mathrm{s}}\right] \quad$ The thermophoretic velocity of soot particles in the axial direction

Xvii 

$W_{k}\left[\frac{g}{m o l}\right]$
The $k^{\text {th }}$ species molar weight
$W_{s}\left[\frac{g}{m o l}\right]$
The molecular weight of soot
$Y_{k}$
The $k^{\text {th }}$ species mass fraction
$Y_{S}$
Mass fraction of soot
$f_{v}[p p m]$
Soot volume fraction
$g_{z}\left[\frac{c m}{s^{2}}\right]$
The axial gravitational acceleration
$h_{k}^{0}\left[\frac{c a l}{g}\right]$
The $k^{\text {th }}$ species specific enthalpy
$h_{s}^{0}\left[\frac{c a l}{g}\right]$
The specific enthalpy of soot
$k_{4}\left[\frac{\mathrm{cm}^{3}}{m o l . s}\right]$
Per-site rate coefficient for $\mathrm{C}_{2} \mathrm{H}_{2}$ addition
$p\left[\frac{g}{c m \cdot s^{2}}\right]$
Pressure
$r[\mathrm{~cm}]$
Radial coordinate
$r_{i}[\mathrm{~cm}]$
Inner radius of the fuel tube
$r_{o}[\mathrm{~cm}]$
Outer radius of the air passage
xviii 
$t[s]$

$u\left[\frac{\mathrm{cm}}{\mathrm{s}}\right]$

$v\left[\frac{\mathrm{cm}}{\mathrm{s}}\right]$

$z[\mathrm{~cm}]$

\section{Greek Symbols}

$\alpha$

$\alpha_{O X}$

$\gamma_{O H}$

$\lambda\left[\frac{\mathrm{cal}}{\mathrm{cm} \cdot \mathrm{s} \cdot \mathrm{K}}\right]$

$\lambda_{E}[n m]$

$\mu\left[\frac{g}{c m . s}\right]$

$\rho\left[\frac{g}{c m^{3}}\right]$
Time

Axial velocity

Radial velocity

Axial coordinate
Portion of active surface sites available for chemical reaction

Portion of active surface sites available for chemical reaction in the oxidation region

OH-soot collision efficiency

The thermal conductivity of the mixture

Extinction measurements wavelength

Viscosity

The density of the mixture 
$\tau[\mathrm{cm}]$

$\dot{\omega}_{k}\left[\frac{m o l}{c m^{3} \cdot s}\right]$

$\dot{\omega}_{s}\left[\frac{m o l}{c m^{3} . s}\right]$

Acronyms
Fuel tube thickness

The $k^{\text {th }}$ species molar production rate per unit volume

The molar production rate of soot per unit volume

CEM Controlled Evaporator and Mixer

DME Dimethyl Ether

DOM Discrete Ordinate Method

GDI Gasoline Direct Injection

GPF Gasoline Particulate Filter

HACA Hydrogen Abstraction Carbon Addition

MON Motor Octane Number

MPI Message Passing Interface

PAH Polycyclic Aromatic Hydrocarbon 
PFI Port-Fuel Injection

RON Research Octane Number

SIMPLE Semi-Implicit Method for Pressure Linked Equations

TDMA Tri-Diagonal Matrix Algorithm 


\section{Chapter 1}

\section{Introduction}

A great portion of all power generation and transportation energy comes from combustion. In fact, combustion has become fundamentally integrated into many aspects of human life, including cooking, home heating, and transportation. Combustion-generated black carbon particulate (soot) emissions are a potent threat to human health and the urban environment [1], and should be avoided in combustion systems. Soot is a major contributor to climate change. Atmospheric soot absorbs sunlight and contributes to global warming. Soot is also a leading contributor to the darkening of cityscapes and to air pollution in the urban environment. Environmental and health issues lead combustion device designers to attempt to reduce combustion emissions. As a result, understanding the complex process of soot formation is of great interest to industry and academia.

The main focus of the present dissertation is to study soot formation in laminar coflow diffusion flames. More specifically, this work concentrates on intermediate steps involved in the formation, growth, and oxidation of soot. The formation of soot particles involves complicated intermediate steps such as inception, condensation, surface growth, aggregation, oxidation, and fragmentation. Inception involves the formation of nascent soot particles from the growth of soot precursor species, i.e., polycyclic aromatic hydrocarbons (PAHs). Incipient soot particles can grow in size through surface reactions with gaseous species, mainly acetylene. This process is referred to as surface growth. Condensation, another soot growth process, occurs when PAHs 
collide with soot and condense onto its surface. Aggregation is the process of soot particles colliding with each other to form larger particles. Oxidation and fragmentation contribute to the destruction of soot particles. Oxidation occurs through the reaction between the soot surface and oxidative species such as $\mathrm{O}_{2}$ and $\mathrm{OH}$. Fragmentation, on the other hand, refers to the process through which large soot agglomerations are broken down into smaller particle chains. The study of these processes and how they affect soot emission in different flame types is conducted here. Figure 1.1 presents a schematic illustration of the soot formation processes. Different regions of the flame are also shown.

This dissertation comprises six chapters. Chapter 1 outlines this dissertation, detailing the relationship of the works presented. Chapter 2 provides details on the numerical modelling methodology, burner configurations and flames, governing equations, boundary conditions, and chemical mechanisms used in simulations. In Chapter 3, soot formation is investigated in laminar coflow diffusion flames of vaporized gasoline and ethanol/gasoline blends, with special attention given to the effects of ethanol addition to gasoline on the flame soot loading. Soot oxidation is studied in Chapter 4. The effects of soot ageing on soot surface reactivity in growth and oxidation is presented in Chapter 5. The format of this dissertation follows a manuscript style, wherein Chapters 3, 4, and 5 each correspond to a journal article, and Chapter 6 draws conclusions on the body of work as a whole. 


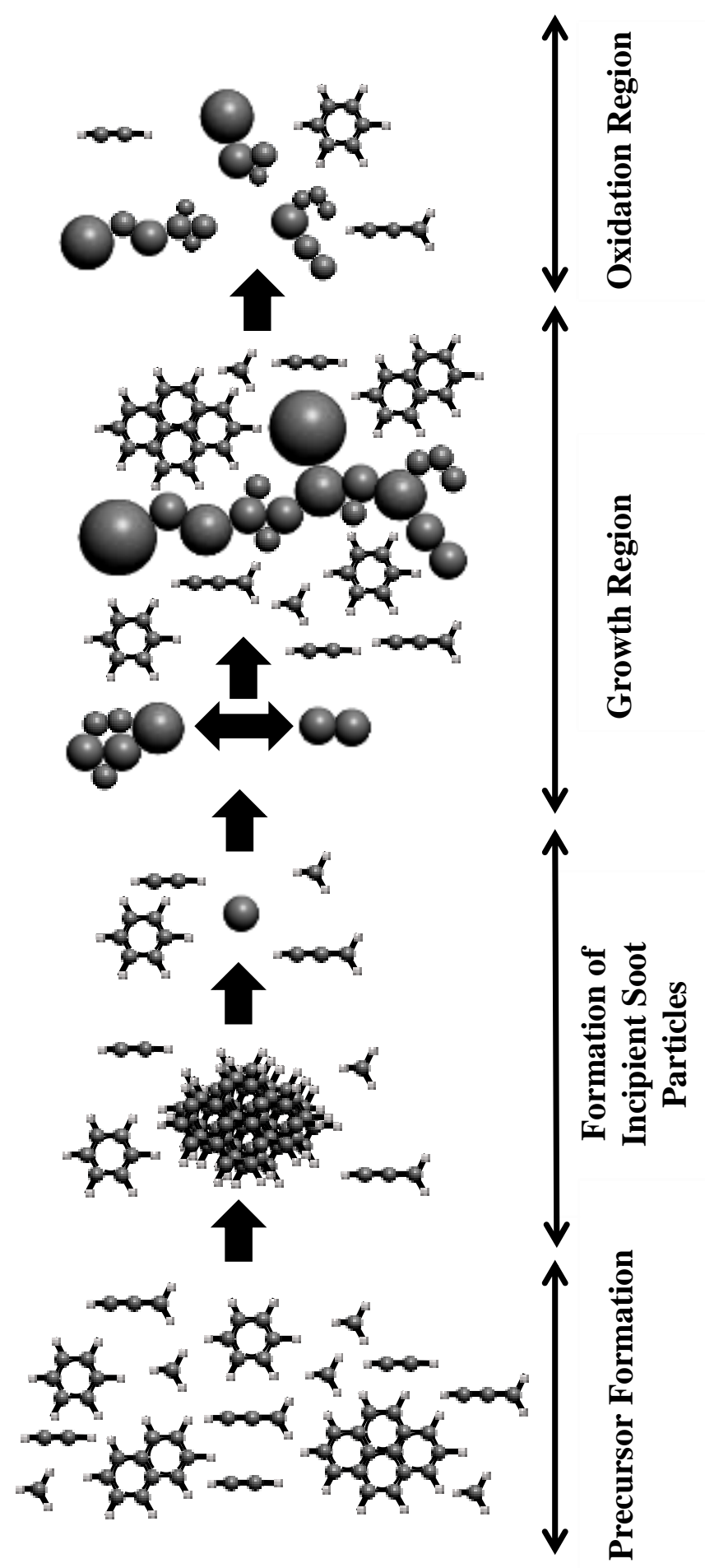

Fig. 1.1. Soot formation processes in different flame regions. 


\subsection{Gasoline/Ethanol Flame Simulations}

In order to investigate different approaches towards reducing soot emissions in various flames, the effects of ethanol addition to gasoline fuel is studied. Ethanol has the potential to enhance engine operation, as it has a higher octane number than gasoline and reduces knock in engines, and reduce soot emission. Chapter 3 presents a multi-institutional collaboration study of soot formation in laminar coflow diffusion flames of vaporized gasoline and ethanol/gasoline blends using experimental and numerical methods.

The experimental measurements of soot volume fraction distributions, which were performed by a separate group, are conducted using the two-dimensional line-of-sight attenuation (2D-LOSA) technique [2]. The study investigates the effects of ethanol addition to gasoline on soot formation in these flames. Different levels of ethanol, i.e., $0 \%, 20 \%, 50 \%$, and $85 \%$, by volume, are blended into gasoline and used for experimental and numerical works, investigating the effects of ethanol addition to gasoline fuel.

Since gasoline is a complex fuel which is composed of many different hydrocarbons [3], it is usually simulated using surrogates that emulate the real gasoline fuel. For the numerical simulations, a gasoline surrogate, which consists of toluene $\left(\mathrm{C}_{6} \mathrm{H}_{5} \mathrm{CH}_{3}\right)$, iso-octane $\left(\mathrm{i}-\mathrm{C}_{8} \mathrm{H}_{18}\right)$, and $n$-heptane $\left(\mathrm{C}_{7} \mathrm{H}_{16}\right)$, also known as a toluene reference fuel (TRF), is used.

For numerical simulations, the CoFlame code [4] [5] is implemented with a detailed chemical mechanism adapted from Raj et al. [6]. A sub-mechanism [7] is added to account for ethanol chemical reactions. The final chemical mechanism consists of 180 species and 1127 reactions. 
The calculations provide temperature and soot volume fraction distributions in the flame field. The results show a change in soot concentrations as ethanol is blended into gasoline surrogate. These results are compared with the experimental data to provide useful insight as to how the model predicts soot propensity of these flames as well as how well the gasoline surrogate replicates the sooting behaviour of gasoline.

The numerical results are further post-processed to inspect the reasons as to why the flames show different soot loading as ethanol is added to gasoline. The processes involved in the formation and oxidation of soot, i.e., inception, surface growth, condensation, and oxidation, are examined to determine the dominant effect contributing to the change in soot concentrations.

This work is published as a peer-reviewed journal paper:

Ali Khosousi, Fengshan Liu, Seth B. Dworkin, Nick A. Eaves, Murray J. Thomson, Xu He, Yujie Dai, Yongli Gao, Fushui Liu, Shijin Shuai, and Jianxin Wang, "Experimental and Numerical Study of Soot Formation in Laminar Coflow Diffusion Flames of Gasoline/Ethanol Blends," Combustion and Flame, Volume 162, Issue 10, 2015, Pages 3925-3933.

\subsection{Soot Oxidation Model}

The process of soot oxidation, which is a complex and poorly understood phenomenon, is studied in Chapter 4. In numerical works, soot oxidation is usually considered to be caused by the reactions between soot particles and $\mathrm{O}_{2}$ molecules as well as $\mathrm{OH}$ radicals. The rate of reactions between soot and $\mathrm{OH}$ is normally calculated based on collision theory. However, the reaction of soot and $\mathrm{O}_{2}$ is modelled as a reaction between soot surface sites and $\mathrm{O}_{2}$ molecules. 
Oxidation rates for $\mathrm{O}_{2}$ suggested in the literature differ by orders of magnitudes. Particular attention has been given to the modelling of soot oxidation by $\mathrm{O}_{2}$.

In modelling soot oxidation caused by $\mathrm{O}_{2}$, a parameter, $\alpha$, is usually used to account for the surface reactivity of soot. This parameter is used to account for the probability of the collision between a gaseous species and a particle's edge carbon that is available for reaction and also reconciles the inaccuracies associated with treating the surface of soot like a PAH. Since there is a lack of understanding as to how $\alpha$ changes with flame properties and in different parts of the flame, many works in the literature have found it sufficient to use a constant value for this parameter in their simulations. As will be discussed in more detail in Chapter 4, some works have developed more sophisticated approaches to implement this parameter in their simulations.

It is suggested in the literature that soot surface reactivity changes as soot particles age [8] [9] [10]. The main subject of Chapter 4 is to present a systematic approach to formulate this idea and implement it in the computations. In Chapter 4, an oxidation model is proposed based on soot ageing effects, accounting for soot surface reactivity changes. This model is used to simulate soot oxidation by $\mathrm{O}_{2}$ in the upper portion of the flame where oxidation mostly occurs.

Using this model, laminar coflow ethylene/air diffusion flames, with different fuel mole fractions, fuel and air flow rates, and burner configurations, are simulated. These flames are chosen for simulations because they provide a wide range of conditions with different sooting behaviour and smoke emission, which makes them suitable for the validation of the oxidation model. The CoFlame code [4] [5] is utilized for the simulations. The focus is on the prediction of maximum soot volume fraction as well as the amount of soot emission. Non-smoking flames, 
those that do not emit soot, are simulated along with smoking flames, those that emit soot. The study further seeks the reasons as to why these flames differ in soot emission characteristics. In addition, the effects of the two major oxidative species, $\mathrm{O}_{2}$ and $\mathrm{OH}$, on soot concentrations are studied, which helps identify the conditions under which these species become the dominant oxidative species.

This work is published as a peer-reviewed journal paper:

Ali Khosousi and Seth B. Dworkin, "Detailed Modelling of Soot Oxidation by $\mathrm{O}_{2}$ and $\mathrm{OH}$ in Laminar Diffusion Flames," Proceedings of Combustion Institute, Volume 35, Issue 2, 2015 , Pages 1903-1910.

\subsection{Surface Reactivity Model}

In processes such as soot oxidation and Hydrogen Abstraction Carbon Addition (HACA) surface growth, surface reactions play significant roles. The rates of oxidation and surface growth are dependent on soot surface reactivity. For the sake of simplicity, the early works in the literature used a constant reactivity for a soot surface and ignored the fact that it changes within the flame and under different conditions. Chapter 5 discusses the effects of soot surface reactivity on soot formation and oxidation processes. Based on various flame parameters, a surface reactivity model is presented which can be applied throughout the flame.

As mentioned before, modelling surface reactions of soot requires taking into account the changes in the reactivity of the surface of a soot particle as it travels through the flame. Soot surface reactivity is found to be a function of the number of active dehydrogenated sites on the surface of a soot particle that are readily available to react with various species such as $\mathrm{C}_{2} \mathrm{H}_{2}, \mathrm{O}_{2}$, 
$\mathrm{H}_{2} \mathrm{O}$, and $\mathrm{H}_{2}$. The reactions of soot with these species result in different phenomenon depending on the species with which soot reacts. The reaction between an active site and $\mathrm{C}_{2} \mathrm{H}_{2}$, for instance, leads to replacing the dehydrogenated site with Carbon atoms, thus contributing to increased soot mass yield and growth of the soot particle. The reaction of an active site with $\mathrm{O}_{2}$, on the other hand, results in reduction of soot mass yield and oxidation of the soot particle.

Depending on the combustion system, a soot particle may exist within the flame environment for as long as $O(0.1)$ s. The surface of a newly formed incipient soot particle is different than that of an aged particle. Apart from the number of active sites on the surface of soot particles, other factors play important roles in determining the surface reactivity of soot. This notion leads to an extensive and detailed study which is presented in Chapter 5 .

The primary focus of Chapter 5 is to study surface reactivity of soot simultaneously in both growth and oxidation regions. One reconciled model, which integrates surface growth and oxidation models for these regions into a unique surface model, is developed and presented. The study considers both peak soot and soot emissions to assure that the surface reactivity is modelled correctly in both oxidation and growth regions. The work utilizes the same approach used in Chapter 4 for the oxidation model, to model surface reactivity for growth and oxidation simultaneously. This work is a continuation of that presented in Chapter 4, which studies the surface reactivity of soot in the oxidation region; Chapter 5 builds upon that and extends the work to implement the same method to consider soot surface reactivity in the surface growth model in the growth region. For this purpose, various laminar coflow ethylene/air and methane/air diffusion flames are simulated. These flames include different fuels, fuel and air 
flow rates, fuel mole fractions, and burner geometries, providing a wide range of flames with different sooting behaviours. The simulations are performed using the CoFlame code [4] [5], with a detailed chemical mechanism. The model, which is applied to simulate nine different flames, correctly predicts soot distribution and emission in all the flames studied.

This work is published as a peer-reviewed journal paper:

Ali Khosousi and Seth B. Dworkin, "Soot Surface Reactivity during Surface Growth and Oxidation in Laminar Diffusion Flames," Combustion and Flame, Volume 162, Issue 12, 2015 , Pages 4523-4532.

\subsection{Relationships between the Journal Papers}

The first topic that is studied in the present dissertation is the soot formation in laminar coflow diffusion gasoline/ethanol flames. Since ethanol has the potential to reduce soot emissions, understanding soot formation processes in gasoline/ethanol flames is of particular interest. The intermediate steps involved in soot formation are studied in detail, providing valuable information as to how PAH and soot formation change as different ethanol levels are added to gasoline. The experimental and numerical results of soot concentration and temperature distributions are compared in order to validate the numerical model. The relative contributions of inception, condensation, surface growth, and oxidation to total soot mass yield are investigated. Further, the possible reasons for changes in soot concentration as a result of ethanol addition to the fuel are discussed. While this work is not directly relevant to the other chapters of this dissertation, it involves a great deal of discussion regarding soot formation and oxidation processes and how they are affected as a result of ethanol addition to gasoline. The lessons 
learned in the study outlined in Chapter 3 are applied to Chapters 4 and 5. Especially, in the work presented in Chapter 3, it was noticed that using a constant value for surface reactivity of soot has some drawbacks and limitations. For this reason, studying soot surface reactivity became the subject of the subsequent chapters.

As mentioned previously, the main objective of the present dissertation is to broaden the knowledge base of soot formation in laminar diffusion flames. In this regard, this dissertation is outlined to study the processes involved in soot formation and oxidation, including inception, HACA surface growth, condensation, and oxidation. As oxidation and HACA surface growth, which are primary contributors to soot mass yield, include surface reactions, correct modelling of soot surface reactions in numerical simulations is required to successfully predict soot concentrations in flames. It is crucial to understand that the reactivity of a soot surface plays an important role in determining soot growth/decay rates [11]. In order to effectively model soot surface reactions, one should consider soot reactivity and its changes. In Chapter 4, which studies soot oxidation, it is introduced that soot surface reactivity changes with particle age. A method, which was originally developed by Veshkini et al. [11], is used to account for soot surface reactivity. Thermal age (temperature history of a soot particle) is introduced to accommodate the effects of soot ageing. The first step, in this regard, is to apply this approach to model soot surface reactivity in the oxidation region and evaluate the model's predictive capability. The surface reactivity in the oxidation region is determined based on particle thermal age, while soot surface reactivity is assumed to be constant in the growth region. This approach was first used to make it possible to model both non-smoking and smoking flames using a unique model. The amount of smoke emission from smoking flames is sensitive to soot surface 
reactivity in the oxidation region. While this model enabled the correct modelling of nonsmoking and smoking behaviour, it has a drawback in the sense that it divides soot particles depending on the part of the flame in which they are located. The model only applies to those soot particles that are located in the oxidation region, and calculates soot surface reactivity based on their thermal age. However, this model allocates a constant surface reactivity for the particles in the growth region, irrespective of their shape, size, and thermal age.

In order to present a comprehensive model for soot surface reactivity to replace previous models that assume a constant soot surface reactivity, a model should be developed that is applicable throughout the flame, and not just to one particulate part of the flame, i.e., growth or oxidation regions. Therefore, the next goal of the present work became to extend this model so that it could be applied to both growth and oxidation regions.

Chapter 5 is an extension to the work presented in Chapter 4. A similar approach to that used to account for surface reactivity of soot in the oxidation region is implemented. The model is modified so that it can be applied to both oxidation and growth regions simultaneously. Based on this model, the surface reactivity of identical soot particles with the same thermal age is calculated by a consistent model regardless of the region in which they are located. The applicability of the model is tested for a wide range of flames. Apart from ethylene/air and diluted ethylene/air flames, methane/air flames are also modelled. Noting that methane is a $\mathrm{C}_{1}$ fuel, unlike ethylene which is a $\mathrm{C}_{2}$ fuel, its pyrolysis, oxidation, and soot formation processes are different than those for ethylene; it provides a suitable testing ground for the model. The results of the modelling are compared against experimental data. 
The topics presented in this dissertation offer an integrated study focusing on soot formation in laminar coflow diffusion flames of various fuels. The subjects are presented in an order to show the progress of the work and reflect the ultimate goal of this dissertation, as a whole, which is to provide a thorough and fundamental understanding on soot formation in flames, and apply that understanding towards new and applicable insights.

\subsection{Statement of Authorship}

The paper presented in Chapter 3, titled "Experimental and Numerical Study of Soot Formation in Laminar Coflow Diffusion Flames of Gasoline/Ethanol Blends," is published in the Journal, Combustion and Flame. The work is divided into experimental and numerical parts. The experimental part was conducted by collaborators He, Dai, Gao, and Liu at the School of Mechanical Engineering, Beijing Institute of Technology, Haidian District, Beijing 100081, China, and Shuai and Wang at the State Key Laboratory of Automotive Safety and Energy, Tsinghua University, Beijing 100084, China. The present author was provided with the experimental results, which were used in preparation of the paper. The numerical part of this work was conducted by the present author at the Department of Mechanical and Industrial Engineering, Ryerson University, 350 Victoria Street, Toronto, Ontario, M5B 2K3, Canada. The preparation of the chemical mechanisms used in the numerical modelling was conducted jointly by the present author and Nick A. Eaves from University of Toronto. In addition to supervision by Professor Seth Dworkin at Ryerson University, Dr. Liu Fengshan at the National Research Council of Canada, and Professor Murray Thomson at University of Toronto, jointly supervised

this work. The manuscript of the paper, except the experimental section, was prepared by the 
present author, revised by Professor Seth Dworkin, Dr. Liu Fengshan, and Professor Murray Thomson.

The manuscript of the paper presented in Chapter 4, titled "Detailed Modelling of Soot Oxidation by $\mathrm{O}_{2}$ and $\mathrm{OH}$ in Laminar Diffusion Flames," is fully prepared by the author of this dissertation. The paper is published in the Proceedings of the Combustion Institute. The work is conducted by the present author at the Department of Mechanical and Industrial Engineering, Ryerson University, 350 Victoria Street, Toronto, Ontario, M5B 2K3, Canada. Professor Seth Dworkin supervised this work and revised the manuscript of the paper before submitting it for publication.

The present author also fully conducted the research and prepared the manuscript of the paper presented in Chapter 5, titled "Soot Surface Reactivity during Surface Growth and Oxidation in Laminar Diffusion Flames." This paper is published in the journal, Combustion and Flame. The work, which is supervised by Professor Seth Dworkin, is conducted at the Department of Mechanical and Industrial Engineering, Ryerson University, 350 Victoria Street, Toronto, Ontario, M5B 2K3, Canada. Professor Dworkin made revisions to the paper before its submission for publication. 


\section{Chapter 2}

\section{Numerical Modelling Methodology}

\subsection{Burner Configurations and Flames}

In the present study, coflow laminar ethylene/air diffusion flames, studied by Santoro and coworkers [12] [13] (referred to as 'Santoro flames'), diluted ethylene/air flames, studied by Smooke et al. [14] (referred to as 'Smooke flames'), and the methane/air flame, studied by Lee et al. [15] (referred to as 'Lee flame') are used for simulations. In addition, laminar coflow diffusion flames of vaporized gasoline/ethanol blends at atmospheric pressure are simulated. Four gasoline/ethanol blends of different ethanol mole fractions in the fuel stream ranging from $0 \%$ up to $85 \%$ (by volume), E0, E20, E50, and E85, are investigated. Figure 2.1 shows a schematic of the coflow burner used for simulations, in which fuel is supplied through the central tube, and air is fed through the coflowing annular region.

The flames studied here represent a vast range of conditions with varying properties, flow conditions and sooting behaviour. They include flames of varying smoke emission character, fuel composition, fuel dilution, residence time, etc. The details of these flames are provided in Table 2.1. 


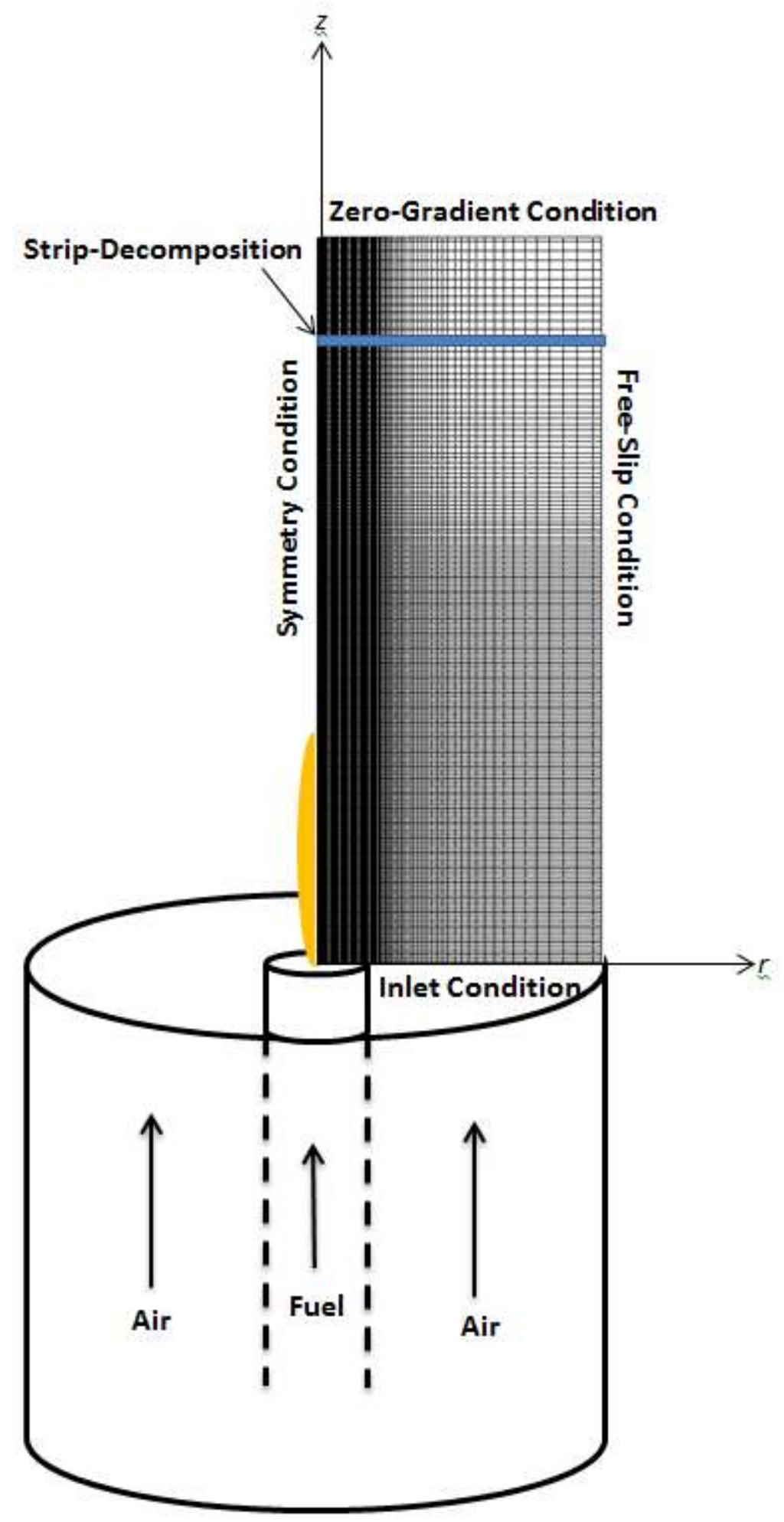

Fig. 2.1. Schematic of the burner showing the flame configuration, boundary conditions, grid distribution, and domain decomposition. 
Table 2.1. Flames investigated in the present study.

\begin{tabular}{cccccccc}
\hline Flame & Fuel/Fuel mixture & $\begin{array}{c}\text { Fuel } \\
\text { velocity } \\
(\mathbf{c m} / \mathbf{s})\end{array}$ & $\begin{array}{c}\text { Air } \\
\text { velocity } \\
(\mathbf{c m} / \mathbf{s})\end{array}$ & $\begin{array}{c}\text { Fuel mole } \\
\text { fraction }\end{array}$ & $\begin{array}{c}\text { Nitrogen } \\
\text { mole } \\
\text { fraction }\end{array}$ & $\begin{array}{c}\text { Ethanol } \\
\text { mole } \\
\text { fraction }\end{array}$ & Reference \\
\hline NSI & Ethylene & 2.38 & 8.90 & 1.0 & 0.0 & 0.0 & {$[12]$} \\
\hline NSII & Ethylene & 3.98 & 8.90 & 1.0 & 0.0 & 0.0 & {$[12]$} \\
\hline IS & Ethylene & 4.75 & 8.90 & 1.0 & 0.0 & 0.0 & {$[12]$} \\
\hline S & Ethylene & 5.05 & 13.30 & 1.0 & 0.0 & 0.0 & {$[12]$} \\
\hline SM32 & Ethylene/Nitrogen & 35.0 & 35.0 & 0.32 & 0.68 & 0.0 & {$[14]$} \\
\hline SM40 & Ethylene/Nitrogen & 35.0 & 35.0 & 0.40 & 0.60 & 0.0 & {$[14]$} \\
\hline SM60 & Ethylene/Nitrogen & 35.0 & 35.0 & 0.60 & 0.40 & 0.0 & {$[14]$} \\
\hline SM80 & Ethylene/Nitrogen & 35.0 & 35.0 & 0.80 & 0.20 & 0.0 & {$[14]$} \\
\hline M/A & Methane & 10.24 & 11.94 & 1.0 & 0.0 & 0.0 & {$[15]$} \\
\hline E0 & Gasoline/Nitrogen & 11.72 & 87.04 & 0.1268 & 0.8732 & 0.0 & Present work \\
\hline E20 & Gasoline/Ethanol/Nitrogen & 11.97 & 87.04 & 0.1163 & 0.8547 & 0.0291 & Present work \\
\hline E50 & Gasoline/Ethanol/Nitrogen & 12.58 & 87.04 & 0.0931 & 0.8138 & 0.0931 & Present work \\
\hline E85 & Gasoline/Ethanol/Nitrogen & 14.16 & 87.04 & 0.0416 & 0.7229 & 0.2355 & Present work \\
\hline
\end{tabular}

\subsection{Governing Equations and Boundary Conditions}

\subsubsection{Governing Equations}

The governing equations, in their steady-state condition, for conservation of mass, momentum, energy, and species mass fractions are solved for the gas phase model. Due to the symmetry of the flame, the governing equations are solved in the two-dimensional cylindrical coordinate system. Therefore, the conservation equations are provided below in the $z-r$ cylindrical coordinate system.

\section{Conservation of Mass:}

$\frac{1}{r} \frac{\partial}{\partial r}(r \rho v)+\frac{\partial}{\partial z}(\rho u)=0$ 


\section{Conservation of Axial Momentum:}

$\rho v \frac{\partial u}{\partial r}+\rho u \frac{\partial u}{\partial z}=-\frac{\partial p}{\partial z}+\frac{1}{r} \frac{\partial}{\partial r}\left(r \mu \frac{\partial u}{\partial r}\right)+2 \frac{\partial}{\partial z}\left(\mu \frac{\partial u}{\partial z}\right)-\frac{2}{3} \frac{\partial}{\partial z}\left[\frac{\mu}{r} \frac{\partial}{\partial r}(r v)\right]-\frac{2}{3} \frac{\partial}{\partial z}\left(\mu \frac{\partial u}{\partial z}\right)+$

$\frac{1}{r} \frac{\partial}{\partial r}\left(r \mu \frac{\partial v}{\partial z}\right)+\rho g_{z}$

\section{Conservation of Radial Momentum:}

$\rho v \frac{\partial v}{\partial r}+\rho u \frac{\partial v}{\partial z}=-\frac{\partial p}{\partial r}+\frac{\partial}{\partial z}\left(\mu \frac{\partial v}{\partial z}\right)+\frac{2}{r} \frac{\partial}{\partial r}\left(r \mu \frac{\partial v}{\partial r}\right)-\frac{2}{3} \frac{1}{r} \frac{\partial}{\partial r}\left[\frac{\mu}{r} \frac{\partial}{\partial r}(r v)\right]-\frac{2}{3} \frac{1}{r} \frac{\partial}{\partial r}\left(r \mu \frac{\partial u}{\partial z}\right)+$

$\frac{\partial}{\partial z}\left(\mu \frac{\partial u}{\partial r}\right)-\frac{2 \mu v}{r^{2}}+\frac{2}{3} \frac{\mu}{r^{2}} \frac{\partial}{\partial r}(r v)+\frac{2}{3} \frac{\mu}{r} \frac{\partial u}{\partial z}$

\section{Conservation of Energy:}

$$
\begin{aligned}
& \rho C_{p}\left(v \frac{\partial T}{\partial r}+u \frac{\partial T}{\partial z}\right)=\frac{1}{r} \frac{\partial}{\partial r}\left(r \lambda \frac{\partial T}{\partial r}\right)+\frac{\partial}{\partial z}\left(\lambda \frac{\partial T}{\partial z}\right)-\sum_{k=1}^{K K} \rho C_{p, k} Y_{k}\left(V_{k, r} \frac{\partial T}{\partial r}+V_{k, z} \frac{\partial T}{\partial z}\right)- \\
& \sum_{k=1}^{K K} h_{k}^{0} \dot{\omega}_{k} W_{k}-\rho C_{p, s} Y_{s}\left(V_{T_{s, r}} \frac{\partial T}{\partial r}+V_{T_{S, z}} \frac{\partial T}{\partial z}\right)-h_{s}^{0} \dot{\omega}_{s} W_{s}+Q_{r}
\end{aligned}
$$

\section{Conservation of Species Mass Fractions:}

$$
\begin{gathered}
\rho v \frac{\partial Y_{k}}{\partial r}+\rho u \frac{\partial Y_{k}}{\partial z}=-\frac{1}{r} \frac{\partial}{\partial r}\left(r \rho Y_{k} V_{k, r}\right)-\frac{\partial}{\partial z}\left(\rho Y_{k} V_{k, z}\right)+W_{k} \dot{\omega}_{k} \\
k=1,2, \ldots, K K
\end{gathered}
$$

In these equations, $r$ is the radial coordinate, $z$ is the axial coordinate, $u$ is the axial velocity, $v$ is the radial velocity, $\rho$ is the density of the mixture, $p$ is pressure, $\mu$ is viscosity, $g_{z}$ is the axial 
gravitational acceleration, $C_{p}$ is the specific heat of the mixture at constant pressure, $C_{p, k}$ is the specific heat of the $k^{\text {th }}$ species at constant pressure, $C_{p, s}$ is the specific heat of soot at constant pressure, $T$ is temperature, $\lambda$ is the thermal conductivity of the mixture, $K K$ is the number of species in the gas phase, $Y_{k}$ is the $k^{\text {th }}$ species mass fraction, $V_{k, r}$ is the $k^{\text {th }}$ species radial diffusion velocity, $V_{k, z}$ is the $k^{\text {th }}$ species axial diffusion velocity, $h_{k}^{0}$ is the $k^{\text {th }}$ species specific enthalpy, $\dot{\omega}_{k}$ is the $k^{\text {th }}$ species molar production rate per unit volume, $W_{k}$ is the $k^{\text {th }}$ species molar weight, $Y_{s}$ is the mass fraction of soot, $V_{T_{s, r}}$ is the thermophoretic velocity of soot particles in the radial direction, $V_{T_{S, Z}}$ is the thermophoretic velocity of soot particles in the axial direction, $h_{s}^{0}$ is the specific enthalpy of soot, $\dot{\omega}_{s}$ is the molar production rate of soot per unit volume, $W_{s}$ is the molecular weight of soot, and $Q_{r}$ is the radiative heat transfer rate from soot and gaseous species ( $\mathrm{CO}, \mathrm{CO}_{2}$, and $\mathrm{H}_{2} \mathrm{O}$ ). The radiative source term in the energy equation, $Q_{r}$, due to the nongrey radiative heat transfer by soot, $\mathrm{H}_{2} \mathrm{O}, \mathrm{CO}_{2}$, and $\mathrm{CO}$, is calculated using the Discrete Ordinate Method (DOM) and a statistical narrow-band correlated-k-based model [16]. The details of the radiation model is available in [17] [18].

Soot particle dynamics are modelled using a fixed sectional approach in which the soot particle mass range is divided logarithmically into 35 discrete sections. Two transport equations for soot aggregate number density and for soot primary particle number density are solved for each section. The governing equations for soot particle dynamics are as follows:

\section{Conservation of Soot Aggregate Number Density:}




$$
\begin{aligned}
& \rho v \frac{\partial N_{i}^{a}}{\partial r}+\rho u \frac{\partial N_{i}^{a}}{\partial z}=\frac{1}{r} \frac{\partial}{\partial r}\left(r \rho D_{i}^{a} \frac{\partial N_{i}^{a}}{\partial r}\right)+\frac{\partial}{\partial z}\left(\rho D_{i}^{a} \frac{\partial N_{i}^{a}}{\partial z}\right)-\frac{1}{r} \frac{\partial}{\partial r}\left(r \rho N_{i}^{a} V_{T_{s, r}}\right)-\frac{\partial}{\partial z}\left(\rho N_{i}^{a} V_{T_{S, z}}\right)+ \\
& \rho\left[\left(\frac{\partial N_{i}^{a}}{\partial t}\right)_{i n c}+\left(\frac{\partial N_{i}^{a}}{\partial t}\right)_{c o n d}+\left(\frac{\partial N_{i}^{a}}{\partial t}\right)_{s g}+\left(\frac{\partial N_{i}^{a}}{\partial t}\right)_{o x}+\left(\frac{\partial N_{i}^{a}}{\partial t}\right)_{c o a g}+\left(\frac{\partial N_{i}^{a}}{\partial t}\right)_{f r}\right]
\end{aligned}
$$

$$
i=1,2, \ldots, M S
$$

\section{Conservation of Soot Primary Particle Number Density:}

$$
\begin{gathered}
\rho v \frac{\partial N_{i}^{p}}{\partial r}+\rho u \frac{\partial N_{i}^{p}}{\partial z}=\frac{1}{r} \frac{\partial}{\partial r}\left(r \rho D_{i}^{a} \frac{\partial N_{i}^{p}}{\partial r}\right)+\frac{\partial}{\partial z}\left(\rho D_{i}^{a} \frac{\partial N_{i}^{p}}{\partial z}\right)-\frac{1}{r} \frac{\partial}{\partial r}\left(r \rho N_{i}^{p} V_{T_{s, r}}\right)-\frac{\partial}{\partial z}\left(\rho N_{i}^{p} V_{T_{S, Z}}\right)+ \\
\rho\left[\left(\frac{\partial N_{i}^{p}}{\partial t}\right)_{\text {inc }}+\left(\frac{\partial N_{i}^{p}}{\partial t}\right)_{c o n d}+\left(\frac{\partial N_{i}^{p}}{\partial t}\right)_{s g}+\left(\frac{\partial N_{i}^{p}}{\partial t}\right)_{o x}+\left(\frac{\partial N_{i}^{p}}{\partial t}\right)_{c o a g}+\left(\frac{\partial N_{i}^{p}}{\partial t}\right)_{f r}\right] \\
i=1,2, \ldots, M S
\end{gathered}
$$

in which $N_{i}^{a}$ is the number of $i^{\text {th }}$ sectional soot aggregates per unit mass of the gaseous mixture, $N_{i}^{p}$ is the number of $i^{\text {th }}$ sectional primary soot particles per unit mass of the gaseous mixture, $D_{i}^{a}$ is the diffusion coefficient of the $i^{\text {th }}$ sectional aggregates, and $M S$ is the total number of soot sections.

The soot sectional model considers inception (inc), PAH surface condensation (cond), surface growth ( $s g$ ), surface oxidation ( ox), coagulation (coag), and fragmentation $(f r)$. The inception model is based on the collisions of two pyrene molecules in the free-molecular regime and therefore connects the gaseous pyrene concentrations with the smallest particle size section. The surface chemistry model considers growth via the HACA mechanism developed in [19], and soot 
size reduction via oxidation [20]. Surface growth via PAH condensation is calculated by considering collisions between pyrene molecules and soot aggregates of any size [21]. Based on a detailed analysis, the probability of sticking in each PAH-soot collision, $c$, is set to 0.5 [22]. Coagulation, which occurs when two soot particles collide and join, is modelled by calculating the collision rates between soot particles and a collision efficiency accounting for the probability of a bounce back. Fragmentation happens when a soot aggregate breaks into two smaller aggregates. In modelling, a fragmentation rate is assigned to each aggregate based on the number of primary particles in the aggregate and its fractal dimension. It is assumed that soot aggregates can only break into two smaller aggregates with equal mass. The details of these models can be found in [17] [18].

\subsubsection{Boundary Conditions}

As shown in Fig. 2.1, the boundary conditions used in the present work include inlet condition, symmetry, free-slip, and zero-gradient at the inlet, centerline, the outer radial boundary, and the outflow boundary, respectively. The details of the boundary conditions are as follows:

\section{Inlet:}

$0 \leq r \leq r_{o}, z=0$ ( $r_{o}$ is the outer radius of the air passage $)$

The inlet line is divided into three regions. The first region is from $r=0$ to $r=r_{i}\left(r_{i}\right.$ is the inner radius of the fuel tube), for which the inlet conditions of the fuel are applied. The second region is the area right above the fuel tube rim, with thickness $\tau$, for which the inlet velocity and mole 
fractions are set to zero. The third region is from $r=r_{i}+\tau$ to $r=r_{o}$, for which the inlet conditions of air are applied. These boundary conditions are provided here:

For $r \leq r_{i}$ :

$$
\begin{gathered}
u=u_{\text {fuel }} \\
v=0 \\
T=T_{\text {fuel }} \\
Y_{\text {fuel }}=1.0 \\
N_{i}^{a}=0 \\
N_{i}^{p}=0
\end{gathered}
$$

For $r_{i}<r \leq r_{i}+\tau$ :

$$
\begin{gathered}
u=0 \\
v=0 \\
T=T_{\text {fuel }} \\
Y_{k}=0
\end{gathered}
$$




$$
\begin{aligned}
N_{i}^{a} & =0 \\
N_{i}^{p} & =0
\end{aligned}
$$

For $r_{i}+\tau \leq r \leq r_{o}$ :

$$
\begin{gathered}
u=u_{\text {air }} \\
v=0 \\
T=T_{\text {air }} \\
Y_{\mathrm{O}_{2}}=0.231 \\
Y_{\mathrm{N}_{2}}=0.769 \\
N_{i}^{a}=0 \\
N_{i}^{p}=0
\end{gathered}
$$

\section{Axis of Symmetry:}

$r=0,0 \leq z \leq H$ ( $H$ is the height of the solution domain in the axial direction)

The zero-gradient conditions are applied at the axis of symmetry (z-axis), as follows: 


$$
\begin{gathered}
\frac{\partial u}{\partial r}=0 \\
v=0 \\
\frac{\partial T}{\partial r}=0 \\
\frac{\partial Y_{k}}{\partial r}=0 \\
\frac{\partial N_{i}^{p}}{\partial r}=0 \\
\frac{\partial N_{i}^{a}}{\partial r}=0
\end{gathered}
$$

\section{Outer Radial Boundary:}

$r=r_{o}, \quad 0 \leq z \leq H:$

At the outer radial boundary, a free-slip boundary condition is applied, as follows:

$$
\begin{gathered}
\frac{\partial u}{\partial r}=0 \\
v=0 \\
\frac{\partial T}{\partial r}=0
\end{gathered}
$$




$$
\begin{gathered}
Y_{\mathrm{O}_{2}}=0.231 \\
Y_{\mathrm{N}_{2}}=0.769 \\
\frac{\partial N_{i}^{p}}{\partial r}=0 \\
\frac{\partial N_{i}^{a}}{\partial r}=0
\end{gathered}
$$

\section{Outflow:}

$0 \leq r \leq r_{o}, z=H$

$$
\begin{aligned}
& \frac{\partial u}{\partial z}=0 \\
& \frac{\partial v}{\partial z}=0 \\
& \frac{\partial T}{\partial z}=0 \\
& \frac{\partial Y_{k}}{\partial z}=0 \\
& \frac{\partial N_{i}^{p}}{\partial z}=0
\end{aligned}
$$




$$
\frac{\partial N_{i}^{a}}{\partial z}=0
$$

Since the conditions on the normal velocity at the boundaries are provided, pressure or pressure correction boundary conditions are not needed in order to solve the systems of equations.

\subsection{Numerical Method}

The governing equations are discretized using the finite volume method. A second-order central difference scheme is used to discretize the diffusive terms, while a power law scheme is used to discretize the convective terms [23].

In order to save computational cost while resolving large spatial gradients, a non-uniform mesh has been implemented, which is finest near the flame centerline and fuel tube. The mesh size stretches in both radial and axial directions and becomes coarser while moving away from the flame region. Grid independence has been achieved by further refinement of the grids and ensuring that the changes in the solution are insignificant.

The numerical solutions are sought using parallel processing due to the high computational intensity of the problem. The computational domain is divided into 192 control volumes in the axial direction and 88 control volumes in the radial direction (the number of control volumes are different for the various flames studied). The actual dimensions of the solution domain, number of cells, and the finest cell size for different flames is provided in Table 2.2. Flat velocity profiles are assumed for the inlet fuel and oxidizer streams. Strip-domain decomposition is implemented in a way that one CPU is assigned to one whole row of control volumes (88 control volumes). A 
sample of grids and the strip-domain decomposition used in the simulations is shown in Fig. 2.1. The interprocess communication is executed using the Fortran Message Passing Interface (MPI) library [24] [25]. The computations are performed on the General Purpose Cluster (GPC) and the Ryerson Sandybridge (Sandy) Cluster of the SciNet Computing Consortium of Compute Canada.

Table 2.2. Solution domain for the flames studied.

\begin{tabular}{cccc}
\hline Flame & $\begin{array}{c}\text { Solution Domain } \\
(\mathbf{c m} \times \mathbf{c m})\end{array}$ & $\begin{array}{c}\text { Number } \\
\text { of cells }\end{array}$ & $\begin{array}{c}\text { Finest } \\
\text { cell size } \\
(\mathbf{c m} \times \mathbf{c m})\end{array}$ \\
\hline NSI & $12.29 \times 4.75$ & $192 \times 88$ & $0.05 \times 0.02$ \\
\hline NSII & $12.29 \times 4.75$ & $192 \times 88$ & $0.05 \times 0.02$ \\
\hline IS & $17.35 \times 4.75$ & $218 \times 88$ & $0.05 \times 0.02$ \\
\hline S & $17.35 \times 4.75$ & $218 \times 88$ & $0.05 \times 0.02$ \\
\hline SM32 & $12.29 \times 4.75$ & $192 \times 88$ & $0.05 \times 0.02$ \\
\hline SM40 & $12.29 \times 4.75$ & $192 \times 88$ & $0.05 \times 0.02$ \\
\hline SM60 & $12.29 \times 4.75$ & $192 \times 88$ & $0.05 \times 0.02$ \\
\hline SM80 & $12.29 \times 4.75$ & $192 \times 88$ & $0.05 \times 0.02$ \\
\hline M/A & $12.29 \times 4.75$ & $192 \times 88$ & $0.05 \times 0.02$ \\
\hline E0 & $12.29 \times 4.75$ & $192 \times 88$ & $0.05 \times 0.02$ \\
\hline E20 & $12.29 \times 4.75$ & $192 \times 88$ & $0.05 \times 0.02$ \\
\hline E50 & $12.29 \times 4.75$ & $192 \times 88$ & $0.05 \times 0.02$ \\
\hline E85 & $12.29 \times 4.75$ & $192 \times 88$ & $0.05 \times 0.02$ \\
\hline
\end{tabular}

Pseudo-time marching is used to obtain a steady-state solution for the problem from an initial guess. The Semi-Implicit Method for Pressure Linked Equations (SIMPLE algorithm), in which the continuity equation is converted into the pressure correction equation, is used along with a staggered mesh to handle the coupling between pressure and velocity [23]. The thermal properties of the gaseous species and chemical reaction rates are obtained using CHEMKIN subroutines [26] [27]. Transport properties which include mixture-averaged quantities for viscosities, conductivities, and diffusion coefficients, as well as thermal diffusion coefficients for $\mathrm{H}$ and $\mathrm{H}_{2}$, are evaluated using TPLIB [28] [29]. 
At each Pseudo-time step, the governing equations that need to be solved for each control volume include 4 governing equations for axial velocity, radial velocity, pressure, and temperature, $\mathrm{KK}$ governing equations for species mass conservation ( $\mathrm{KK}$ is the number of species in the chemical mechanism, for instance, it is 93 for the ethylene chemical mechanism [4]), and 70 governing equations for particle dynamics. Therefore, at each time step, KK+74 equations are to be solved for each control volume. 


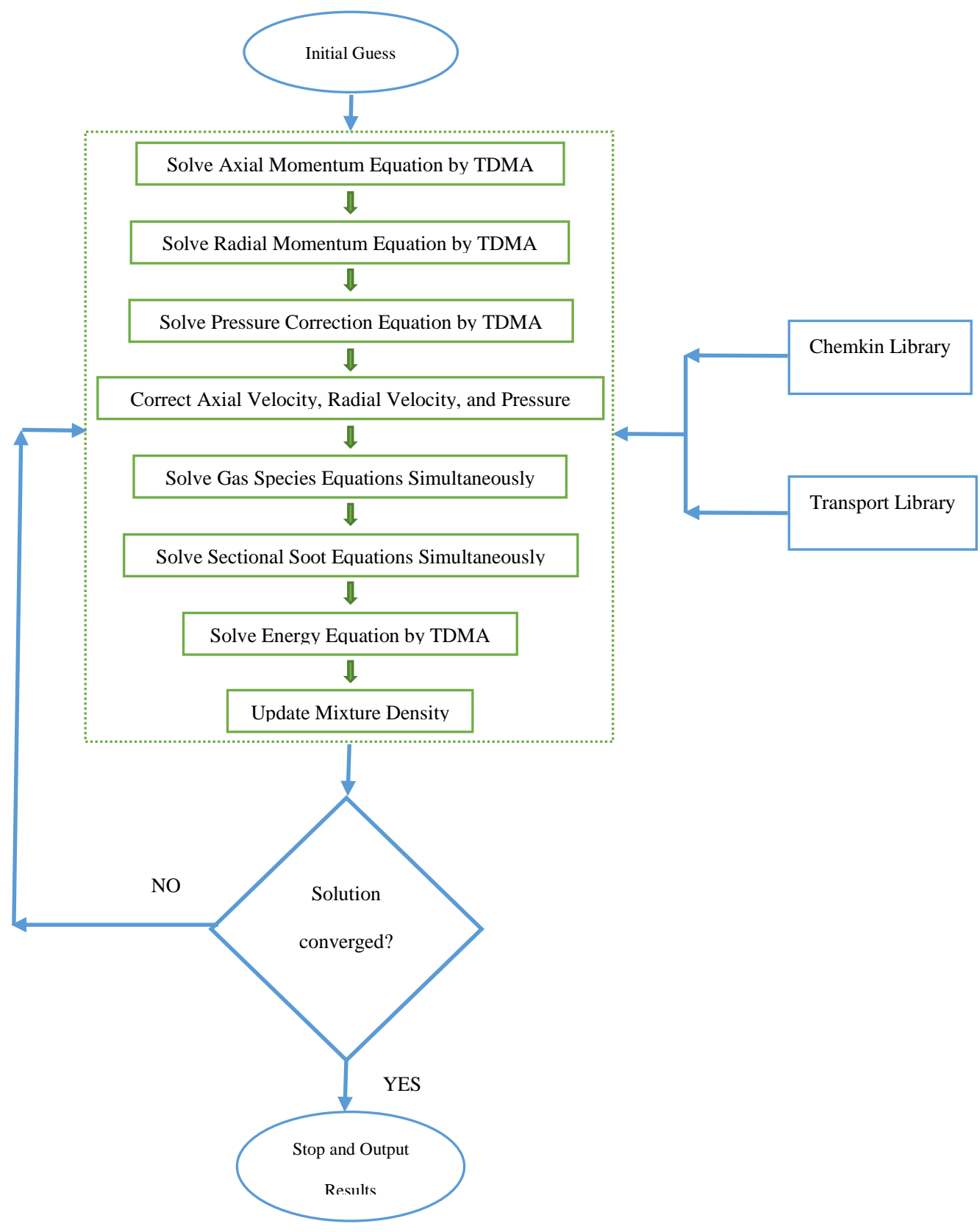

Fig. 2.2. Numerical Procedure 
Figure 2.2 shows the numerical procedure implemented in the CoFlame code to solve the systems of equations. The numerical procedure requires an initial guess for the velocity and temperature fields, mole fraction, and other variables. The speed of convergence is highly dependent on the initial guess. For the simulations starting from scratch, the initial parameters are set to constant values. However, in some cases, it is possible to use the solution of previous simulations as a starting estimate for the simulations. This helps decrease the convergence time significantly. The numerical procedure begins by solving the axial momentum, the radial momentum, and the pressure correction equations globally. Afterwards, the gaseous species equations are solved for each control volume simultaneously to handle the stiffness of the problem. Then, the conservation equations of sectional soot aggregate number density and primary particle number density are solved for each control volume. Since 35 sections are used to divide soot mass, at each control volume, 35 equations for soot aggregate number density and 35 equations for primary particle number density are solved. These equations are solved controlvolume by control-volume in the same manner as the species equations. The next step is to solve the energy equation to provide an updated temperature field.

The governing equations of radial momentum, axial momentum, pressure correction, and energy are linearized and the resulting sets of linear equations are solved using a Tri-Diagonal Matrix Algorithm (TDMA). The non-linear source terms in the gas species equations are linearized using their Taylor series obtained on the previous timestep values, while neglecting the second and higher order terms. Gauss elimination method is used to solve these liner systems at each control volume. At the end of the iteration, the mixture density is updated and a convergence check is performed. The solution is assumed to have converged when the maximum relative 
error of the flame temperature, species concentrations, and soot volume fraction become less than $1 \times 10^{-4}$. If the convergence criterion is not satisfied, the solution will proceed and the next pseudo-time step starts, again with the solution of axial momentum equation followed by radial momentum and pressure correction equations. In order to ensure that the effects of convergence tolerance are insignificant on the solution, the convergence tolerance is reduced by one order of magnitude and the solution is monitored for any meaningful changes. A typical solution requires about 25000 to 35000 iterations, which can vary considerably depending on the initial guess. Each iteration (pseudo-time step) takes about 3.5-5.8 s of wall-clock time, which is strongly dependent on the number of species and in turn the chemical mechanism used for simulations.

\subsection{Chemical Mechanism}

The chemical mechanisms used in the present study include a shortened version of the mechanism developed by Raj et al. [6] and the one developed by the German Aerospace Center (DLR) chemical kinetics department [4], henceforth referred to as the DLR mechanism.

The mechanism of Raj et al. [6] consists of 231 species and 1500 reactions and includes PAHs up to coronene (A7). In order to use this mechanism in the present work, the PAHs beyond A4 were removed to make the chemical mechanism consistent with the soot model, which assumes that inception and condensation involve only A4. Another 53 species that were believed to be unimportant, including those contributing to the formation of PAHs larger than A4, were removed to arrive at this shortened version. When PAHs larger than A4 are removed from the chemical mechanism, they will be treated as soot particles, thereby accounting for the error of 
neglecting their growth in soot modelling. The resulting mechanism, which consists of 175 chemical species and 1086 reactions, is used to model the E0 flame (pure gasoline). So as to make the mechanism suitable to model the flames of gasoline/ethanol blends, a sub-mechanism for the ethanol chemical reactions adopted from Andrae [7] was added to the Raj et al. [6] mechanism. This sub-mechanism for ethanol reactions consists of five additional chemical species $\left(\mathrm{C}_{2} \mathrm{H}_{5} \mathrm{OH}, \mathrm{CH}_{3} \mathrm{CHOH}, \mathrm{C}_{2} \mathrm{H}_{4} \mathrm{OH}, \mathrm{CH}_{3} \mathrm{CH}_{2} \mathrm{O}\right.$, and $\left.\mathrm{HOC}_{2} \mathrm{H}_{4} \mathrm{O}_{2}\right)$ and 41 reactions. The subsequent mechanism, consisting of 180 species and 1127 reactions, is used in the simulations of gasoline/ethanol blended fuel flames.

The DLR mechanism is used to simulate ethylene flames in Chapters 4 and 5. This mechanism contains 93 species and 719 reactions, and provides reactions of PAHs up to A5. This mechanism has been validated for flame speeds, profiles of small and large aromatics, and soot volume fraction. Based on an updated literature review and the current understanding of PAH formation processes, Chernov et al. [30] enhanced this mechanism to accommodate the PAH gas phase growth associated with methane combustion, with the addition of 6 reactions and updating 15 reactions. This updated mechanism is used to simulate the methane/air flame in Chapter 5. 


\title{
Chapter 3
}

\section{Experimental and Numerical Study of Soot Formation in}

\section{Laminar Coflow Diffusion Flames of Gasoline/Ethanol}

\section{Blends}

Corresponding Publication: A. Khosousi, F. Liu, S.B. Dworkin, N.A. Eaves, M.J. Thomson, X. He, Y. Dai, S. Shuai, J. Wang, "Experimental and Numerical Study of Soot Formation in Laminar Coflow Diffusion Flames of Gasoline/Ethanol Blends," Combustion and Flame 162 (2015) 3925-3933.

\begin{abstract}
This paper reports the experimental and numerical results of soot formation in laminar coflow diffusion flames of vaporized gasoline/ethanol blends at atmospheric pressure to gain improved understanding of ethanol addition to gasoline on soot formation. Four gasoline/ethanol blends of different ethanol mole fractions in the fuel stream ranging from $0 \%$ up to $85 \%$ (by volume), E0, E20, E50, and E85, were investigated to quantify how soot loading varies with the amount of ethanol blending in the fuel. The laminar coflow diffusion flames were generated using a burner system designed for vaporized liquid fuels. The fuel stream was heavily diluted with nitrogen to lower the boiling points and to prevent the flames from smoking. The soot volume fraction distributions were measured using a 2D line-of-sight attenuation (LOSA) technique. These flames were also modelled numerically using the extensively validated CoFlame code and a recently developed reaction mechanism for gasoline surrogates including PAH formation. The
\end{abstract}


results of experiment and numerical modelling agree quite well in terms of the levels of soot volume fraction and they both show a decrease in the soot loading as more ethanol is added in the fuel stream. The measured peak soot volume fraction occurs in the flame centerline region. The soot model used in this study is unable to capture this experimental feature and predicts the peak soot volume fraction in the co-annular region. Ethanol addition reduces the soot loading primarily by lowering soot inception and PAH condensation rates through decreasing the concentrations of aromatics. Additional measurements in gasoline surrogate/ethanol blend flames indicate that the gasoline surrogate model emulates well the sooting propensity of the real gasoline fuel.

Keywords: Laminar diffusion flame, Soot, Gasoline, Ethanol, Gasoline Surrogate

\subsection{Introduction}

Combustion-generated soot (also known as black carbon particulate) emission has been identified to be a serious threat to human health and the urban environment [1] and should be mitigated in combustion systems. The environmental and health issues and the increasingly more stringent soot particulate emission regulations have generated unprecedented motivations and pressure for combustion researchers and combustion device designers to gain better understanding of soot formation mechanisms and attempt to reduce pollutant and particulate emissions. Approaches that could help achieve this goal include reducing dependence on traditional fossil fuels, increasing efficiency of combustion systems, and the use of alternative renewable fuels. Renewable fuels have received world-wide attention in recent years due to the 
carbon-neutral nature of these fuels and the concerns of the limited reserve of petroleum based fuels. Biofuels have a great potential for renewability and reduction of greenhouse gases. According to the projection of the International Energy Agency, biofuels have the potential to provide up to $27 \%$ of the world demand for transportation fuels by 2050 [31].

The transportation sector accounts for approximately one-fifth of the global black carbon emissions and is therefore a major black carbon emission source. Gasoline vehicles constitute the larger portion of light-duty vehicles world-wide. Soot emissions from traditional port-fuel injection (PFI) gasoline engines had not been a serious concern since combustion takes place in stoichiometric mixtures and soot emissions are in general very low. Although the gasoline direct injection (GDI) engines offer several advantages over the conventional PFI engines and have become increasingly popular among passenger car manufactures in recent years, they cause significantly higher soot emissions [32] [33]. One strategy to reduce soot emissions from GDI vehicles to meet the emission regulations is to use a gasoline particulate filter (GPF). However, GPF is not cost-effective and it is highly desirable to reduce soot emissions from GDI engines through improved engine design [33]. Another strategy for GDI vehicles to meet emission regulations is to use blends of gasoline and biofuels, which in turn requires improved understanding of soot formation in such blended fuel flames and the role of fuel chemistry on formation of aromatics, polycyclic aromatic hydrocarbons (PAHs), and soot.

Among various oxygenated biofuels for blending with gasoline, ethanol has received the most attention since it has the potential to enhance engine operation, reduce soot emissions, and can be produced from a wide variety of renewable feed stocks, such as potato, brewery waste, sugar 
cane, bagasse, and cellulosic biomass, through the steps of microbial fermentation of sugars, distillation, and dehydration. Ethanol is rapidly biodegraded in surface water, groundwater, and soil. With improving technologies used in ethanol production, the water usage is declining. Moreover, with the development and application of cellulosic ethanol production approach, the production of ethanol can further alleviate the land and water use and the related ecological concerns. Ethanol has a higher octane number than gasoline and therefore its mixtures with gasoline are of particular interest to the automotive industry [34] [35]. These blends can be readily used in spark ignition engines without any modifications.

Using ethanol as an additive to a hydrocarbon fuel changes its sooting propensity. Although it is useful and necessary to investigate the effects of ethanol blending on soot emissions from GDI engines, it is also important and necessary to study the fuel chemistry effect on formation of aromatics, PAHs, and soot in well-controlled laboratory flames, since the sensitivity of soot emissions from a GDI engine to various engine parameters can mask the effect of fuel blending on soot formation [33]. The influence of ethanol on soot formation has been studied by researchers in different flames and for different fuels, including ethylene and gasoline [33] [36] [37] [38] [39]. Most of the studies conducted so far, both in engines and in flames, suggest that adding ethanol to diesel, gasoline, and ethylene reduces PAH and soot formation, e.g., [33] [36] [37] [40] [41]. Lemaire et al. [36] studied the effects of addition of ethanol to gasoline and to a gasoline surrogate on soot and PAH formation in turbulent spray flames. They observed substantial reductions in the concentrations of soot and PAHs when adding ethanol to the fuel. They also reported that soot particles are oxidized faster as ethanol percentage increases in the fuel mixture. Lemaire et al. [36] also found that addition of ethanol suppresses soot formation 
not only by the dilution effect, but also by chemical (oxygen) effect [36]. The effects of ethanol addition on PAH and soot formation in flat rich premixed ethylene/air flames were investigated by $\mathrm{Wu}$ et al. [37] both experimentally and numerically. Both their experimental and numerical results showed that addition of ethanol reduces PAH and soot formation. Through analyzing the decomposition pathways of ethanol, Wu et al. [37] concluded that addition of ethanol to the rich ethylene/air mixture reduces the aromatic species concentrations by lowering the amount of carbon available to form precursor species of aromatics. Maricq [33] investigated the effect of adding ethanol to gasoline at different levels in laminar coflow diffusion flames on soot particle size distributions. The flames investigated by Maricq [33] were smoking, except the E85 (85\% ethanol/15\% gasoline blend) one. It was observed that adding small amounts of ethanol results in slight changes in flame properties and size distributions compared to the base gasoline fuel case. However, a different behaviour was also observed when adding more ethanol in terms of flame shape and soot emissions. Maricq [33] pointed out that other factors like fuel volatilization and mixing might play more important roles than combustion chemistry at low levels of ethanol addition. The diesel engine emission measurements of Chen et al. [40] and Lapuerta et al. [41] found that addition of ethanol to diesel up to $20 \%$ by volume reduces soot emissions rather significantly.

In some cases, however, an increase in soot formation has been reported as a response to the addition of small percentages of ethanol to fuel in ethylene diffusion flames [38] [39]. McNesby et al. [38] studied the effects of ethanol addition to opposed-flow ethylene/air diffusion flames. They noted that depending on how ethanol was added, either in the fuel or air stream, increases or decreases in soot formation could be observed, respectively. The increase was due to 
enhanced fuel pyrolysis leading to increased soot precursor concentrations, and the decrease was due to higher temperature and $\mathrm{OH}$ concentrations, leading to increased oxidation. In turbulent, or co-flowing laminar systems, both of these effects may occur simultaneously, depending on fuel/air conditions and mixing. McEnally and Pfefferle [39] conducted an experimental study of the effects of up to $10 \%\left(Q_{\mathrm{C} 2 \mathrm{H} 5 \mathrm{OH}}: Q_{\mathrm{C} 2 \mathrm{H} 4}, Q\right.$ is the volumetric flow rate) ethanol addition to fuel on benzene and soot formation in a laminar coflow ethylene/air diffusion flame. It was observed that addition of relatively small amounts of ethanol results in higher benzene and soot concentrations [39]. Based on their detailed species concentration measurements, McEnally and Pfefferle [39] explained the increased formation of benzene and soot by the enhanced formation of methyl radical, which prompts the $\mathrm{C}_{1}+\mathrm{C}_{2}$ addition reactions to form propargyl radical. The self-reaction of propargyl then leads to the enhanced formation of benzene. Subsequently, more PAHs and soot are formed. The reason for the sensitive response of the ethylene diffusion flame to the enhanced methyl radical formation is because methyl radical concentrations are very low in this flame. In other systems, such as those of addition of dimethyl ether (DME) to fuel in ethylene/air diffusion flames studied in [39] [42], the synergistic effects on soot formation have also been observed with the addition of oxygenated fuel components, and have been attributed to specific chemical pathways, in particular the interactions of $\mathrm{C}_{1}$ and $\mathrm{C}_{2}$ to form propargyl. As pointed out by McEnally and Pfefferle [39], however, the larger alkanes, which are a major constituent of gasoline [3], decompose more readily to methyl. Therefore, the synergistic effect of adding a small amount of oxygenated fuels (DME and ethanol) to fuel in ethylene/air diffusion flames [38] [39] [42] is likely a phenomenon to $\mathrm{C}_{2}$ fuels, but not to transportation fuels, such as gasoline. 
There is currently a lack of experimental data of detailed soot volume fraction distributions in laminar coflow diffusion flames of vaporized gasoline and gasoline/ethanol blends. Such experimental data are highly desirable for the purposes of validating the gasoline surrogate models in terms of soot formation [3] and gaining better fundamental understanding of the role of fuel chemistry in soot formation reduction by ethanol addition to gasoline observed experimentally in [33] [36]. It is noticed that the diffusion flames investigated in [33] [36] do not serve such purposes since Lemaire et al. [36] studied turbulent spray flames, while Maricq [33] measured only soot particle size distributions in laminar coflow smoking flames.

The present study investigates soot formation in laminar coflow diffusion flames of vaporized gasoline and ethanol/gasoline blends using experimental and numerical methods. Radiallyresolved soot volume fraction distributions were measured using the two-dimensional line-ofsight attenuation (2D-LOSA) technique [2] and an Abel inversion algorithm [43]. Numerical calculations are conducted using a gasoline surrogate model with a fairly detailed reaction mechanism and a sectional soot model. The effect of ethanol addition to gasoline is investigated for different levels of blending, ranging from E0 up to E85. The high computational intensity of the flame modelling requires parallel processing. An in-house algorithm, known as the CoFlame code, is used to perform the computations in the present study. The CoFlame code has been validated for a variety of fuels [4] [5] [22] [30] [42] [44] [45] [46] [47] [48]. However, it has not been applied to laminar coflow gasoline/ethanol diffusion flames. The objectives of this study are twofold: (1) to present experimental data of soot volume fraction distributions in laminar coflow diffusion flames of gasoline and gasoline/ethanol blends that can be used for validation of gasoline surrogate models, and (2) to gain further fundamental insights into how addition of 
ethanol to gasoline affects PAH and soot formation in laminar coflow diffusion flames. The results of this study provide valuable information on how soot formation and emissions may be affected by addition of ethanol to gasoline.

\subsection{Experimental Setup}

\subsubsection{Fuels}

In the present study, four liquid fuels were investigated. They comprise the pure No. 92 gasoline (from a commercial gas station in Beijing, China), known hereafter as E0, and three gasoline/ethanol blends, E20, E50, and E85, which consist of 20\%, 50\%, and 85\% ethanol (volume basis), respectively. The No. 92 gasoline, which has a research octane number (RON) of 92, used in the experiments consists of $49.2 \%$ saturates, $36.1 \%$ aromatics, and $14.7 \%$ olefins (volume basis). In all the experiments the carbon flow rate was kept constant at $6.05 \mathrm{~g} / \mathrm{h}$ (with an uncertainty of about $0.05 \mathrm{~g} / \mathrm{h}$ ). The blending ratio, elemental mass distributions, and the fuel flow rates are summarized in Table 3.1.

Table 3.1. Gasoline and ethanol volume percentages in the four liquid fuel blends, elemental mass distributions, and fuel mass flow rates ( $\left({ }^{\mathrm{a}}\right.$ Volume \%, ${ }^{\mathrm{b}}$ Weight $\left.\%\right)$.

\begin{tabular}{ccccc}
\hline & E0 & E20 & E50 & E85 \\
\hline Gasoline $^{\mathrm{a}}$ & 100 & 80 & 50 & 15 \\
\hline Ethanol $^{\mathrm{a}}$ & 0 & 20 & 50 & 85 \\
\hline Carbon content $^{\mathrm{b}}$ & 86.4 & 79.2 & 68.7 & 57.0 \\
\hline Oxygen content $^{\mathrm{b}}$ & $<0.05$ & 7.32 & 17.93 & 29.8 \\
\hline Hydrogen content $^{\mathrm{b}}$ & 13.59 & 13.49 & 13.35 & 13.2 \\
\hline Flowrate $\mathrm{g} / \mathrm{h}$ & 7 & 7.63 & 8.82 & 10.6 \\
\hline
\end{tabular}




\subsubsection{The Burner System}

The burner system shown schematically in Fig. 3.1 comprises the laminar coflow diffusion flame burner, fuel reservoir, controlled evaporator and mixer (CEM), mass flow controllers, air compressor, fuel and air lines, and heating tapes for both the air and fuel lines. It is useful to point out that only the fluid in the top part of the accumulator and in the tube connecting the fuel accumulator and the CEM is in liquid phase; all the fluids in other parts in Fig. 3.1 are in gas phase.

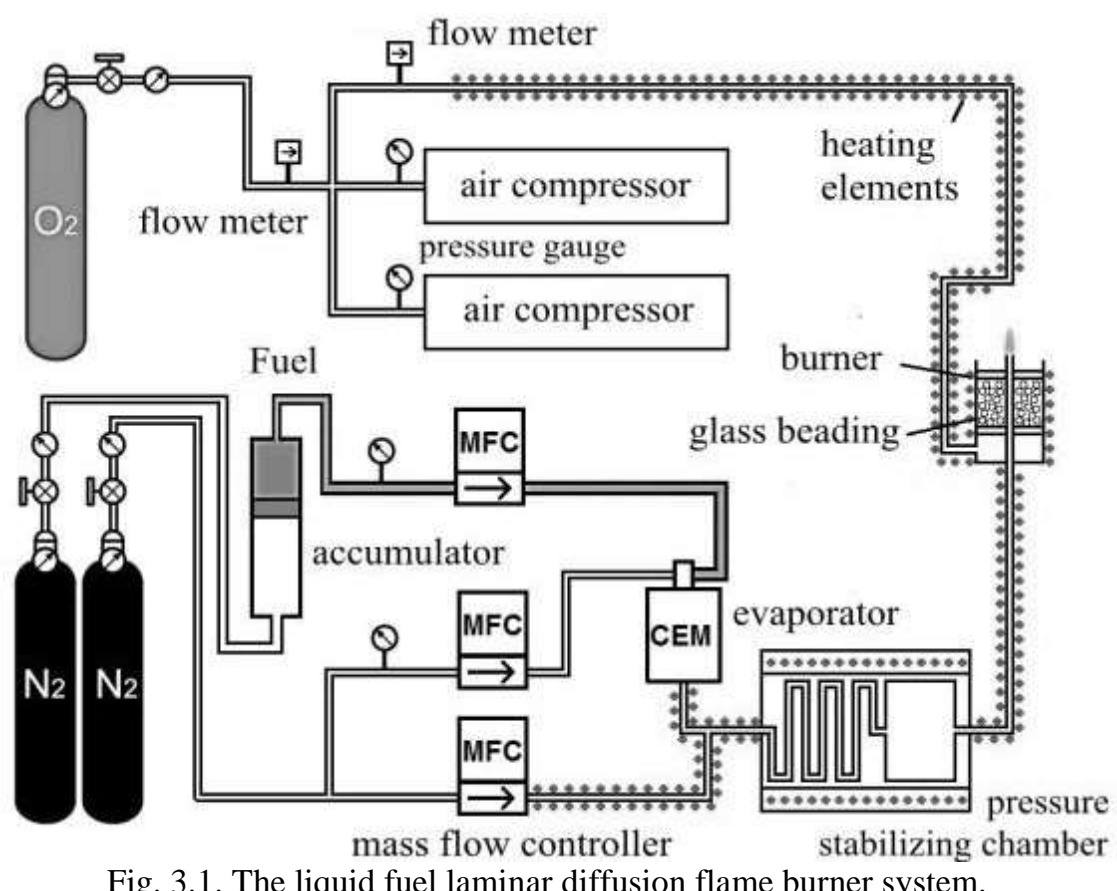

Fig. 3.1. The liquid fuel laminar diffusion flame burner system.

The coflow flame burner is a modified version of the Gülder burner [49]. The inner diameter of the fuel tube is $10.9 \mathrm{~mm}$ and the inner diameter of the outer air tube is $89 \mathrm{~mm}$. Porous sintered metal plates and glass beads used in the air stream help generate uniform flows, reduce flow fluctuations, and improve the flame stability. The entire burner assembly below the gas exit 
plane is surrounded by an outer heating unit to maintain the whole burner at a temperature up to about $573 \mathrm{~K}\left(300^{\circ} \mathrm{C}\right)$ to prevent condensation of vaporized fuel inside the burner assembly.

Instead of a syringe pump, the device to store and supply the liquid fuel is a commercial liquidgas piston-type accumulator with a volume of 11 and a maximum working pressure of 3000 psi. Vaporization of heavy components of a transportation fuel, such as gasoline, is a challenge because of their fairly high and different boiling points. To produce non-smoking laminar diffusion flames, and to ensure that all components of the liquid fuel are vaporized at a relatively low temperature around $473 \mathrm{~K}\left(200^{\circ} \mathrm{C}\right)$, the fuel is heavily diluted with nitrogen. Although the present design allows some carrier/diluent nitrogen to be delivered without going through the CEM device, as shown in Fig. 3.1, all the nitrogen was delivered through the CEM device in all the experiments conducted in this study at $0.3 \mathrm{l} / \mathrm{min}$ (at $273 \mathrm{~K}, 1 \mathrm{~atm}$ ) with an uncertainty of about $0.5 \%$.

Stable vaporization of the liquid fuel was achieved using a Bronkhorst CEM device. Inside the CEM unit, the liquid fuel is first mixed with the diluent gas (here nitrogen) and then vaporized at a prescribed temperature of $451 \mathrm{~K}( \pm 2 \mathrm{~K})$. This CEM temperature was selected based on a sensitivity study in which the effect of the CEM temperature on the visible flame height and soot volume fraction distribution was investigated by varying the CEM temperature from $423 \mathrm{~K}$ (150 $\left.{ }^{\circ} \mathrm{C}\right)$ to $451 \mathrm{~K}\left(178{ }^{\circ} \mathrm{C}\right)$, and finally to $473 \mathrm{~K}\left(200{ }^{\circ} \mathrm{C}\right)$. It is noticed that $473 \mathrm{~K}\left(200{ }^{\circ} \mathrm{C}\right)$ is the maximum temperature allowed for the CEM device used in this study. It was found that there are appreciable increases in the visible flame height and the soot loadings when the CEM temperature is increased from $423 \mathrm{~K}\left(150{ }^{\circ} \mathrm{C}\right)$ to $451 \mathrm{~K}\left(178{ }^{\circ} \mathrm{C}\right)$; however, the variations are 
negligibly small when the CEM temperature is further increased from $451 \mathrm{~K}\left(178{ }^{\circ} \mathrm{C}\right)$ to $473 \mathrm{~K}$ $\left(200{ }^{\circ} \mathrm{C}\right)$. After leaving the CEM device, the fuel mixture passes through a pressure stabilizing chamber to dampen any pressure fluctuations in the system before being delivered to the burner via heated tubes kept at $573 \mathrm{~K}$. In the present experiments, the fuel mixture after the CEM device, the pressure stabilizing chamber, the fuel tube connected to the burner, the burner assembly, and the air flow tube were all maintained at $573 \mathrm{~K}$ to avoid fuel condensation in the burner system. The air flow rate was maintained at 167 1/min (at $273 \mathrm{~K}, 1 \mathrm{~atm}$ ) throughout this study. All the experiments were conducted at atmospheric pressure. Under these experimental conditions, fairly stable diffusion flames can be achieved over a sufficiently long time at a visible flame height of $50 \mathrm{~mm}$ with a vertical fluctuation of about $1-2 \mathrm{~mm}$.

\subsubsection{Soot Volume Fraction Measurement}

The soot volume fraction distributions in the laminar axisymmetric coflow diffusion flames were measured using the 2D-LOSA technique [2]. The 2D-LOSA setup is shown schematically in Fig. 3.2. The system consists of a point light source, a reflecting mirror, a concave mirror, the flame, lenses, a pin-hole aperture, an interference filter, and a high-speed CMOS camera. The light source is provided by a halogen lamp and an aperture. The combination of the reflecting and concave mirrors transforms the point light source into a parallel light beam. The aperture between the two convex lenses is used to reduce the flame radiation to the detector. The aperture is selected large enough (1 $\mathrm{mm}$ in this work) to minimize the Schlieren effects due to beam steering by the flame. The diameter and focal length of the two convex lenses are 50.8 and 250 $\mathrm{mm}$, respectively. The detector is a VRI Phantom v7.3 CMOS camera. The detector array size is 
$512 \times 512$ pixels with a square pixel size of $196.2 \mu \mathrm{m}$. The camera was set at a speed of 30 frame/s and an exposure time of 1/10,000 s.

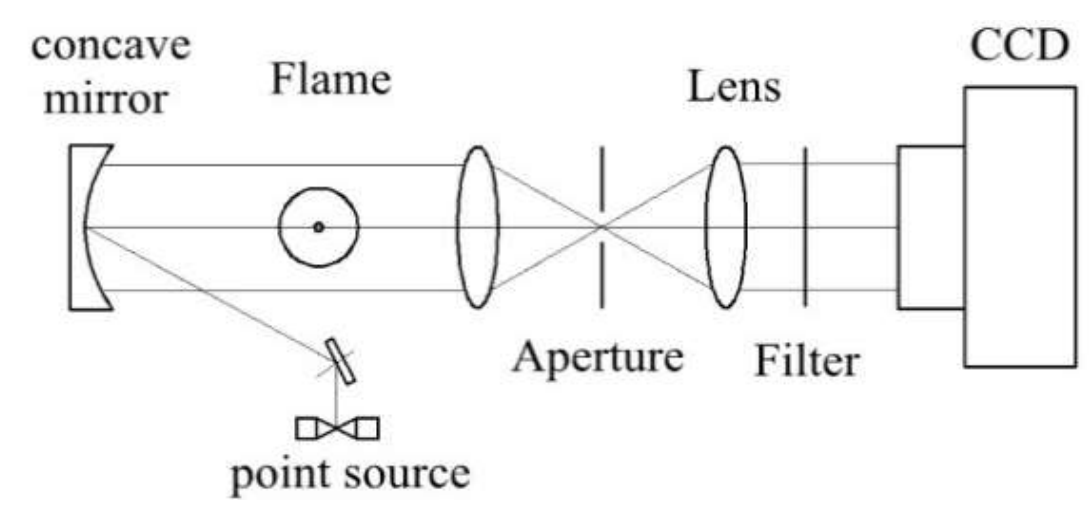

Fig. 3.2. A schematic of the 2D-LOSA setup for soot volume fraction measurements.

The experimental procedures follow closely those described in Snelling et al. [2], except the bandpass filter in front of the camera (577 nm in [2], but $675 \mathrm{~nm}$ in this study). It is noticed that an interference filter centered at $675 \mathrm{~nm}$ (with a bandwidth of $30 \mathrm{~nm}$ ) was used in this study to avoid light absorption by PAHs and minimize light attenuation by soot scattering based on two recent studies [50] [51], which recommend conducting extinction measurements at wavelengths in the upper visible or the near infrared spectral range. In laminar coflow ethylene/air diffusion flames with soot loadings even somewhat higher than those in the present study, the contribution of soot scattering to extinction was estimated to be fairly insignificant compared to absorption by less than about $10 \%$ at $500 \mathrm{~nm}$ [50] [52]. Therefore, soot scattering contribution to light attenuation at $675 \mathrm{~nm}$ is significantly smaller and can be neglected in the present data analysis.

Although the laminar flames produced using the liquid burner described above are fairly stable, they are not as stable as gaseous flames, such as methane and ethylene flames, and slight to modest flame instability can be observed. To suppress the flame instability effects in the LOSA 
measurements, at least 100 flame images were acquired for each fuel conditions and the averaged image was used in the data analysis. The three-point Abel inversion method of Dasch [43] was used to obtain the radially resolved soot absorption coefficient from LOSA measurements. It should be pointed out that the acquired transmission images were first smoothened using the Gaussian spatial filter in Matlab before further data analysis. The conversion of the local soot absorption coefficient to soot volume fraction is achieved by assuming that soot particles are in the Rayleigh scattering regime using the following expression:

$f_{v}=\frac{K_{a} \lambda_{E}}{6 \pi E(m)}$

where $K_{a}$ is the soot absorption coefficient reconstructed from the Abel inversion, $E(m)$ is the soot absorption function at the extinction measurement wavelength of $\lambda_{E}=675 \mathrm{~nm}$. In this study, $E(m)$ was assumed to be 0.35 based on the recent study of Coderre et al. [53], who found that the $E(m)$ value of soot is constant at about 0.35 in the visible spectral range between 450 and 750 nm.

The error and uncertainty in the measured soot volume fraction are mainly due to beam steering, smoothing of transmissivity by the Gaussian filter, and the uncertainty in the value of $E(m)$. The uncertainty in the value of $E(m)$ at $675 \mathrm{~nm}$ is estimated to be less than $20 \%$ [53]. The uncertainty in the measured soot volume fraction is estimated to be $30 \%$. 


\subsection{Numerical Method}

The governing equations for mass, momentum, energy, species, primary particle number densities, and soot aggregate number densities are solved in a coupled manner. The details of the CoFlame code's numerical model can be found in previous studies [5] [22] [46] [47]. The computational domain consists of 88 control volumes in the radial direction and 192 control volumes in the axial direction. The domain is divided into 192 subdomains in order to implement parallelization using 192 CPUs, each of which is responsible for a single row of 88 control volumes in the radial direction. A soot sectional model consisting of 35 sections is utilized and each section considers primary particle size and aggregate structure. The particle dynamics model includes inception, based on pyrene dimerization [21], hydrogen abstraction $\mathrm{C}_{2} \mathrm{H}_{2}$ addition (HACA) [19] [21] [54], PAH (pyrene) condensation, coagulation, and fragmentation [22]. The radiation model is the discrete ordinate method coupled with a statistical narrow-band correlated- $k$-based model [55], which accounts for soot, $\mathrm{H}_{2} \mathrm{O}, \mathrm{CO}_{2}$, and $\mathrm{CO}$ as radiating species. The oxidation model considers only $\mathrm{O}_{2}$ molecules and $\mathrm{OH}$ radicals, which have been identified to be the primary oxidative species [20] [56] [57] [58] [59] [60]. OH oxidation is based on a collision theory, which uses a constant collision efficiency between soot and $\mathrm{OH}$ of 0.13 [20]. $\mathrm{O}_{2}$ oxidation is based on the oxidation of phenyl proposed by Frenklach and Wang [54]. In previous numerical studies based on the CoFlame code [5] [22] [30] [44] [46] [47] [48], the steric factor $\alpha$, which represents the fraction of soot surface sites for HACA surface reactions (except oxidation by $\mathrm{OH}$ ) [21] [54], was considered to be a model parameter, whose value was tuned to provide good agreement with available experimental data. Although various efforts have been made to correlate $\alpha$ as a function of temperature, particle size, and in a recent study as a function of 
thermal age [11], it is unlikely to establish a generic expression for $\alpha$ that can be applied for flames of different fuels. This is because there are currently large uncertainties in the PAH formation sub-mechanism, which has a significant influence on the soot inception rate and the subsequent surface growth modelling. In this study, a constant $\alpha$ of 0.19 was used based on a sensitivity study to obtain good agreement in the peak soot volume fraction between modelling and experiment.

Gasoline is a complex mixture composed of hundreds of hydrocarbons [3]. Such a large number of compositions makes it impossible to model a real gasoline fuel in numerical simulations because of limited computational resources and the unknown kinetic mechanisms for many of them. Therefore, it is necessary to use a gasoline surrogate to emulate the real gasoline fuel. Most gasoline surrogates are mainly composed of toluene $\left(\mathrm{C}_{6} \mathrm{H}_{5} \mathrm{CH}_{3}\right)$, iso-octane $\left(\mathrm{i}-\mathrm{C}_{8} \mathrm{H}_{18}\right)$, and $n$-heptane $\left(\mathrm{C}_{7} \mathrm{H}_{16}\right)$, also known as toluene reference fuels (TRFs), at the current stage of gasoline surrogates development [3] [61] [62] [63] [64], though 4-component gasoline surrogates have also been proposed [7] [65]. It has been found that these gasoline surrogates replicate well the ignition delay times [61] [63], main heat release event and pressure profile of HCCI experiments [63], and soot formation and particle morphology in laminar coflow gasoline doped methane diffusion flames [66]. In this study, the No. 92 gasoline was represented by a gasoline surrogate model in the numerical simulations of gasoline/ethanol blend flames. The particular gasoline surrogate model employed in the present study is comprised of $19 \% n$-heptane, $38 \%$ toluene, and 43\% iso-octane (volume basis), which was formulated using the method of Morgan et al. [63] for $\mathrm{RON}=92$ and an assumed MON $=85$. It is noticed that the content of toluene, which is used not only to emulate the fuel sensitivity of real gasoline [63], but also to mimic the behaviour of the 
aromatics of a real gasoline fuel [66], in this surrogate model (38\% in volume) is very close to the aromatic content in the No. 92 gasoline studied (36.1\% given in Section 4.2.1). As mentioned earlier, the fuel stream is heavily diluted with nitrogen to lower the saturation vapor pressures of the surrogate fuel components and produce non-smoking laminar diffusion flames.

The chemical reaction mechanism used for the simulations in this work is adopted from [6] and [7]. The mechanism of Raj et al. [6] consists of 231 species and 1500 reactions and was developed from that of Marchal et al. [67], which was also developed for gasoline surrogate fuels and included PAHs up to pyrene (A4), by extending PAHs up to coronene (A7) and by adding several new PAH reactions to provide more reliable predictions of the concentrations of large PAHs. These modifications were found to improve the calculated concentrations of pyrene in $n$ heptane flames [6]. A shortened version of the Raj et al. [6] mechanism used in the present study for modelling the E0 (pure gasoline) consists of 175 chemical species and 1086 reactions. In the shortened version of the Raj et al. [6] mechanism, the PAHs beyond A4 were removed to keep the chemical mechanism consistent with the soot model, which assumes that inception and condensation involve only A4. In addition, another 53 species that are believed to be unimportant were removed from the Raj et al. [6] mechanism to arrive at this shortened version. This shortened mechanism has been used recently by Consalvi and Liu [48] in the simulation of soot formation in a laminar coflow $n$-heptane diffusion flame at elevated pressures.

To extend the shortened Raj et al. [6] mechanism to model gasoline/ethanol flames, the submechanism for the ethanol chemical reactions adopted from Andrae [7] was added to it. This sub-mechanism for ethanol reactions consists of five chemical species $\left(\mathrm{C}_{2} \mathrm{H}_{5} \mathrm{OH}, \mathrm{CH}_{3} \mathrm{CHOH}\right.$, 
$\mathrm{C}_{2} \mathrm{H}_{4} \mathrm{OH}, \mathrm{CH}_{3} \mathrm{CH}_{2} \mathrm{O}$, and $\mathrm{HOC}_{2} \mathrm{H}_{4} \mathrm{O}_{2}$ ) and 41 reactions. So the mechanism used in this study for gasoline/ethanol blended fuel flames consists of 180 species and 1127 reactions.

Four fuels were studied in this work, namely E0, E20, E50, and E85, as shown in Table 3.1. The base case, E0, is the pure gasoline fuel, i.e., without ethanol blending. Comparison between the calculated and measured soot volume fraction distribution gives an indication of the validity of the gasoline surrogate in soot formation modelling. The effect of ethanol addition to gasoline on soot formation has been studied with respect to E0 (pure gasoline) at three different levels of blending, i.e., $20 \%, 50 \%$, and $85 \%$ by volume. The fuel compositions specified at different levels of ethanol blending in the numerical simulations are chosen to provide the same carbon flowrate as in the experimental work. Table 3.2 shows the compositions (mole fraction), the inlet velocities, and temperature in the fuel stream. The air stream velocity is kept constant at 84.1 $\mathrm{cm} / \mathrm{s}$ for all the cases, with an inlet temperature of $523 \mathrm{~K}$ and compositions of $0.791 \mathrm{~N}_{2}$ and $0.209 \mathrm{O}_{2}$ by volume. These inlet values reproduce fairly well the visible flame heights observed in the experiments.

Table 3.2. The mean velocities, temperatures, and mole fractions of compositions at the inlet of the fuel stream of the four flames used in the simulations (gasoline was modelled by the surrogate).

\begin{tabular}{ccccc}
\hline & $\mathbf{E 0}$ & $\mathbf{E 2 0}$ & $\mathbf{E 5 0}$ & $\mathbf{E 8 5}$ \\
\hline $\boldsymbol{V}(\mathbf{c m} / \mathbf{s})$ & 11.72 & 11.97 & 12.58 & 14.16 \\
\hline $\boldsymbol{T}(\mathbf{K})$ & 573 & 573 & 573 & 573 \\
\hline $\mathbf{N}_{\mathbf{2}}$ & 0.8732 & 0.8547 & 0.8138 & 0.7229 \\
\hline Toluene & 0.0482 & 0.0442 & 0.0354 & 0.0158 \\
\hline iso-octane & 0.0545 & 0.0500 & 0.0400 & 0.0179 \\
\hline $\boldsymbol{n}$-heptane & 0.0241 & 0.0221 & 0.0177 & 0.0079 \\
\hline Ethanol & 0.0000 & 0.0291 & 0.0931 & 0.2355 \\
\hline $\mathbf{C} / \mathbf{O}$ & - & 31.72 & 9.43 & 3.31
\end{tabular}




\subsection{Results and Discussion}

\subsubsection{Experimental Results}

The visible appearance of the E0, E20, E50, and E85 flames is compared in Fig. 3.3. The visible (due to soot luminosity) flame heights are 50.0, 48.7, 46.5, and $45.6 \mathrm{~mm}$ for the E0, E20, E50, and E85 flames, respectively, i.e., the visible flame height decreases with increasing ethanol blending to gasoline. The decrease of the visible flame height is quite small at $20 \%$ ethanol blending, but becomes modest at $50 \%$ and $85 \%$ blending. The increased ethanol content in the fuel mixture results in not only a shorter visible flame, but also a larger distance between the burner exit and the base of the luminous flame wing and an extended region of low image intensity in the centerline, suggesting that soot inception is further delayed as more ethanol is blended into the fuel stream.

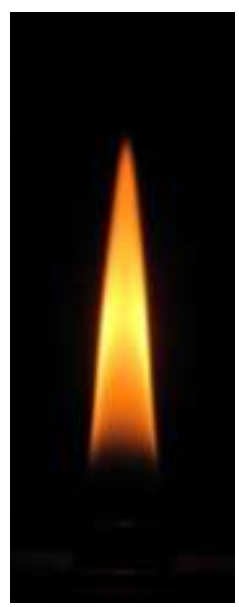

E0

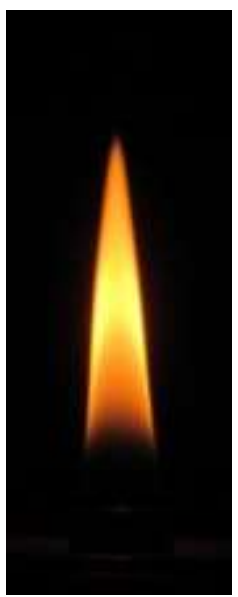

E20

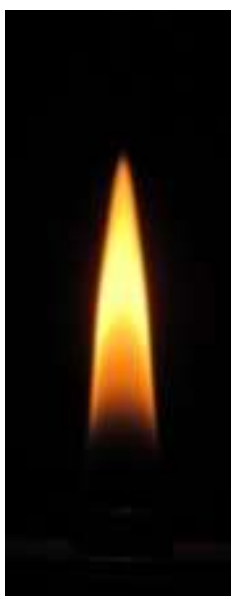

E50

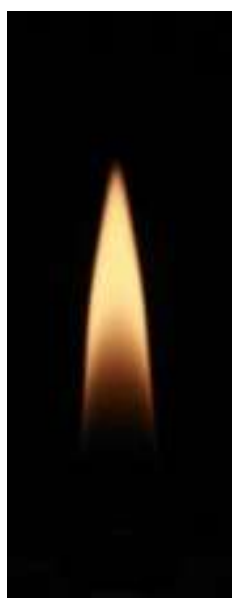

E85

Fig. 3.3. Photographs of the visible appearance of the E0, E20, E50, and E85 flames. 
The measured soot volume fraction distributions in the four flames using the 2D-LOSA technique are shown in Fig. 3.4. The peak soot volume fractions in each flame are indicated. It is interesting to observe that the high soot concentrations occur in the flame centerline region, which is in contrast to laminar coflow diffusion flames of gaseous fuels with comparable peak soot volume fractions, where the peak soot volume fraction occurs in the flame wing, e.g., [5] [22]. The occurrence of the peak soot volume fraction in the flame centerline region in coflow diffusion flames of doped methane by gasoline, diesel, and primary reference fuels has also been shown in several recent experimental studies [66] [68] [69]. The soot volume fractions and the visible flame size are reduced significantly as more ethanol is blended into gasoline. In the E85 flame, the peak soot volume fraction is less than half of that in the E0 flame.

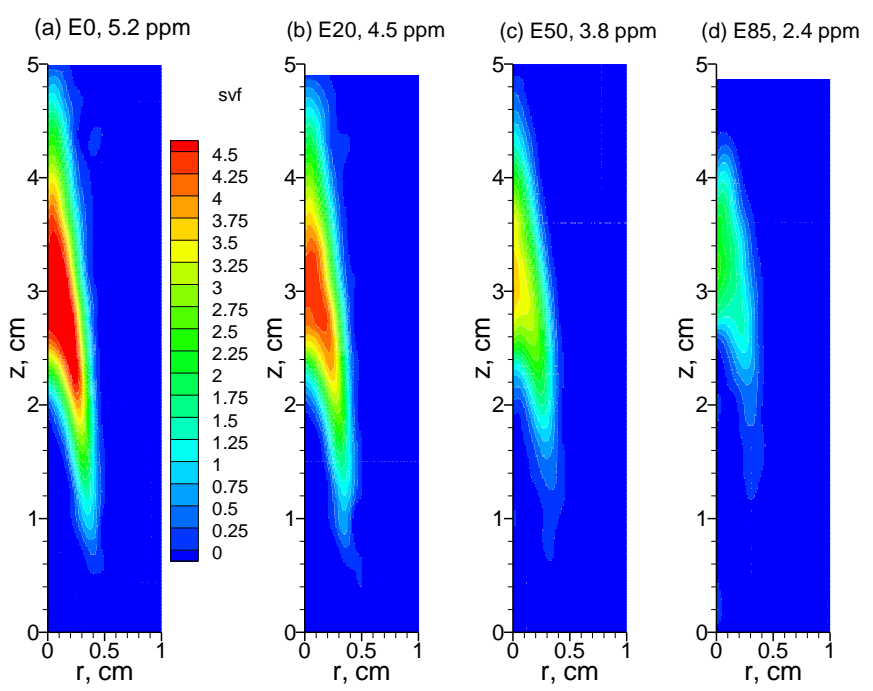

Fig. 3.4. Measured soot volume fraction distributions in the E0, E20, E50, and E85 flames. The peak soot volume fraction in each flame is indicated.

Figure 3.5 displays the measured radial distributions of soot volume fraction in the E0, E20, E50, and E85 flames at four heights of $z=10,20,30$, and $40 \mathrm{~mm}$ above the burner exit. It is seen that 
soot volume fraction monotonically decreases as more ethanol is blended in the fuel stream throughout the flame, as expected from the 2D distributions shown in Fig. 3.4. At $z=10 \mathrm{~mm}$, the soot volume fractions are very low in the E50 and E85 flames. The measured soot volume fractions in the E50 flame at this height are likely not reliable because they are at the detection limits of the LOSA technique. The soot volume fractions in the E85 flame at $z=10 \mathrm{~mm}$ are too low to be measured by LOSA. The trend of soot reduction as a result of ethanol addition to gasoline is consistent with the findings of Lemaire et al. [36] and Maricq [33]. Since the minimum level of ethanol addition considered in this study is $20 \%$ (E20), the present results cannot be used to confirm if there is a synergistic effect of adding a small amount of ethanol to gasoline on soot formation observed in the study of McEnally and Pfefferle [39], where ethanol was added to ethylene, though such effect is unlikely to occur when ethanol is added to gasoline. 

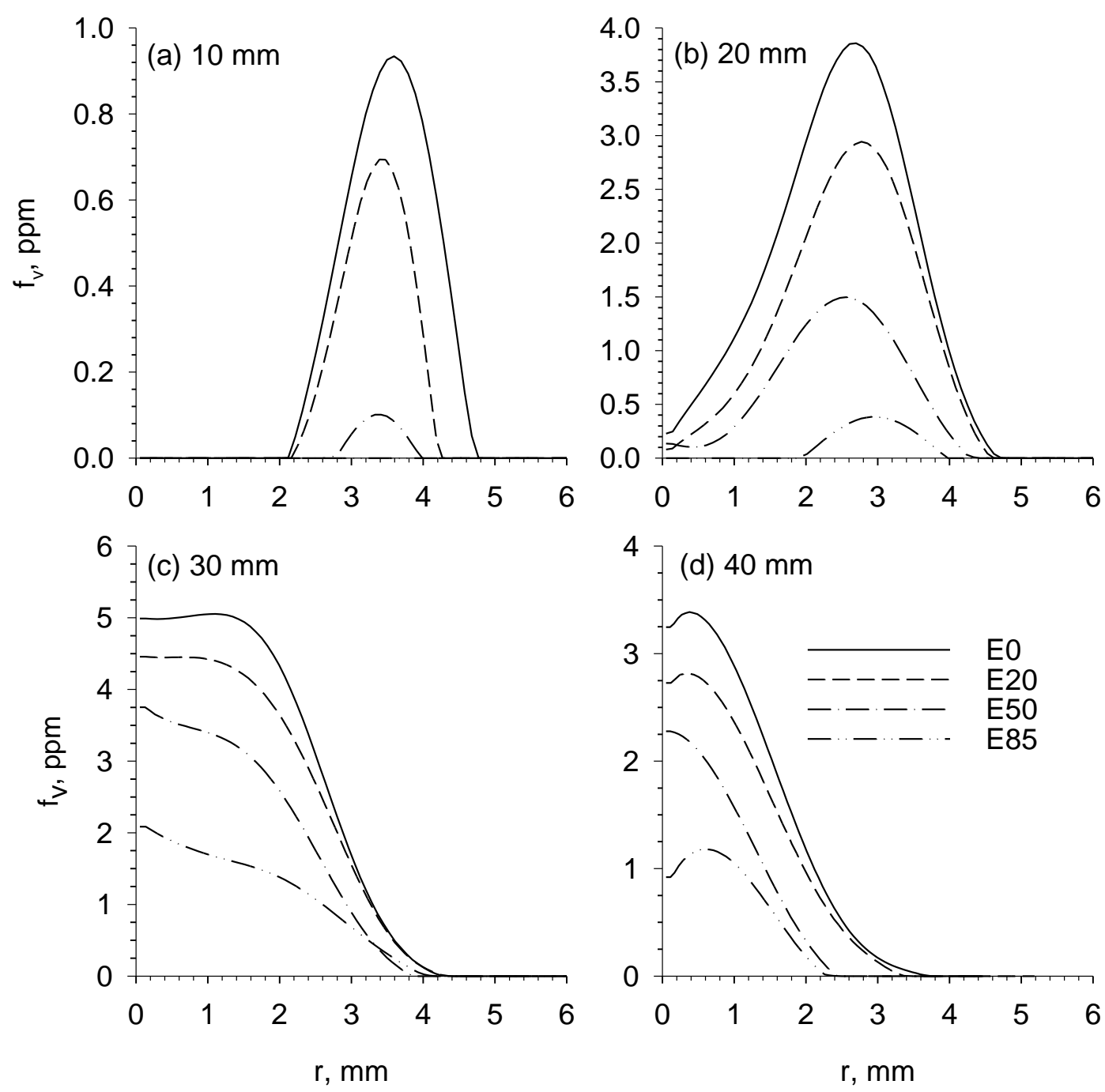

Fig. 3.5. Experimental radial soot volume fraction profiles in the four flames at fours heights above the burner: (a) $10 \mathrm{~mm}$, (b) $20 \mathrm{~mm}$, (c) $30 \mathrm{~mm}$, and (d) $40 \mathrm{~mm}$.

At a height above the burner of $20 \mathrm{~mm}$, as the ethanol blending increases from $0 \%$ to $20 \%$, the peak soot volume fraction drops by approximately $24 \%$ from about 3.86 ppm to 2.94 ppm (Fig. 3.5(b)). Further addition of ethanol to $50 \%$ and $85 \%$ causes soot volume fraction to further decrease to peaks of $1.5 \mathrm{ppm}$ and $0.39 \mathrm{ppm}$, respectively. Similar trends showing the decrease in soot volume fraction with increasing ethanol blending to gasoline are also observed at heights of $30 \mathrm{~mm}$ and $40 \mathrm{~mm}$ above the burner exit (Figs. 3.5(c) and (d)). 
In addition to the four flames of gasoline/ethanol blends, experimental measurements were conducted in four corresponding flames of surrogate/ethanol blends. The flames fuelled with surrogate/ethanol blends are qualitatively similar to those fuelled with gasoline/ethanol blends in terms of the visible flame heights and the overall suppressive effects of ethanol blending. However, the soot volume fractions in the surrogate/ethanol flames are about $15-20 \%$ higher than those in the gasoline/ethanol flames. A direct comparison of the peak soot volume fractions in these flames is presented at the end of the next section.

\subsubsection{Numerical Results}

Computations were performed for the four sets of flame conditions shown in Table 3.2. Figures 3.6 and 3.7 display the computed two-dimensional distributions of temperature and soot volume fraction, respectively, for the E0, E20, E50, and E85 flames obtained using the CoFlame code described in several previous publications [4] [5] [22] [45] [46] [47] and outlined earlier. Figure 3.6 shows that the peak flame temperature, which occurs in the co-annular region low in the flame between $z=1$ and $2 \mathrm{~cm}$, decreases with increasing level of ethanol addition, while the temperatures in the flame centerline region around the flame tip increase with increasing ethanol addition. The peak flame temperature in the E85 flame (1979.6 K) is only about 35 K lower than that in the E0 flame $(2015 \mathrm{~K})$. The relatively small decrease in the peak temperature is attributable to the constant carbon content of the fuel stream for the four flame conditions. The increase in the flame temperatures in the centerline region around the flame tip with increasing ethanol addition is due to reduced radiation heat loss associated with the reduced soot loading shown in Fig. 3.7. The computed soot volume fraction distributions shown in Fig. 3.7 indicate that the experimentally observed visible flame heights (about $50 \mathrm{~mm}$, based on soot radiation) 
are well predicted for the E0, E20, and E50 flames, but somewhat underpredicted for the E85 flame. The predicted visible flame height remains almost unchanged when $20 \%$ ethanol is added to the fuel stream. However, at higher levels of ethanol addition, the predicted visible flame height starts to decrease, especially in the E85 flame. These predicted effects of ethanol blending to gasoline are in agreement with the flame photos and the $2 \mathrm{D}$ measured soot volume fraction distributions shown in Figs. 3.3 and 3.4. Figure 3.7 also shows that the predicted peak soot volume fraction decreases as more ethanol is added to the fuel stream. Overall, the trends in the numerical results of soot volume fraction agree well with the experimental results, i.e., the soot concentration is monotonically reduced as more ethanol is added to the gasoline surrogate. Despite the fairly small differences in temperature in the co-annular region in the four flames (Fig. 3.6), the computed peak soot volume fraction decreases significantly from $5.67 \mathrm{ppm}$ in the E0 flame to $2.81 \mathrm{ppm}$ in the E85 flame (Fig. 3.7).
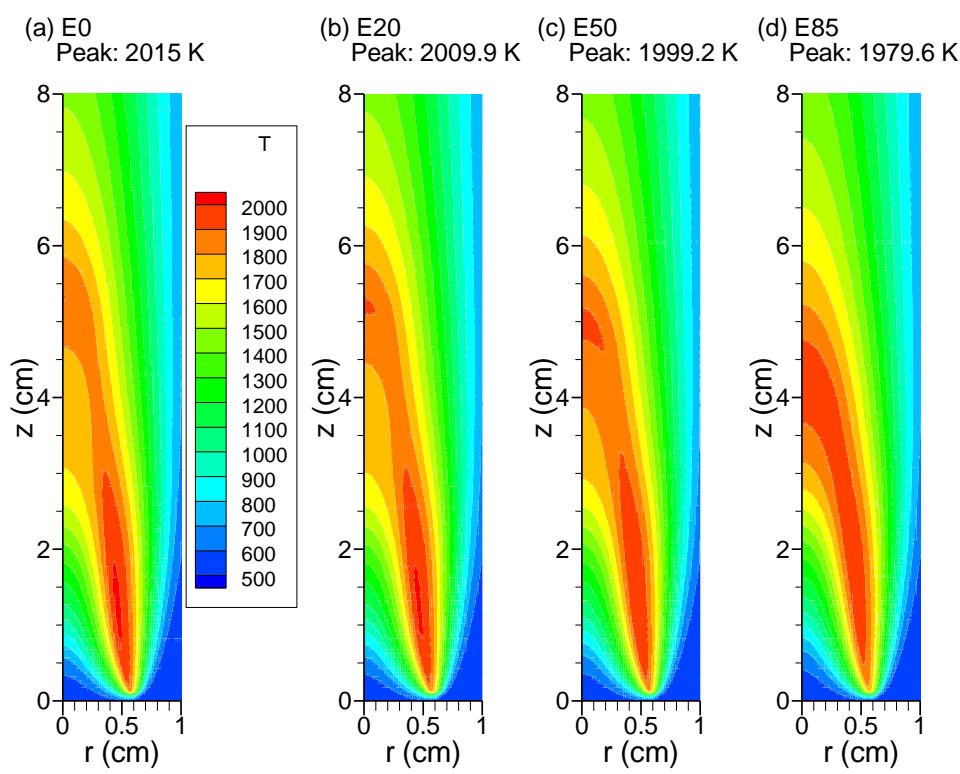

Fig. 3.6. The calculated temperature distributions in the four flames. The peak temperature is indicated for each flame. 


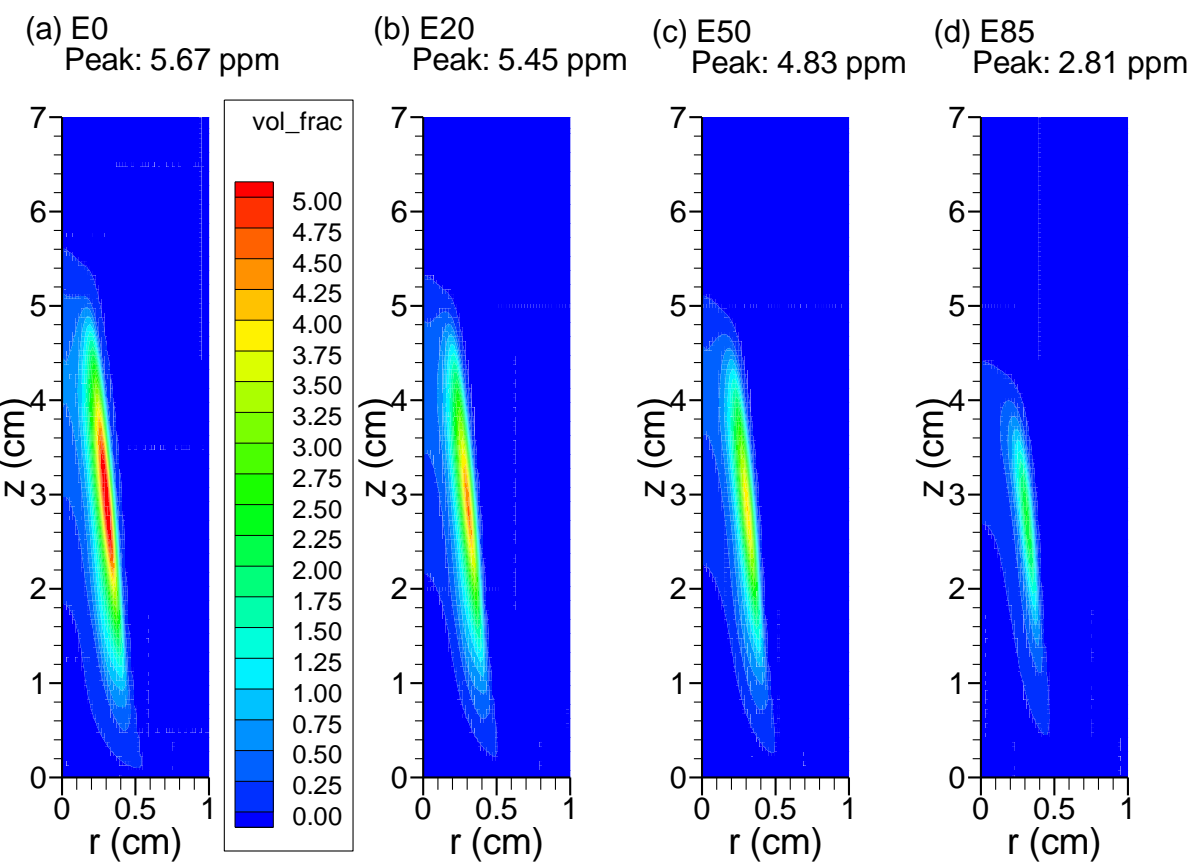

Fig. 3.7. The calculated soot volume fraction distributions in the four flames. The peak soot volume fraction is indicated for each flame.

Although the model correctly captures the overall effects of ethanol blending to gasoline on the visible flame appearance and the suppressive effects of ethanol addition, it fails to predict the measured distribution of soot volume fraction. As shown in Fig. 3.4, the measured soot volume fractions peak in the flame centerline regions, regardless of the level of ethanol blending. The predicted peak soot volume fraction in each flame, however, always occurs in the outer edge of the co-annular sooting region, i.e., along the flame wing (Fig. 3.7). Such predicted sooting structure is very similar to that in a laminar coflow diffusion flame of gaseous fuels, e.g., methane [70] and ethylene [71]. Therefore, the model fails to predict the correct distribution of soot volume fraction in the flames fuelled with gasoline/ethanol blends. Understanding why the peak soot volume fraction in liquid fuel coflow diffusion flames occurs in the centerline region and how to improve the present soot model to better predict the soot distribution will be pursued in future studies. 
The computed radial distributions of soot volume fraction at $z=10,20,30$, and $40 \mathrm{~mm}$ are shown in Fig. 3.8. The computed levels of soot volume fraction at each of these four heights are in relatively good correspondence with the measured ones shown in Fig. 3.5. However, the computed peak soot volume fractions remain in the outer co-annular region of the flame while they quickly shift to the flame centerline regions at $z=30 \mathrm{~mm}$ and above in the experiment (Fig. 3.5). As more ethanol is blended into the gasoline surrogate, soot volume fraction is reduced throughout the flame and a dramatic reduction takes place in the E85 flame. 

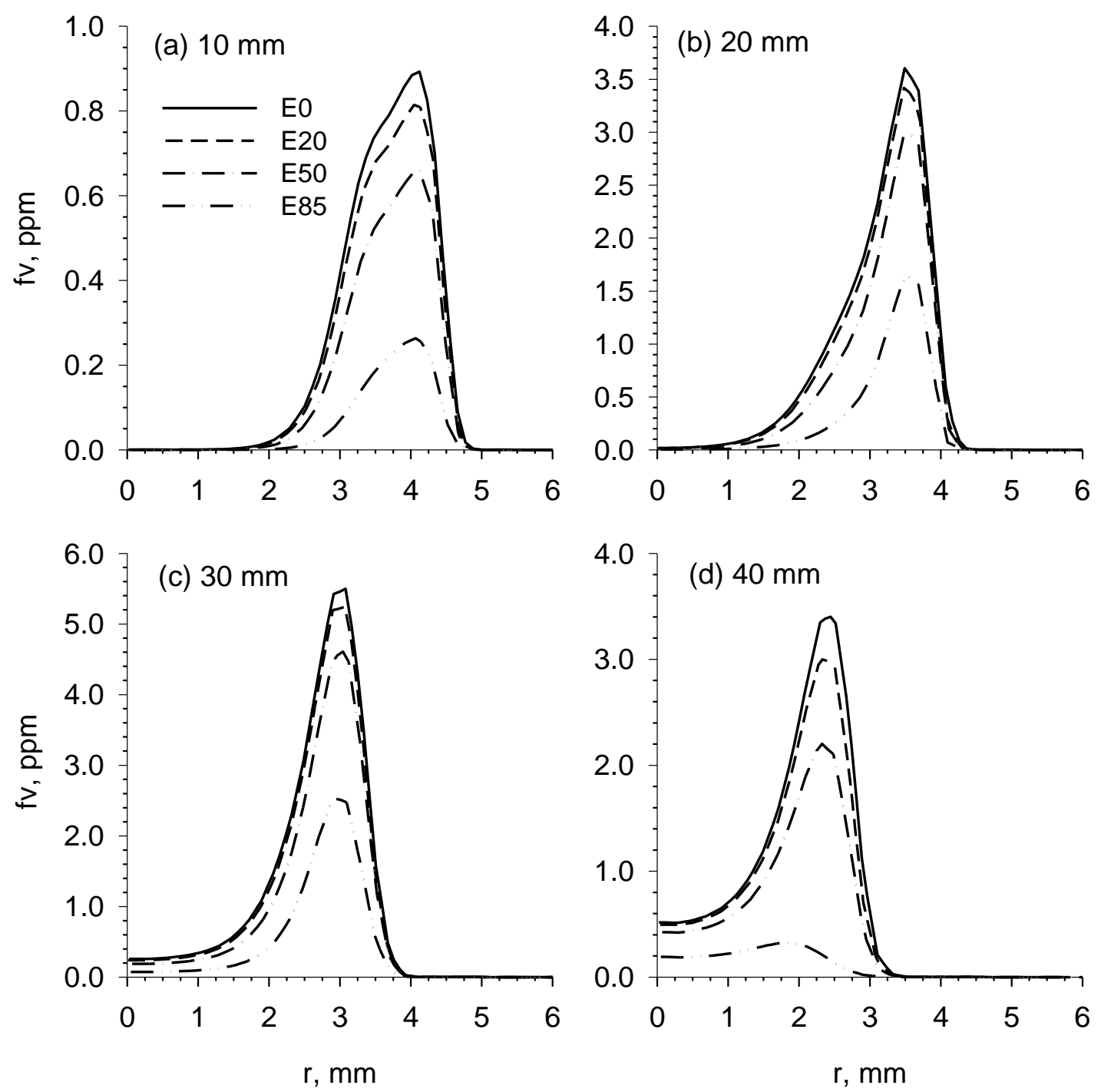

Fig. 3.8. Computed radial soot volume fraction profiles in the four flames at fours heights above the burner: (a) 10 $\mathrm{mm}$, (b) $20 \mathrm{~mm}$, (c) $30 \mathrm{~mm}$, and (d) $40 \mathrm{~mm}$.

The peak soot volume fraction is an important indicator of soot propensity of flames and different fuel mixtures. To gain a quantitative understanding of the effectiveness of the gasoline surrogate in emulating the sooting propensity of gasoline and the effect of ethanol blending to gasoline on soot formation, the measured and calculated peak soot volume fractions in the four flames are compared in Fig. 3.9. When the fuel is the No. 92 gasoline, the experimental peak 
soot volume fraction in the E0 flame is $5.2 \mathrm{ppm}$. Adding $20 \%$ ethanol reduces the experimental peak to $4.5 \mathrm{ppm}$ (13\% reduction). The measured peak soot for E50 is $3.8 \mathrm{ppm}$, decreasing by $27 \%$ compared to that for E0. The decrease in the peak soot volume fraction is more significant for E85 as the experimental peak decreases to $2.4 \mathrm{ppm}$, a $54 \%$ reduction with respect to that for E0. Although the computed results are higher than the measured values in all four flames, the model captures the trend of ethanol addition to gasoline on soot formation reduction fairly well, in particular the more significant reduction between the E50 and E85 flames; however, the model predicts a small decrease in the peak soot volume fraction in the E20 and E50 flames. The percentages of the modelled peak soot volume fraction reduction in the E20, E50, and E85 flames, relative to the E0 flame, are respectively $3.9 \%, 14.8 \%$, and 50\%, which are somewhat lower than but comparable to the measured peak soot reductions. Therefore, the gasoline surrogate model used in this study is capable of predicting the effects of ethanol addition to gasoline on soot formation reduction revealed in the experimental results. 


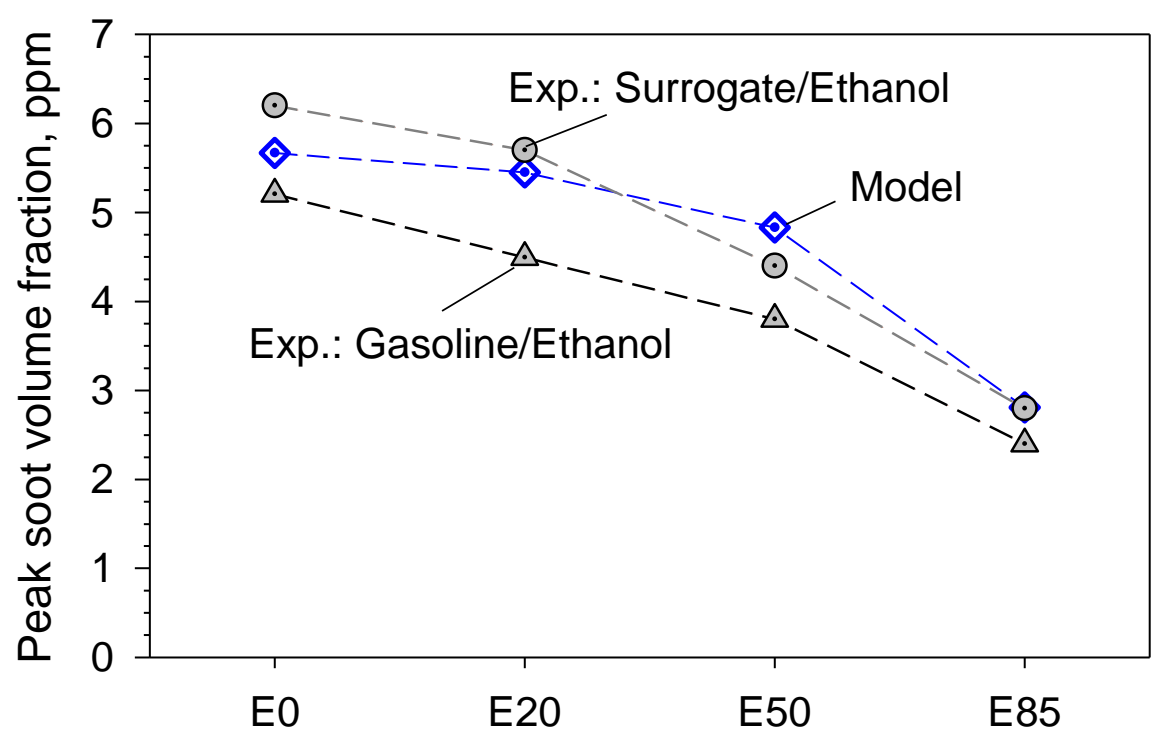

Fig. 3.9. Comparison between the measured and the calculated peak soot volume fractions in the four flames.

Also plotted in Fig. 3.9 are the measured peak soot volume fractions in flames of gasoline surrogate/ethanol blends. The flames of the gasoline surrogate/ethanol blends produce somewhat more soot than the No. 92 gasoline/ethanol blends. The measured peak soot volume fraction in the gasoline surrogate flame is $6.2 \mathrm{ppm}, 20 \%$ higher than that in the No. 92 gasoline flame. At $85 \%$ ethanol blending, the measured peak soot volume fraction in the gasoline surrogate/ethanol flame is $2.8 \mathrm{ppm}, 15 \%$ higher than that in the corresponding No. 92 gasoline/ethanol flame. It is noticed that the discrepancies between the two sets of measured soot volume fractions or between the computed and the measured ones are within the experimental uncertainty. Therefore, it can be concluded that the gasoline surrogate model can emulate fairly well the sooting behaviour of the No. 92 gasoline/ethanol blends based on the present experimental measurements and numerical modelling. 
To investigate the causes of soot reduction by ethanol addition to gasoline, the effects ethanol addition has on the mechanisms of soot formation and oxidation are analyzed in more detail. The computed data have been post-processed using a Lagrangian particle tracking technique [5], wherein a fluid parcel is tracked along a given streamline, and then its trajectory is corrected for soot particle transport so as to trace out a soot particle's history. Figure 3.10(a) compares the contributions of $\mathrm{O}_{2}$ and $\mathrm{OH}$ oxidation to total soot particle mass reduction along the pathline of maximum soot on the wings for the four flames. The data correspond to collective oxidation history from inception to the location of maximum soot. The reduction in soot mass from oxidation by both $\mathrm{O}_{2}$ and $\mathrm{OH}$ decreases or stays relatively constant with increasing ethanol addition. For the E85 flame, the reduction of soot mass caused by $\mathrm{O}_{2}$ is substantially less than the other flames. Although there is a slight decrease in the contribution of $\mathrm{OH}$ oxidation in the E85 flame, it is much smaller than the decrease in the $\mathrm{O}_{2}$ contribution reduction. In fact, the influence of ethanol addition is less oxidative, demonstrating that oxidation is not responsible for the reduction in soot concentrations with increasing ethanol addition seen in Figs. 3.4, 3.5, 3.7-3.9, but rather it is attributed to changes in the soot inception and surface growth processes brought by ethanol addition. This finding is consistent with that of McNesby et al. [38], who showed a decrease in soot precursors, rather than enhanced oxidation, when ethanol was added to their fuel stream. 


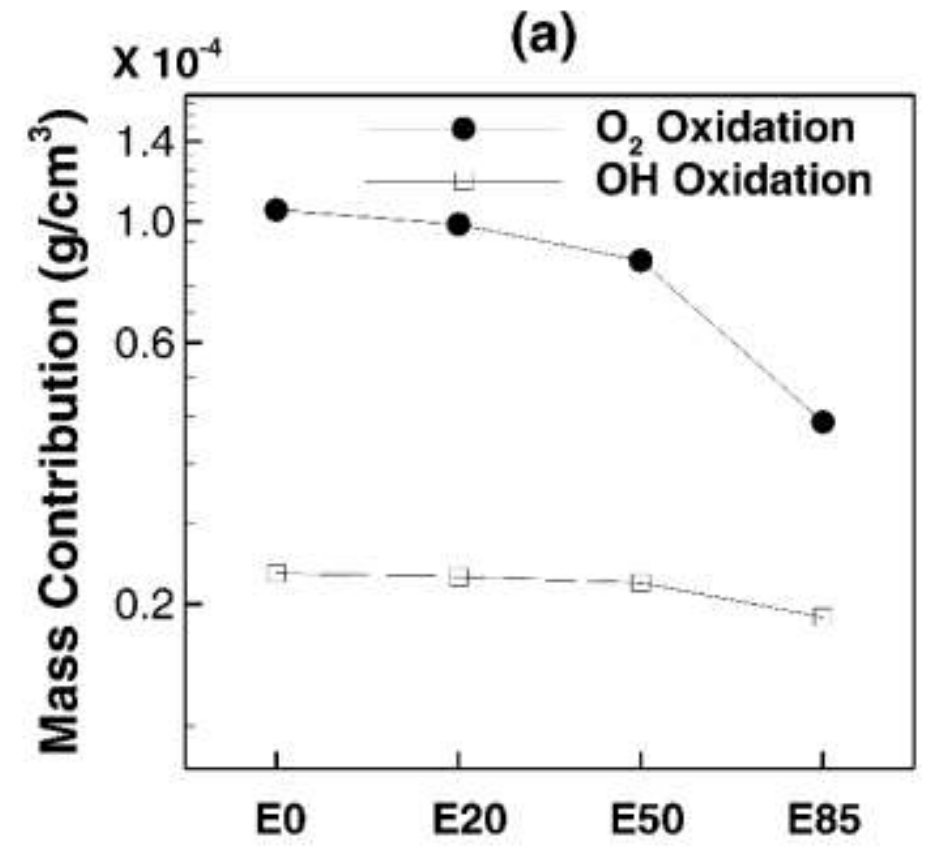

(b)

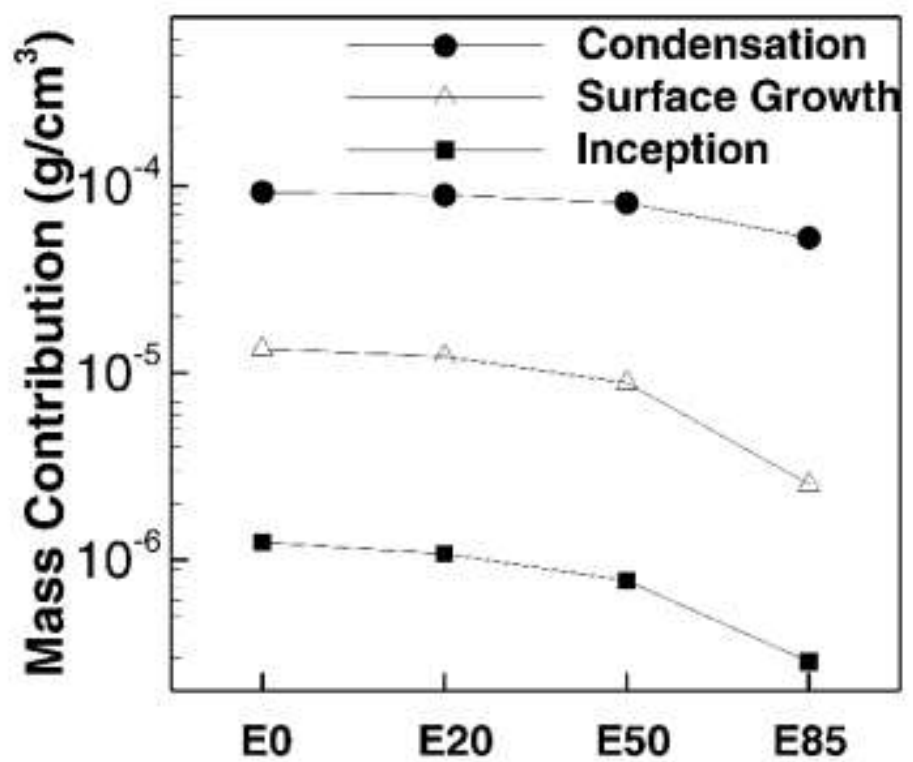

Fig. 3.10. (a) The cumulative contributions of soot oxidation by $\mathrm{O}_{2}$ and $\mathrm{OH}$ to soot mass reduction, and (b) cumulative contributions of inception, surface growth by HACA, and PAH condensation to soot mass increase, along the pathline of the maximum soot between soot inception and the peak soot in the four flames studied.

To better understand the effects that ethanol has on the soot formation processes, a comparison of the contributions to soot particle mass from the three dominant soot production mechanisms, 
namely inception, surface growth by HACA mechanism, and PAH condensation, is shown in Fig. 3.10(b). Again, these results are the cumulative contributions from the three processes along the pathline of the maximum soot from inception to the peak soot volume fraction. Unlike other systems in which computations have shown that soot surface growth through the HACA mechanism dominates soot mass addition on the flame wings [5] [14] [21], here PAH condensation is the dominant mechanism contributing to soot particle mass. This result is expected since with toluene being a major component of the fuel surrogate, the ratio of aromatics to $\mathrm{C}_{2} \mathrm{H}_{2}$ is much higher compared to when $\mathrm{C}_{2}$ fuels are considered. Although all three mechanisms exhibit a similar decreasing trend as the amount of ethanol is increased, noting the $\log$ scale, it is the decrease in PAH condensation that dominates the changes in soot volume fraction. The decrease in mass contributions is more pronounced for the E85 flame which explains the significant soot reduction for this flame (seen in Figs. 3.4, 3.5, 3.7-3.9).

The inception and PAH condensation mechanisms are modelled based on collisions between pyrene (A4) molecules and soot particles, respectively [21]. To further understand the varying contribution of PAH condensation to soot growth with ethanol addition, the A4 mole fractions along the pathline of the maximum soot in the four flames are analyzed. Figure 3.11 displays the A4 mole fractions along the streamline of maximum soot in the E0, E20, E50, and E85 flames versus height above the burner. It is observed that the A4 mole fractions decrease significantly as a result of adding ethanol, especially in E85, which explains why soot volume fractions are reduced with ethanol addition. These results also indicate that the reduction is primarily through reduced soot inception and PAH surface condensation processes, as a result of the decrease in the A4 concentrations. 


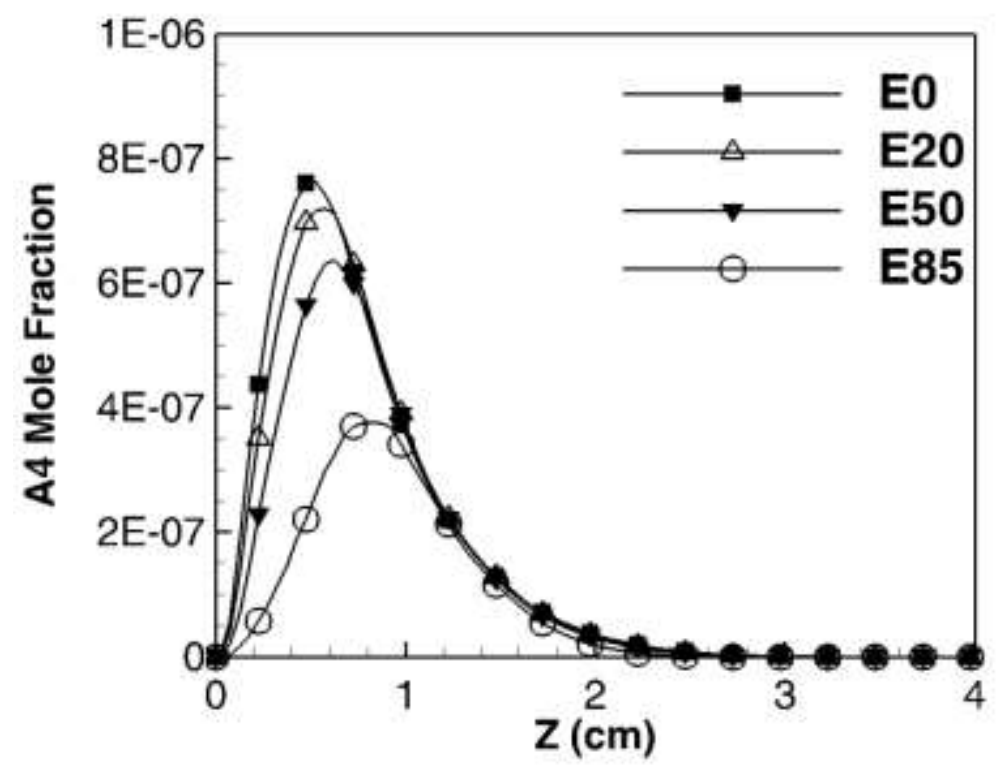

Fig. 3.11. Distributions of the calculated A4 mole fraction along the pathline of the maximum soot in the E0, E20, E50, and E85 flames against the vertical distance above the burner exit.

Although iso-octane, $n$-heptane, and ethanol all form aromatic soot precursors predominantly through a pathway of oxidation down to acetylene, followed by aromatic growth via HACA, the aromatic character of toluene is much more efficient in benzene and PAH formation since it leads directly to PAH formation via $\mathrm{C}_{6} \mathrm{H}_{5} \mathrm{CH}_{3}+\mathrm{H} \rightarrow \mathrm{A} 1+\mathrm{CH}_{3}, \mathrm{C}_{6} \mathrm{H}_{5} \mathrm{CH}_{3}+\mathrm{CH}_{2} \rightarrow \mathrm{A}_{1} \mathrm{C}_{2} \mathrm{H}_{3}+\mathrm{H}_{2}$, $\mathrm{C}_{6} \mathrm{H}_{5} \mathrm{CH}_{3} \rightarrow \mathrm{A} 1-+\mathrm{CH}_{3}$, and $\mathrm{C}_{6} \mathrm{H}_{5} \mathrm{CH}_{3}+\mathrm{H} \rightarrow \mathrm{A} 1-+\mathrm{CH}_{4}$ [6]. Subsequently, the resulting A1, $\mathrm{A}_{1} \mathrm{C}_{2} \mathrm{H}_{3}$, and $\mathrm{A} 1$ - grow to naphthalene and larger aromatics through a variety of HACA and PAH-PAH combination reactions [6]. The numerical results show that the ethanol addition slightly lowers the $\mathrm{C}_{2} \mathrm{H}_{2}$ concentrations (the peak mole fraction decreases from 0.0326 for $\mathrm{E} 0$ to 0.0289 for E85); however, the effects of ethanol addition on $\mathrm{C}_{2} \mathrm{H}_{2}$ are considered very small compared to its effects on aromatics (almost a factor of 2 decrease from E0 to E85). Therefore, it can be concluded that the reduction in soot volume fraction when ethanol is added to gasoline is caused by a sequence of phenomena. The dilution effect of ethanol results in lower aromatic 
(toluene) concentrations in the fuel stream, which in turn lowers the rates of aromatic soot precursor formation and reduces the reaction rates of $\mathrm{PAH}$ condensation. These reduced formation rates result in decreased soot particle mass and lower soot volume fractions. Therefore, in the system studied in the present work, the reduction of soot as a result of ethanol addition can be attributed to the dilution effects of ethanol as proposed in [37] rather than enhanced oxidation, possibly attributable to the oxygen content of the fuel as observed in [36], or to increased temperature and $\mathrm{OH}$ oxidation as noted in [38].

\subsection{Conclusions}

The present work investigated the effects of adding ethanol to fuel on soot formation in gasoline/air coflow diffusion flames at atmospheric pressure experimentally and numerically. Stable laminar coflow diffusion flames of $\mathrm{N}_{2}$ diluted prevaporized gasoline/ethanol blends were produced using the burner system developed in this study. Soot volume fractions were measured using a 2D-LOSA technique. A gasoline surrogate identified in the literature was employed in the numerical modelling to replicate the No. 92 gasoline used in the experiments. This study represents the first effort to establish stable laminar coflow diffusion flames of nitrogen diluted prevaporized gasoline and ethanol blends and to obtain quantitative measurements of soot volume fraction distribution in such flames.

Both the experimental measurements and numerical results reveal that blending ethanol to gasoline suppresses soot formation. However, the soot formation suppression remains not very significant until the blending ratio of ethanol is more than 50\%. The E85 flame produces much 
less soot than the E0, E20, and E50 flames. This behaviour is observed in both the experimental and numerical results and has also been reported in the literature. The visible flame heights and soot volume fractions are fairly well predicted in terms of the magnitude. Although the location of peak soot volume fraction was not correctly predicted in comparison to the measurements, the overall effects of ethanol addition to gasoline on soot formation reduction were captured by the numerical model. Both the experimental measurements in the No. 92 gasoline/ethanol blend and gasoline surrogate/ethanol blend flames and the numerical results suggest that the gasoline surrogate model used in this study emulates the gasoline fuel quite well in terms of sooting propensity. Understanding why the peak soot volume fraction location shifts to the flame centerline in laminar coflow liquid fuel flames and how to improve the current soot model to capture such shift should be investigated.

The numerical predictions were leveraged for further information by tracking the pathlines of soot particles through the flames. This analysis demonstrated that the reduced soot concentrations with ethanol addition can be attributed to the dilution effects (due to the resulting aromatic content reduction in the fuel stream) as opposed to the increased oxygen content of ethanol, enhanced oxidation, or temperature changes. 


\title{
Chapter 4
}

\section{Detailed Modelling of Soot Oxidation by $\mathrm{O}_{2}$ and $\mathrm{OH}$ in}

\section{Laminar Diffusion Flames}

Corresponding Publication: A. Khosousi, S.B. Dworkin, "Detailed Modelling of Soot Oxidation by $\mathrm{O}_{2}$ and $\mathrm{OH}$ in Laminar Diffusion Flames," Proceedings of the Combustion Institute 35 (2015) 1903-1910.

\begin{abstract}
A detailed knowledge of soot formation and oxidation processes is desired to reduce the soot emissions in combustion devices. Soot oxidation is one of the most complex processes in the numerical modelling of soot. In this work, the oxidation of soot has been numerically studied in laminar ethylene/air coflow diffusion flames. There has been disagreement in the literature over the rates of soot oxidation by $\mathrm{O}_{2}$ molecules and $\mathrm{OH}$ radicals. A sensitivity analysis has been performed on the roles of $\mathrm{O}_{2}$ and $\mathrm{OH}$ in various parts of the diffusion flame, isolating the effects these species have on soot oxidation. A new oxidation model is developed based on the observation that soot ageing reduces surface reactivity and is primarily based on temperature and residence time. A function for surface reactivity of soot, based on the temperature history a soot particle experiences, has been proposed to model soot oxidation. Using this new model, it is now possible to capture the correct behaviour of both smoking and non-smoking flames in various flame configurations. Along with a detailed sectional soot model, the new oxidation model
\end{abstract}


predicts the correct soot volume fractions, smoke emission characteristics, and primary particle diameters for different flames without any variation in model parameters between cases.

Keywords: Soot, Oxidation, Smoking Flames, Laminar Flames

\subsection{Introduction}

The continued development of quantitatively accurate soot particle formation models is of interest to both academia and industry. Such models have the potential to increase our fundamental understanding of soot formation processes and provide tools for engineers to aid in their design of cleaner combustion devices. Numerical modelling of combustion-generated soot is very challenging since it involves complex processes including inception, condensation, surface growth, coagulation, oxidation, and fragmentation. Therefore, an accurate model which predicts soot volume fraction in flames requires precise models for these processes. Inception, condensation, and surface growth contribute to the formation and growth of soot particles, while oxidation accounts for their destruction. Soot oxidation occurs due to the collisions between soot particles and $\mathrm{O}_{2}$ molecules or $\mathrm{OH}$ radicals [20] [56] [57] [58] [59] [60]. Although soot formation modelling for non-smoking flames is well-grounded in the literature, smoking flames (those that emit soot) have received little attention.

Oxidation rates for $\mathrm{O}_{2}$ have been suggested in the literature. The most commonly used $\mathrm{O}_{2}$ rate by Frenklach and Wang [54] has recently been shown to overpredict the kinetic effect [72]. However, use of the $\mathrm{O}_{2}$ rate from [54] as part of a soot model has permitted quantitative agreement with experiment in a variety of non-smoking flames [4] [5]. Since all of the soot gets 
oxidized in these flames, primarily in the post-flame region, overprediction of the oxidation rates does not degrade comparisons of soot growth and peak concentrations. Predicting both nonsmoking and smoking flames is a challenging test for a soot oxidation model and has only been achieved once in the literature [73] with what is by present standards of statistical particle tracking, a less detailed two-equation model. Liu et al. [73] proposed two temperature-dependent correction factors for the oxidation rates by $\mathrm{O}_{2}$ and $\mathrm{OH}$, which permitted them to correctly predict the behaviour of both non-smoking and smoking flames.

The present work considers the soot oxidation caused by $\mathrm{O}_{2}$ and $\mathrm{OH}$ in different smoking and non-smoking ethylene/air coflow diffusion flames. A new oxidation model based on the consideration of soot ageing effects has been proposed, and is used in conjunction with a detailed sectional soot model that tracks particle size and aggregate structure [4] [5]. Explanation and physical justification of the model is in the following section. The model is applied to a variety of non-smoking and smoking flames, in multiple burner configurations, from various studies, without any modification between cases. In generating the model, a parameter, $\alpha_{o x}$ is introduced, which, accounting for soot particle age, reconciles the inaccuracies of treating the surface of the soot particle like a corresponding PAH. This parameter is based on an analogous one that has been proposed and heavily utilized in the literature for HACA growth, which also requires an accurate characterization of surface reactivity. 


\subsection{Burner and Numerical Model}

The flames modelled in this work are the laminar coflow ethylene/air diffusion flames studied originally by Santoro and coworkers [12] [13], and the diluted ethylene flames studied by Smooke et al. [14]. The flames in [12] [13] have been studied subsequently by a variety of other researchers both experimentally and numerically [4] [5] [73] [74] [75]. For each computation, the burner geometry is adapted to be the same as in [13] or [14], in which the dimensions and other specifications of the burner and flow conditions can be found. Table 4.1 summarizes the flow conditions of the eight flames studied in the present work. According to the flow rates and inlet conditions, the flames are either non-smoking (NS), incipient sooting (IS), or smoking (S), as defined in [13].

Table 4.1. Inlet conditions of the fuel and air streams

\begin{tabular}{cccc}
\hline Flame No. & Fuel velocity $(\mathbf{c m} / \mathbf{s})$ & Air velocity $(\mathbf{c m} / \mathbf{s})$ & Fuel mole fraction \\
\hline $\mathbf{1}$ & 2.38 & 8.90 & 1.0 \\
\hline $\mathbf{2}$ & 3.98 & 8.90 & 1.0 \\
\hline $\mathbf{3}$ & 4.75 & 8.90 & 1.0 \\
\hline $\mathbf{4}$ & 5.05 & 13.30 & 1.0 \\
$\mathbf{5}$ & 35.0 & 35.0 & 0.32 \\
\hline $\mathbf{6}$ & 35.0 & 35.0 & 0.40 \\
\hline $\mathbf{7}$ & 35.0 & 35.0 & 0.60 \\
\hline $\mathbf{8}$ & 35.0 & 35.0 & 0.80 \\
\hline
\end{tabular}

The governing equations for mass, momentum, energy, species, primary particle number densities, and soot aggregate number densities are solved in a coupled manner using the CoFlame code. The details of the CoFlame code's numerical model can be found in [4] [5]. The computational domain comprises a non-uniform axi-symmetric mesh with approximately 100 control volumes in the radial direction and 200 control volumes in the axial direction (varying 
slightly for each flame). The computations require parallel processing carried out using 192 CPUs for the NS flames, and 216 CPUs for the IS and S flames.

A soot sectional model consisting of 35 sections is utilized and each section considers primary particle size and aggregate structure. The particle dynamics model includes inception, based on pyrene dimerization [21], Hydrogen Abstraction Carbon Addition (HACA) [21] [54], condensation, and coagulation. To accurately predict temperature in heavily sooting flames, soot radiation (luminosity) should be considered. The radiation model used here is the Discrete Ordinate Method and a statistical narrow-band correlated-k-based model [76] considering soot, $\mathrm{H}_{2} \mathrm{O}, \mathrm{CO}_{2}$, and $\mathrm{CO}$. The oxidation model considers only $\mathrm{O}_{2}$ molecules and $\mathrm{OH}$ radicals, and is described in the following section. While oxidation-induced fragmentation affects particle structure in the post-flame region, it has little effect on soot concentration, and is not included here. Nonetheless, particle structure is of interest and modelling oxidation-induced fragmentation remains an important research topic. Further details on the governing equations and boundary conditions can also be found in [4] [5] [77].

\subsection{Oxidation Model Development}

\subsubsection{Background}

Most works in the literature [20] [56] [57] [58] [59] [60] consider $\mathrm{O}_{2}$ and $\mathrm{OH}$ to be the major species contributing to the surface oxidation of soot particles. Xu et al. [78] experimentally examined other possible candidates for soot oxidation including $\mathrm{CO}_{2}, \mathrm{H}_{2} \mathrm{O}$, and $\mathrm{O}$ in addition to $\mathrm{O}_{2}$ and $\mathrm{OH}$. They came to the conclusion that among these species, $\mathrm{OH}$ is mainly responsible for 
the oxidation of soot over the temperature range of $1570 \mathrm{~K}$ to $1870 \mathrm{~K}$ and in the $\mathrm{O}_{2}$ mole fraction range of $10^{-5}$ to 0.03 . They also point out that $\mathrm{OH}$ may not be the main oxidative species in all conditions, especially at higher temperatures and also fuel lean conditions where the concentration of $\mathrm{O}_{2}$ is high.

In a variety of numerical soot modelling studies, the oxidation of soot is considered to be due to the reactions between soot particles and $\mathrm{O}_{2}$ molecules as well as $\mathrm{OH}$ radicals [4] [5] [54] [73]. The reaction rate of soot oxidation by $\mathrm{OH}$ is calculated as the product of the frequency of collision between soot and $\mathrm{OH}$, and a collision efficiency, defined as the fraction of collisions resulting in soot oxidation. Based on the early work of Neoh et al. [20], an $\mathrm{OH}$ collision efficiency of 0.13 has been widely used in the literature [4] [5] [21] [54]. However, other studies propose values ranging from 0.01 to 0.27 for $\mathrm{OH}$ collision efficiency [58] [78] [79] [80]. This large range demonstrates the uncertainty existing in the literature associated with the collision efficiency of $\mathrm{OH}$ and its variation with temperature [5] [58] [59] [60] [81]. The effect of collision efficiency on soot formation is considered in the following section.

By contrast, the oxidation rates used to model soot oxidation due to $\mathrm{O}_{2}$ differ by orders of magnitudes in the literature [54] [72] [82]. Nagle and Strickland-Constable (NSC) [82] proposed an expression for the rate of soot oxidation by $\mathrm{O}_{2}$, which was used widely both in numerical and experimental works [20] [58] [73] [78] [81] [83]. Kennedy et al. [81] applied this rate to model smoking flames, but their result failed to capture the soot emission behaviour of the smoking flame. They point out that this is because of the overprediction of soot oxidation by $\mathrm{O}_{2}$ in the post-flame region estimated by the NSC rate. The same observation was made by Liu et al. [73]. 
Introducing two temperature-dependent functions that reduced oxidation rates, Liu et al. [73] modified the rates of oxidation by $\mathrm{O}_{2}$ and $\mathrm{OH}$ proposed by Nagle and Strickland-Constable [82] and Fenimore and Jones [56], respectively, such that they were able to model the transition from a non-smoking to a smoking flame.

The rate of oxidation of phenyl by $\mathrm{O}_{2}$ based on the experiments of Lin and Lin [84] was used by Frenklach and Wang [54] to model soot oxidation by $\mathrm{O}_{2}$ in premixed flames. They found that the rate was comparable to that predicted by Nagle and Strickland-Constable [82]. Later, this rate was introduced in the soot mechanism known as $A B F$, for its authors, Appel, Bockhorn and Frenklach [21] and in other mechanisms [85] [86] as the reaction rate of $\mathrm{PAH}$ oxidation by $\mathrm{O}_{2}$ for one to four ring PAHs.

Consistent with [73] and [81], Celnik et al. [72] observed significant underprediction in soot volume fraction when using the $\mathrm{ABF}$ rate. They presented different oxidation rates that are orders of magnitude lower than that of the Appel et al. [21]. While the ABF mechanism has been a mainstay in soot modelling for over a decade, Celnik et al. [72] point out that it has provided the foundation for further model development. A recent work by Raj et al. [87] studied the oxidation by $\mathrm{O}_{2}$ of PAHs using density function theory. They too point out that the use of the oxidation rate of phenyl to model soot oxidation, as was carried out in [21] [54] [85] [86], leads to overprediction of soot oxidation, as the character of the soot surface, especially that of mature soot, is not identical to that of PAHs. They also mentioned that the rate proposed by Celnik et al. [72] is too low to be used for soot oxidation predictions. 


\subsubsection{Determination of Model Parameters}

Since $\mathrm{O}_{2}$ and $\mathrm{OH}$ are the main oxidative species, as discussed above, the study of their individual effects on soot formation and oxidation is of great interest. In order to isolate the effects $\mathrm{O}_{2}$ and $\mathrm{OH}$ have on oxidation in non-premixed flames, a sensitivity analysis is performed varying $\mathrm{O}_{2}$ oxidation levels and $\mathrm{OH}$ collision efficiencies. Figure 4.1 depicts the variation of soot volume fraction in response to $\mathrm{O}_{2}$ (left) and $\mathrm{OH}$ (right) oxidation rates for Flame 4 (Tabel 4.1). As observed, decreasing $\mathrm{O}_{2}$ oxidation results in less soot oxidation in the post-flame region and therefore more soot emission from the flame. However, $\mathrm{O}_{2}$ has a negligible effect in the lower portions of the flame where soot growth is occurring, as well as on the peak soot volume fraction; it starts to play a role only after the location of peak soot volume fraction. From Fig. 4.1 (right), it is clearly observed that the peak soot volume fraction decreases significantly when decreasing $\mathrm{OH}$ collision efficiency. This means that $\mathrm{OH}$ radicals, unlike $\mathrm{O}_{2}$ molecules, are very important in the soot formation region (lower in the flame), competing with other soot formation mechanisms, including inception, condensation, and surface growth and contributing significantly to total soot mass. The dominant effect of $\mathrm{OH}$ on soot oxidation has been previously confirmed when the oxidation is completed near the flame sheet [58] [60] [79]. Since the $\mathrm{O}_{2}$ oxidation is important in the post-flame region, it is suggested that $\mathrm{O}_{2}$ is solely responsible in determining the non-smoking or smoking behaviour of these flames. These observations allow the isolation of each of the two oxidative effects. In the coflow diffusion flames studied herein, peak soot volume fraction, which was unaffected by $\mathrm{O}_{2}$ oxidation, can be used to study $\mathrm{OH}$ oxidation, and the amount of smoke emitted, which is insensitive to $\mathrm{OH}$ oxidation, can be used to study $\mathrm{O}_{2}$ oxidation. Since peak soot volume fraction has been well predicted [4] [5] [14], and 
predicting the smoking behaviour of flames remains a challenge, model development efforts therefore focus on $\mathrm{O}_{2}$ oxidation.
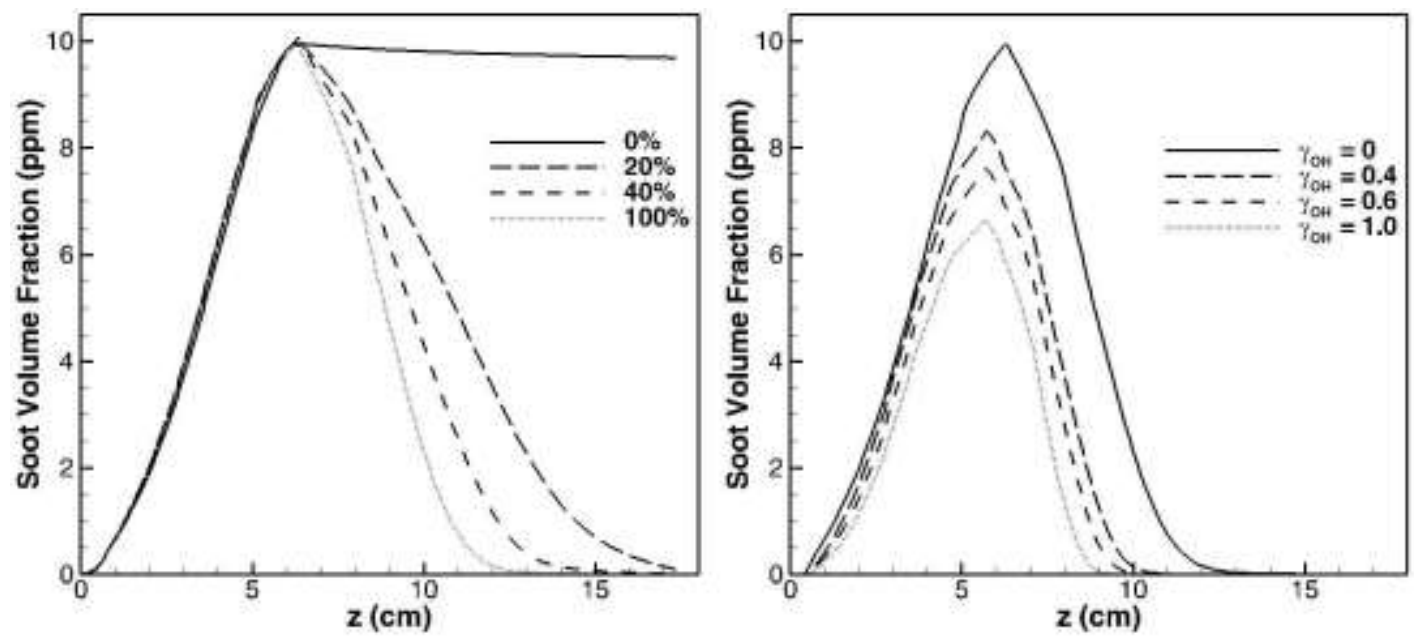

Fig. 4.1. Variation of soot volume fraction along the streak line exhibiting maximum soot in response to varied $\mathrm{O}_{2}$ oxidation, as a percentage of the rate in [21] (left) and $\mathrm{OH}$-soot collision efficiency, $\gamma_{\mathrm{OH}}$ (right) for Flame 4.

Oxidation of soot by $\mathrm{O}_{2}$ is a surface reaction requiring an active surface site that is generated from $\mathrm{H}$ abstraction via collision of soot with a radical such as $\mathrm{H}$ or $\mathrm{OH}$. The active site can then react with either $\mathrm{C}_{2} \mathrm{H}_{2}$ (HACA growth) or $\mathrm{O}_{2}$ (oxidation). Reaction rates with $\mathrm{C}_{2} \mathrm{H}_{2}$ or $\mathrm{O}_{2}$ are based on analogous reactions with PAHs, with the number of active surface sites on the soot replacing the PAH concentration in the computation. The rate of HACA surface growth is calculated by,

$R_{S G}=C_{S G} k_{4}\left[\mathrm{C}_{2} \mathrm{H}_{2}\right] A_{S, i} N_{i} \alpha$

where $C_{S G}$ is a constant that considers Avogadro's number and the mass of a carbon atom, $k_{4}$ is per-site rate coefficient for $\mathrm{C}_{2} \mathrm{H}_{2}$ addition, $A_{s, i}$ is the surface density of soot particle $i, N_{i}$ is the number density of particle $i$, and $\alpha$ is the portion of active surface sites available for chemical 
reaction [54]. The rate of $\mathrm{O}_{2}$ oxidation is calculated in the same manner relying on $\mathrm{O}_{2}$ concentration instead of $\mathrm{C}_{2} \mathrm{H}_{2}$ concentration, and on $\alpha_{o x}$ rather than $\alpha$ of HACA growth. $\alpha$, which varies from 0 to 1 , is used to account for the probability of the collision between a gaseous species and a particle's edge carbon that is available for reaction, [54] and also reconciles the inaccuracies associated with treating the surface of soot like a PAH. In the literature, various constant values and functions for $\alpha$ have been used in simulations for different flame conditions [4] [21] [54] [73] [88] [89]. However, most of these works focus on HACA surface growth in determining $\alpha$. There have been some studies which effectively used a constant or near constant $\alpha$ for HACA surface growth to model different flames [4] [5] [44] [54] [73], however, they predominantly rely on the non-smoking nature, overprediction of oxidation, and resulting insensitivity to $\mathrm{O}_{2}$ oxidation of the flames studied. Deficiencies in using a constant $\alpha$ have also been reported in the literature [21] [90].

It has been suggested in the literature that $\alpha$ can be expressed as a function of temperature, particle residence time and/or particle size [8] [11] [21] [85] [88] [89] [91] [92] [93] [94] [95] [96] [97] [98]. Therefore, using a constant value of $\alpha$ is not perfectly accurate. This idea motivated many researchers to seek a broadly applicable temperature dependent function for $\alpha$ to implement in HACA models [11] [21] [85] [90] [99]. As will be discussed in the next section, the computations in the present work revealed that there is no constant $\alpha$ for oxidation which can predict the correct smoking nature of both Flames 2 and 4 (Tabel 4.1), thus, further suggesting the need for a function for $\alpha$ to implement in the oxidation model. 
Based on the conjecture that $\alpha$ is a function of temperature and residence time, similar to [11] for HACA surface growth, it is suggested that $\alpha_{o x}$ can be expressed as a function of thermal age, $T_{a}$, which is defined as the integral of the temperature a soot particle experiences over its residence time in the flame.

$T_{a}=\int T d t$

$T_{a}$ is calculated using Lagrangian particle tracking of a fluid parcel through the energy and velocity field with corrections for soot transport. Thermal age accounts for the effects of both temperature and residence time. The focus of Veshkini et al. [11] was on HACA surface growth, proposing a function for soot surface reactivity, whereas the present work studies the oxidation process and how soot particles interact with $\mathrm{O}_{2}$ molecules. In [11], it has been shown that $\alpha$ can decrease significantly at longer thermal age - i.e., in the $\mathrm{O}_{2}$ oxidation region of diffusion flames. Using the procedure detailed in [11], in the present work, a similar function for $\alpha$ is used for oxidation which accounts for the ageing of soot particles and allows the use of PAH kinetics for soot surface chemistry. The function is shown in Fig. 4.2. $\alpha_{o x}$ is expressed as a function of thermal age $\left(T_{a}\right)$, which is calculated using Eq. 4.2, and of thermal age at the point of maximum soot $\left(T_{a, \max }\right)$, which differs depending on the flame being studied. As thermal age increases, $\alpha_{o x}$ increases, peaks, and then decreases. As in [11], the function is determined by considering the optimal constant values of $\alpha$ for a variety of datasets, and then combining them into a single function. 


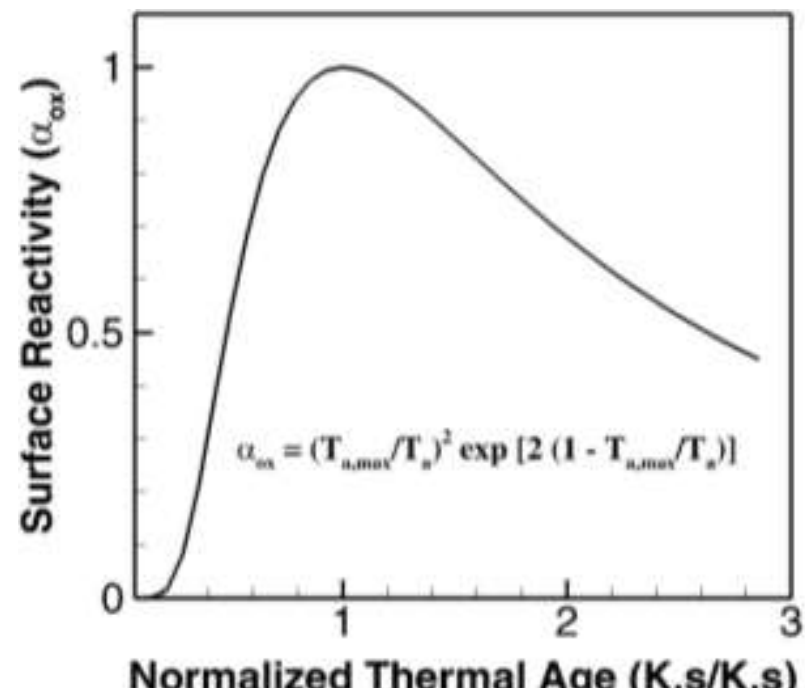

Fig. 4.2. The function proposed for $\alpha_{o x}$ as a function of thermal age, normalized by the thermal age at the point of maximum soot denoted by $T_{a, \max }$ in the equation.

The reason for the increasing and then decreasing shape of the curve in Fig. 4.2 is a result of competing factors. In the growth region of the flame, incipient particles grow from approximately $1 \mathrm{~nm}$ to $35 \mathrm{~nm}$ in diameter. As the particle size increases, increased internal pressure leads to a rise in thermodynamic activity of the particle substance [100]. The resulting increase in the equilibrium constant is most pronounced for the smallest particles and contributes to the upward slope of the $\alpha_{o x}$ curve. The increase in $\alpha_{o x}$, can also be attributed to an increase in active sites during the growth phase [101]. Results of detailed Monte-Carlo simulations performed by Whitesides and Frenklach [102] verified the increasing trend.

The increasing and then decreasing trend in $\alpha_{o x}$ is a result of the balance between the factors described above (increasing $\alpha_{o x}$ ) and the carbonization (decreasing $\alpha_{o x}$ ) that occurs by exposure to high temperature. Carbonization (polymerization, dehydrogenation, and bond rearrangements) in the soot particle, is characterized by the $\mathrm{C} / \mathrm{H}$ ratio. Surface reactivity of soot particles is 
inversely proportional to $\mathrm{C} / \mathrm{H}$ ratio. Since $\mathrm{C} / \mathrm{H}$ ratio increases with residence time, $\alpha_{o x}$ decreases with $T_{a}$ as the soot continues to mature [97] [103] [104] [105].

\subsection{Results and Discussion}

A constant value for surface reactivity of soot for HACA surface growth has been used in many works in the literature [4] [5] [44] [54] [73]. This idea suggests the possibility of using a constant $\alpha$ for the oxidation region as well. Only Flames 2 and 4 (Tabel 4.1) are considered here in order to investigate the effectiveness of implementing a constant $\alpha$ to predict the sooting behaviour of non-smoking (Flame 2) and smoking (Flame 4) flames. Figure 4.3 shows the soot volume fraction for these flames along the particle path exhibiting maximum soot with the experimental results from [13] using a constant $\alpha=0.3$. As was also the case in [73] [81] [87], the nonsmoking characteristic of Flame 2 is captured, however the model is incapable of predicting the

smoking nature of the Flame 4. The computations further revealed that no constant $\alpha$ for oxidation can be found to capture the emission behaviour of these two flames. 


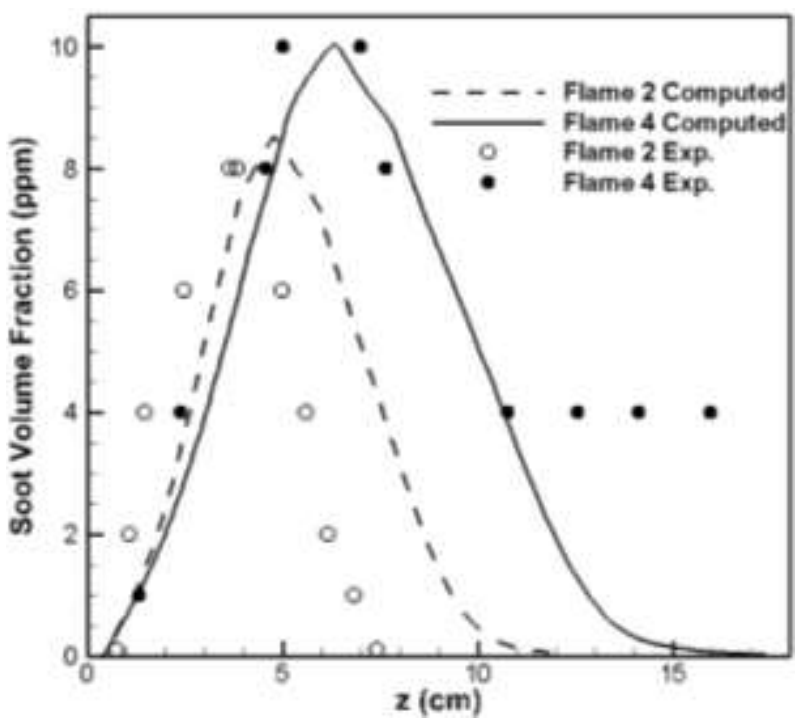

Fig. 4.3. Soot volume fraction along the streak line exhibiting maximum soot with the experimental results [13] for Flames 2 and 4 using a constant $\alpha(0.3)$ for oxidation.

As discussed in the previous section, the model proposed in this work is based on considering soot ageing effects - in particular the thermal age, $T_{a}$. The $\mathrm{O}_{2}$ oxidation model uses the $\alpha_{o x}$ function for oxidation outlined in the previous section to account for the surface reactivity of soot combined with the kinetic rate proposed by Frenklach and Wang [54]. As $T_{a}$ increases in the oxidation region, $\alpha_{o x}$ reduces until $\mathrm{O}_{2}$ oxidation is arrested at $1500 \mathrm{~K}$, which is slightly higher than the cessation value suggested by Lee and $\mathrm{Na}$ [106]. This model was implemented to simulate Flames 1 through 4 . The results of soot volume fraction along the particle path exhibiting maximum soot are plotted in Fig. 4.4 with the experimental results of [13]. The peak soot volume fraction for all the flames is predicted well and is within experimental uncertainty (error bars not shown). More interestingly, the correct emissions behaviour of all four flames is captured, including Flame 2 (2 ppm emitted) and Flame 4 (4 ppm emitted). The sudden change in the slope of soot volume fraction for Flames 3 and 4 is due to a sudden drop in temperature beyond the tip of the flame, after which oxidation does not occur. To the authors' knowledge, 
this is the first such result using a detailed sectional soot model and no variation of model parameters between cases.

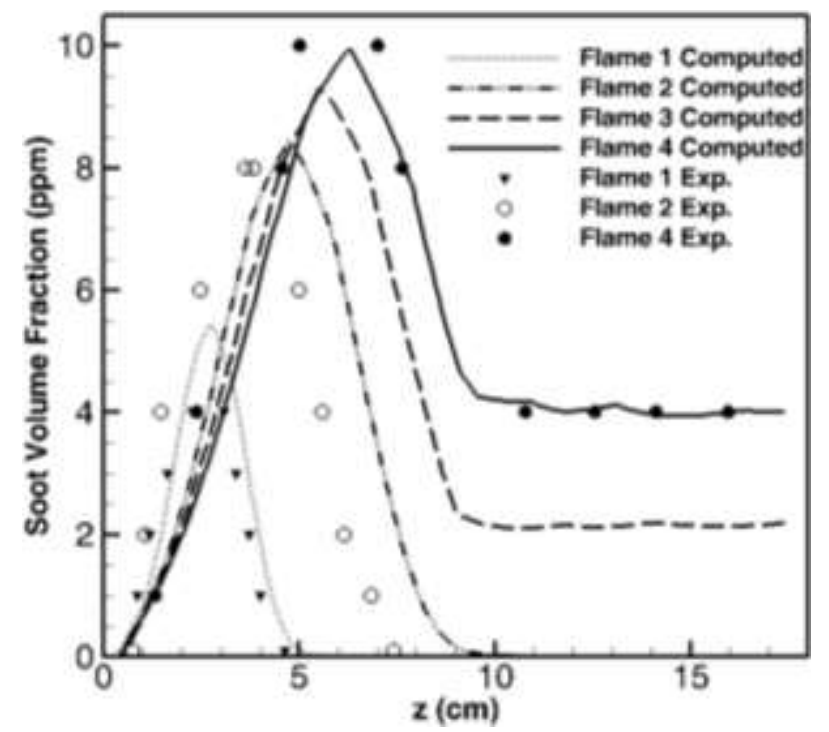

Fig. 4.4. Soot volume fraction along the streak line exhibiting maximum soot with the experimental results [13] for Flames 1 through 4 using the $\alpha_{o x}$ function for oxidation (Experimental results of soot volume fraction along the wings for Flame 3 were not available).

To further validate the model against other experimental datasets, the diluted ethylene/air laminar diffusion flames of Smooke et al. [14] were also simulated using the CoFlame code and the new oxidation model. The Smooke et al. [14] flames were on a different burner, representing widely varying dilution ratios, and the soot particles in them experienced vastly differing residence times compared to Flames $1-4$. Consideration of these eight flames facilitates the validation of the model in a variety of systems, and also verifies its applicability to smoking and non-smoking flames, with differing burners and residence times. Table 4.2 compares the predictions of peak soot volume fraction and smoking behaviour of the eight flames studied here with the experimental results. Value ranges in brackets represent the experimental uncertainty. The predictions of the model for peak soot volume fractions are within the experimental 
uncertainty for all eight flames, and also the correct smoking behaviour of each flame is captured. The model also predicts the correct amount of soot emission for Flame 4. Local and maximum temperatures were found not to be key parameters in determining soot oxidation rates, compared to ageing and surface character. Therefore, the model has proven to be widely applicable, without any modification between cases, to a variety of flames that include different burner geometries, smoking characteristics, dilution, and residence times.

Table 4.2. Comparison of the model predictions with experiments

\begin{tabular}{|c|c|c|c|c|}
\hline \multirow{2}{*}{ Flames } & \multicolumn{2}{|c|}{$\begin{array}{l}\text { Peak Soot volume } \\
\text { fraction (ppm) }\end{array}$} & \multicolumn{2}{|c|}{$\begin{array}{c}\text { Smoke Emission } \\
(\text { ppm })\end{array}$} \\
\hline & Exp. & $\begin{array}{l}\text { Present } \\
\text { Model }\end{array}$ & Exp. & $\begin{array}{c}\text { Present } \\
\text { Model }\end{array}$ \\
\hline Flame $1(\mathrm{NS})^{\mathrm{a}}$ & {$[3,6]$} & 5.5 & NS & NS \\
\hline Flame $2(\mathrm{NS})^{\mathrm{a}}$ & {$[6,10]$} & 8.7 & NS & NS \\
\hline Flame $3(\text { IS })^{\mathbf{a}}$ & {$[6,13]$} & 9.2 & IS & 2.1 \\
\hline Flame $4(S)^{a}$ & {$[8,13]$} & 9.9 & {$[3,5]$} & 4.0 \\
\hline Flame $5(\mathbf{N S})^{b}$ & {$[0.1,0.3]$} & 0.2 & $\mathrm{NS}$ & NS \\
\hline Flame $6(\mathrm{NS})^{\mathrm{b}}$ & {$[0.3,0.6]$} & 0.4 & NS & NS \\
\hline Flame $7(\mathrm{NS})^{\mathrm{b}}$ & {$[1.1,2.1]$} & 1.2 & NS & NS \\
\hline Flame $8(\mathrm{NS})^{\mathrm{b}}$ & {$[2.4,4.4]$} & 3.3 & NS & NS \\
\hline
\end{tabular}

Predicting primary particle size distribution is a challenging task as it requires correct modelling of the soot formation, as well as condensation, particle coalescence, and soot oxidation processes. In the growth region, soot particle diameters increase, while in the oxidation region, they decrease. An effective oxidation model should predict the decreasing trend of soot particle size in the oxidation region. Fig. 4.5 shows the predicted primary particle size as a function of height above the burner for Flame 2 (NS) and Flame 4 (S), compared with the experimental measurements by Megaridis and Dobbins [75]. The model shows excellent agreement with the experimental results for both flames. Both growth and oxidation regions are clearly observed in 
this figure. Peak particle diameters occur at heights of about $5 \mathrm{~cm}$ and $6 \mathrm{~cm}$ for Flames 2 and 4, respectively, which are close to the locations of peak soot for these two flames. This is the location beyond which oxidation is dominant and particle size decreases. For Flame 2, oxidation continues and particle size decreases until complete oxidation has occurred. However, for Flame 4 (Tabel 4.1), oxidation rates decrease significantly at around $7 \mathrm{~cm}$ above the burner, beyond which primary particle size remains almost constant. To the authors' knowledge, this work represents the first time that a single model has been used to predict both soot volume fraction and primary particle diameter for both smoking and non-smoking flames.

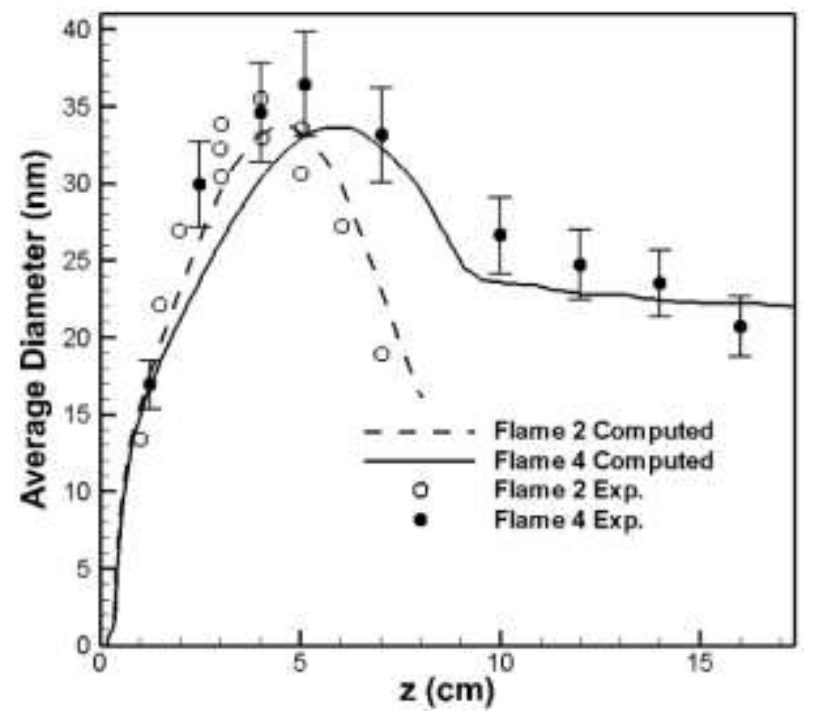

Fig. 4.5. Primary particle size as a function of height above the burner for soot particles traveling along the particle path exhibiting maximum soot for Flames 2 and 4 . The experimental data is from [75].

\subsection{Conclusions}

Soot oxidation in a variety of laminar coflow ethylene/air diffusion flames is investigated. The oxidation by $\mathrm{O}_{2}$ was found in the post-flame oxidation region and was mainly responsible for the 
smoking behaviour of the flames, while the effect of $\mathrm{OH}$ oxidation was only significant on the peak soot volume fraction. A new soot oxidation model for $\mathrm{O}_{2}$ was proposed based on soot particle thermal age. Using a constant ageing parameter, $\alpha_{o x}$ for oxidation proved unsuccessful in predicting the smoking behaviour of the flames. The dependence of surface reactivity of soot on temperature and residence time led to a function for $\alpha_{o x}$ based on thermal age, which was implemented in the oxidation model. The model was applied to simulate eight flames with different flow conditions and fuel dilution ratios. The model was successfully able to capture the transition of the flames from non-smoking to smoke emission. The model also correctly reproduced peak soot volume fraction and primary particle sizes without any variation in model parameters between cases. 


\title{
Chapter 5
}

\section{Soot Surface Reactivity during Surface Growth and}

\section{Oxidation in Laminar Diffusion Flames}

Corresponding Publication: A. Khosousi, S.B. Dworkin, "Soot Surface Reactivity during Surface Growth and Oxidation in Laminar Diffusion Flames," Combustion and Flame 162 (2015) 4523-4532.

\begin{abstract}
Soot surface reactivity is numerically studied in laminar ethylene/air and methane/air coflow diffusion flames. Surface reactions are found to be important for many processes involved in soot formation, including surface growth and oxidation which contribute significantly to soot yield. It has recently been shown that soot particle reactivity changes as particles age during both surface growth (Veshkini et al., 2014) and oxidation (Khosousi and Dworkin, 2015). A newly developed surface character model simultaneously accounts for soot surface reactivity in surface growth and oxidation by considering soot ageing and its effects on the particle surface, reconciling the aforementioned works. This new development eliminates tuning from case to case of one parameter used in soot numerical simulations, $\alpha$, the portion of soot surface sites available for reaction, which is implemented as a function of temperature and residence time (particle history). Thus, the new model reconciles the quantification of the evolving soot surface character for both growth and oxidation. The model is shown to be uniquely capable of
\end{abstract}


predicting soot concentrations and smoke emissions within experimental uncertainty in a wide range of laminar diffusion sooting flames, without any variation of model parameters.

Keywords: Combustion, Numerical Modelling, Soot, Surface reactivity, Surface growth, Oxidation

\subsection{Introduction}

Soot emissions pose a potent threat to human health and should be avoided in combustion systems [107]. Soot is a leading contributor to the darkening of cityscapes and air pollution in the urban environment [107]. Environmental and health issues lead combustion device designers to

attempt to reduce combustion-generated soot emissions; however, this challenge requires a comprehensive understanding of the physics of combustion, especially that of soot formation, which is particularly complex and remains poorly understood today. A complete understanding of this phenomenon is crucial to meet the required demands of reduced pollution. Since soot is a major health hazard in the urban environment, its pre-emission consumption in combustion is extremely important. Soot particle formation is a highly complex multi-physics phenomenon that includes fluid mechanics, heat transfer, thermodynamics, and multiphase flows [108]. Much progress has been made in the numerical modelling of combustion and soot formation in recent years [4] [5] [21] [22] [86] [109] [110] [111] [112]. Numerical modelling of soot formation and oxidation is very challenging in that it involves complex processes including those contributing to the formation and growth of soot particles, such as inception, condensation, surface growth, and coagulation, and those contributing to the destruction of soot particles, such as oxidation and 
fragmentation. Therefore, an accurate model which predicts soot formation in flames requires precise models for these processes.

The precision of soot particle dynamics models strongly depends on the accuracy of the predictions for species and PAH concentrations, which are used in the sectional particle dynamics submodels to compute soot growth and oxidation rates. Therefore, for accurate prediction capabilities of the numerical modelling of soot formation, detailed chemical kinetic mechanisms for gas-phase reactions are required. The widely used mechanism developed by [21] attributes the growth of PAH soot precursors and also the growth of soot surfaces to hydrogenabstraction-carbon-addition (HACA). This mechanism has been effectively used in various numerical studies to model soot formation [22] [109] [110] [113] [114], representing a major step towards quantitative prediction. Slavinskaya and Frank [111] presented a more comprehensive PAH growth mechanism, which introduced additional reaction pathways for PAH formation and allowed for abstraction and growth in the HACA mechanism by additional species. This mechanism that has been widely validated for a variety of flames and conditions [4] [5] [30] [115] permits the use of more physical assumptions about the number of active sites on the soot particle and is used in the present study. The use of this mechanism has been shown to produce more accurate predictions of aromatic and soot concentrations on the centerline, providing a better foundation to study the surface reactivity of soot. 


\subsection{Soot Surface Reactivity}

The primary processes contributing to formation and growth of soot particles are inception, condensation, and surface growth. The surface reactivity of soot particles is an important factor in soot formation as surface growth is a significant contributor to soot yield and in some systems, it dominates [12]. Polycyclic Aromatic Hydrocarbons (PAHs), which are known to be the precursors to soot formation, collide and dimerize to form PAH clusters, which further combine or grow, leading to inception of soot particles. These incipient soot particles condense, aggregate, and grow through surface reactions, forming larger soot particles. Surface growth has been found to have a major impact on soot formation on the wings of the coflow diffusion flames [11].

In order to study the surface reactivity of soot, it is crucial to understand how surface reactions of soot and other species such as $\mathrm{H}_{2}, \mathrm{H}_{2} \mathrm{O}, \mathrm{H}, \mathrm{C}_{2} \mathrm{H}_{2}$, or $\mathrm{O}_{2}$ could lead to soot growth/decay. Hydrogen-abstraction-Carbon-addition (HACA) is known to be the main mechanism accountable for soot surface growth, while oxidation contributes to the decay of soot. Abstraction of an $\mathrm{H}$ atom from an arm-chair site on the soot particle provides a soot particle with an active (dehydrogenated) site which can react with $\mathrm{H}_{2}, \mathrm{H}_{2} \mathrm{O}, \mathrm{H}, \mathrm{C}_{2} \mathrm{H}_{2}$, or $\mathrm{O}_{2}$. The reaction of this active site with acetylene $\left(\mathrm{C}_{2} \mathrm{H}_{2}\right)$ leads to addition of two carbon atoms to the soot particle and formation of an additional aromatic ring at the active site, thus contributing to its surface growth. The reaction of the active site with $\mathrm{O}_{2}$, however, leads to removal of carbon from the soot particle, translating into its decay. The rate expressions for HACA-based soot surface growth and oxidation, adopted from [21], are provided in Table 5.1. 
Table 5.1. HACA-based soot surface growth and oxidation reactions [21], $k=A T^{b} e^{-E_{a} / R T}$.

\begin{tabular}{|c|c|c|c|c|}
\hline No. & Reaction & $\boldsymbol{A}\left(\frac{\mathrm{cm}^{3}}{\mathrm{~mol} . \mathrm{s}}\right)$ & $b$ & $\boldsymbol{E}_{\boldsymbol{a}}\left(\frac{\mathrm{kcal}}{\mathrm{mol}}\right)$ \\
\hline S1 & $\mathrm{C}_{\text {soot }}-\mathrm{H}+\mathrm{H} \Longleftrightarrow \mathrm{C}_{\text {soot }}{ }^{\circ}+\mathrm{H}_{2}$ & $4.2 \times 10^{13}$ & 0.0 & 13.0 \\
\hline S2 & $\mathrm{C}_{\text {soot }}-\mathrm{H}+\mathrm{OH} \Longleftrightarrow \mathrm{C}_{\text {soot }}{ }^{\circ}+\mathrm{H}_{2} \mathrm{O}$ & $1.0 \times 10^{10}$ & 0.73 & 1.43 \\
\hline S3 & $\mathrm{C}_{\text {soot }}{ }^{\circ}+\mathrm{H} \longrightarrow \mathrm{C}_{\text {soot }}-\mathrm{H}$ & $2.0 \times 10^{13}$ & 0.0 & 0.0 \\
\hline S4 & $\mathrm{C}_{\mathrm{soot}}{ }^{\mathrm{o}}+\mathrm{C}_{2} \mathrm{H}_{2} \longrightarrow \mathrm{C}_{\mathrm{soot}}-\mathrm{H}+\mathrm{H}$ & $8.0 \times 10^{7}$ & 1.56 & 3.8 \\
\hline S5 & $\mathrm{C}_{\mathrm{soot}} \mathrm{o}^{\mathrm{O}}+\mathrm{O}_{2} \longrightarrow 2 \mathrm{CO}+$ product & $2.2 \times 10^{12}$ & 0.0 & 7.5 \\
\hline S6 & $\mathrm{C}_{\mathrm{soot}}-\mathrm{H}+\mathrm{OH} \longrightarrow \mathrm{CO}+$ product & \multicolumn{3}{|c|}{$\gamma_{\mathrm{OH}}=0.13$} \\
\hline
\end{tabular}

It is known that the surface growth of the soot particles is a major contributor to soot mass yield. The surface of the soot particles reacts with the gaseous species when exposed to high temperatures. Reactivity of the soot surface, however, depends on the number of active/dehydrogenated sites which are available to react with stable gaseous species. The number of active sites per unit surface area is correlated to the concentration of $\mathrm{C}-\mathrm{H}$ sites. It has been observed that the concentration of $\mathrm{C}-\mathrm{H}$ sites decreases as soot matures, which confirms the experimental observations suggesting that the reactivity of surface sites changes with particle ageing [8] [9] [10] [54]. It has been observed that the $\mathrm{C} / \mathrm{H}$ ratio of a soot particle increases with particle residence time [97] [103], resulting in the reduction of $\mathrm{C}-\mathrm{H}$ sites and consequently, reduced soot surface reactivity.

Frenklach and Wang [54] introduced the parameter $\alpha$, which is based on the number of surface sites available for a given reaction, to account for particle orientation/collision probabilities and soot surface ageing. This parameter is used in numerical works to reconcile the inaccuracies associated with treating the sites on the soot surface like those on the corresponding PAH. The 
surface ageing effects were taken into account using $\alpha$ for calculation of reaction rates. Therefore, the rate of HACA surface growth (reaction S4) is calculated by

$R_{4}=\alpha k_{4}\left[\mathrm{C}_{2} \mathrm{H}_{2}\right]\left[\mathrm{C}_{\text {soot }^{\circ}}\right]$

where $k_{4}$ is the per-site rate coefficient for $\mathrm{C}_{2} \mathrm{H}_{2}$ addition (for reaction $\mathrm{S} 4$ ), $\left[\mathrm{C}_{2} \mathrm{H}_{2}\right]$ is the concentration of acetylene, and $\left[\mathrm{C}_{\text {soot }}{ }^{\circ}\right]$ is the concentration of dehydrogenated sites given by

$\left[\mathrm{C}_{\text {soot }^{\circ}}\right]=\frac{A_{s}}{A_{v}} \chi_{C_{\text {soot }^{\circ}}}$

in which $A_{S}\left(\mathrm{~cm}^{2} / \mathrm{cc}\right)$ is the surface density of soot particles, $A_{v}$ is Avogadro's number, and $\chi_{C_{\text {soot }^{\circ}}}$ is the number of dehydrogenated sites per unit soot surface area.

How best to implement $\alpha$ in the numerical models has been the subject of various studies [4] [11] [54]. It has been shown in the literature that treating $\alpha$ as a single, unchanged constant inhibits broad model applicability [11]. As a result, there have been many works suggesting that $\alpha$ varies with different flame properties. Much attention has been given to investigate the correlation between $\alpha$ and flame temperature, particle residence time, and particle size. A constant $\alpha$ has effectively been used in many numerical works to model HACA surface growth and soot formation [4] [5] [54] [73], which provides sufficient accuracy to capture the correct trend of soot formation within different flame configurations. However, the value for $\alpha$ often needs to be adjusted as flame conditions vary. Using a constant value for $\alpha$ decreases the accuracy of soot modelling and adds a tunable modelling parameter as the peak soot is matched to the experimental values. It has been shown in [11] how the accuracy of using a constant $\alpha$ decreases 
as the dilution levels of the fuel increases. Referring to the importance of $\alpha$ to model surface growth using the HACA mechanism in soot formation, it is suggested that accurately predicting soot volume fraction in different flames requires using a non-constant (functional form) $\alpha$. The use of a function for $\alpha$ is found to be crucial to capture the correct soot volume fraction on the wings of coflow flames due to the fact that surface growth is the primary process contributing to soot formation in this region. Different functions for $\alpha$ have been proposed in the literature, summarized in [11]. The initial focus of most works was on temperature-dependent functions. However, it soon became apparent that incipient soot particles, usually comprising small PAHs, are covered with more dense active sites. Therefore, the use of a function, dependent only on local temperature, results in unphysically low values of $\alpha$ for the young soot particles, suggesting that $\alpha$ should be a function of more than just local flame temperature. Furthermore, considering only local temperature in determining $\alpha$ ignores the relatively long characteristic times of soot growth, and the importance of particle history.

Veshkini et al. [11] studied various flame properties and their impact on $\alpha$ in surface growth regions. Their work showed that it is impossible to find a function for $\alpha$ based on either flame peak temperature or local temperature at the location of peak soot, which was also observed previously in the work of Singh et al. [99]. Veshkini et al. [11] further studied other flame properties and based their work on experimental observations suggesting that the age of a soot particle is a significant contributor to soot surface reactivity [91] [116]. They combined the effects of temperature and the age of a soot particle, into one parameter, thermal age, defined as the integral of the temperature that a soot particle experiences over its residence time, $T_{a}=$ $\int T d t$. This parameter accommodates the effects of both temperature and residence time. This 
definition implies that a soot particle could have equal thermal age in either of these cases: first, when the soot particle stays in a high temperature region for a short period of time; second: when the soot particle stays in a low temperature region for a long period of time. They proposed a systematic method to define a function for $\alpha$. In their work, it was suggested that soot surface reactivity, and consequently $\alpha$, are exponentially dependent on thermal age, adopted from [93] [104]. This idea was implemented in a detailed numerical algorithm to study various flames with a wide range of burner configurations and fuel inlet dilution levels and velocities. They ultimately presented an exponential function to calculate $\alpha$, to be applied to HACA growth, which was validated against experimental data for twelve different flames. The model considered only the growth region of diffusion flames, however, neglecting oxidative effects.

In Khosousi and Dworkin [117], a similar approach was used to employ thermal age as defined above in the simulations. However, focus was on the post-flame oxidation region in nonpremixed systems, neglecting growth. The models of soot oxidation consider $\mathrm{OH}$ and $\mathrm{O}_{2}$ to be the primary oxidative species. The effects of these species on soot oxidation are discussed in detail in [117]. Oxidation of soot is attributed to the surface reactions between soot and $\mathrm{O}_{2}$ and/or $\mathrm{OH}$. These species, $\mathrm{O}_{2}$ and $\mathrm{OH}$, are found to be effective in different parts of diffusion flames. The oxidation of soot by $\mathrm{OH}$ is more pronounced in the lower portion of the coflow diffusion flames (also known as the soot growth region), where soot is still growing, whereas the oxidation by $\mathrm{O}_{2}$ occurs mostly in the upper portion of the flame (also known as the oxidation region), where $\mathrm{O}_{2}$ has significantly penetrated via diffusion from the oxidizer zone. The rate of oxidation by $\mathrm{OH}$ is modelled based on collision theory using a collision efficiency, correcting for the possibility that not all collisions between soot and $\mathrm{OH}$ lead to oxidation. However, due to the 
radical nature of $\mathrm{OH}$, there is no need for an active site for $\mathrm{OH}$ oxidation to proceed. The rate of oxidation by $\mathrm{O}_{2}$, however, is calculated using chemical reactions between soot and $\mathrm{O}_{2}$. Finding the rate for this reaction has remained challenging as the rates proposed in the literature widely differ [117]. Apart from broadly varied rates, modellers use different approaches to account for soot surface reactivity, as oxidation by $\mathrm{O}_{2}$, like $\mathrm{HACA}$, proceeds through surface reactions between soot active sites and $\mathrm{O}_{2}$.

In the literature, consideration has mostly been given to soot surface growth in the growth region, and correct predictions of peak soot for non-smoking flames. However, $\mathrm{O}_{2}$ is found to have insignificant effects in this region as well as on the peak soot concentration. $\mathrm{O}_{2}$ effects are only noticeable in the upper portion of the flame where soot has already peaked and volume fraction is in decline. The study of non-smoking flames provides a practical ground to investigate the surface growth mechanism in the growth region and consider the effects of HACA on peak soot volume fraction in isolation, while not involving the effects of oxidation. Focusing on the growth region and the reliance on the non-smoking nature, overprediction of oxidation, and resulting insensitivity to $\mathrm{O}_{2}$ oxidation, have led to successful simulations for the non-smoking flames [4] [5] [11] [54] [73]. However, these models, as they focus on studying non-smoking flames, do not perfectly describe soot surface reactivity in the oxidation region. Oxidation by $\mathrm{O}_{2}$ occurs when it reacts with an active site on the soot surface. As a result, this process follows the same path as surface growth. In Khosousi and Dworkin [117], the present authors diverted attention to the study of soot surface reactivity in the oxidation region. It was determined that there was no constant $\alpha$ which could effectively predict the correct smoking nature of both nonsmoking and smoking flames in the study, realizing that in order to have an effective oxidation 
model, surface reactivity of soot and its variation should be accounted for in the simulations. Therefore, the use of a varying $\alpha$ was suggested when modelling oxidation. Following a similar approach as in [11], and taking into account the effects of soot ageing, a function for $\alpha$ was proposed based on the parameter, $T_{a}$, as defined in [11], to model soot oxidation by $\mathrm{O}_{2}$ in the oxidation region. This function was validated when used to model soot formation in different non-smoking and smoking flames.

The focus of the present work is to study surface reactivity of soot simultaneously in both growth and oxidation regions. One reconciled model, which integrates the two models for these regions into a unique surface model, is developed and presented. This study considers both peak soot and soot emissions to assure that the surface reactivity is modelled correctly in both oxidation and growth regions.

\subsection{Numerical Model}

The present work studies soot formation and oxidation in atmospheric pressure, coflow laminar ethylene/air diffusion flames, studied by Santoro and coworkers [12] [13] (referred to as 'Santoro flames'), diluted ethylene/air flames, studied by Smooke et al. [14] (referred to as 'Smooke flames'), and methane/air flame, studied by Lee et al. [15] (referred to as 'Lee flame'). These flames have been chosen not just because of the abundance of experimental data for different flame properties which makes them suitable for model verification, but also because of the fact that they represent a vast range of flames with varying properties, flow conditions and sooting behaviour. They include flames of varying smoke emission character, fuel composition, fuel 
dilution, residence time, etc. Table 5.2 presents the list of these flames, flow velocities and fuel mole fractions.

Table 5.2. Inlet conditions of the fuel and air streams

\begin{tabular}{ccccc}
\hline Flame & $\begin{array}{c}\text { Fuel velocity } \\
(\mathbf{c m} / \mathbf{s})\end{array}$ & $\begin{array}{c}\text { Air velocity } \\
(\mathbf{c m} / \mathbf{s})\end{array}$ & Fuel mole fraction & Reference \\
\hline NSI & 2.38 & 8.90 & 1.0 & {$[12]$} \\
\hline NSII & 3.98 & 8.90 & 1.0 & {$[12]$} \\
\hline IS & 4.75 & 8.90 & 1.0 & {$[12]$} \\
\hline S & 5.05 & 13.30 & 1.0 & {$[12]$} \\
\hline SM32 & 35.0 & 35.0 & 0.32 & {$[14]$} \\
\hline SM40 & 35.0 & 35.0 & 0.40 & {$[14]$} \\
\hline SM60 & 35.0 & 35.0 & 0.60 & {$[14]$} \\
\hline SM80 & 35.0 & 35.0 & 0.80 & {$[15]$} \\
\hline M/A & 10.24 & 11.94 & 1.0 & \\
\hline
\end{tabular}

The governing equations for conservation of mass, momentum, energy, species mass fractions, primary particle number densities, and soot aggregate number densities are solved for the gas phase model. The CoFlame code (details are provided in [4] [5]) has been utilized for the simulations. The governing equations can be found in [4] [5] [77]. The burner configuration is axi-symmetric, making it possible to project the three-dimensional computational domain onto a two-dimensional rectangular plane. The boundary conditions include symmetry, free-slip, and zero-gradient at the centerline, the outer radial boundary, and the outflow boundary, respectively. In order to save computational cost while resolving large spatial gradients, a non-uniform mesh has been implemented, which is finest near the flame centerline and fuel tube, coarsening moving away from the flame region. Depending on the flame, the domain is divided into approximately 200 control volumes in the axial direction and 100 control volumes in the radial direction. The numerical solutions are sought using parallel processing due to the high computational intensity of the problem. The domain is decomposed uniformly into 200 
subdomains, with the boundaries of each subdomain perpendicular to the $z$-axis. Each CPU is responsible for a single row of 100 control volumes in the radial direction. The interprocess communication is executed using the Fortran Message Passing Interface library [24] [25]. The computations are performed on the General Purpose Cluster (GPC) and the Ryerson Sandybridge (Sandy) Cluster of the SciNet Computing Consortium of Compute Canada.

Soot particle dynamics are modelled using a fixed sectional approach in which the soot particle mass range is divided logarithmically into 35 discrete sections. Two transport equations for primary spherical particle number density and for soot aggregate density are solved for each section. The soot sectional model considers inception, surface growth, PAH surface condensation, surface oxidation, coagulation, fragmentation, particle diffusion, thermophoresis, and particle radiation. The inception model is based on the collisions of two pyrene molecules in the free-molecular regime and therefore connects the gaseous pyrene concentrations with the smallest particle size section. Care is taken to ensure species mass and energy conservation laws are applied properly; inception acts as a negative source term for the species conservation equation of pyrene, in addition to being a positive source term for the sectional equations. In addition, the net difference in enthalpy from the destruction of pyrene and the generation of particles is accounted for as a source term in the energy equation. The surface chemistry model, to be discussed in detail in the following section, considers growth via the HACA mechanism developed in [19], and soot size reduction via oxidation [20]. Surface growth via PAH condensation is calculated by considering collisions between pyrene molecules and soot aggregates of any size [21]. Based on a detailed analysis, the probability of sticking in each PAH-soot collision, $c$, is set to 0.5 [22]. The radiation model used here is the Discrete Ordinate 
Method and a statistical narrow-band correlated-k-based model [16] which considers a source term in the energy equation due to the nongrey radiative heat transfer by soot, $\mathrm{H}_{2} \mathrm{O}, \mathrm{CO}_{2}$, and CO. For more details about the numerical model, the reader is referred to [4] [5] [22] [109] [110].

\subsection{Results and Discussion}

The model proposed in this work uses the soot ageing effects - in particular the thermal age. The model takes into account the effects of soot ageing in the soot growth and oxidation regions. The surface reactivity of soot is modelled using a single function that is applied to both growth and oxidation processes throughout the flame.

As mentioned in the previous section, the surface reactivity of soot is sought to be represented as a function of thermal age, $T_{a}$. Similar to Khosousi and Dworkin [117], in the present work, thermal age, $T_{a}$, is normalized using the thermal age at the point of maximum soot, $T_{a, \max }$, to make the function applicable to a broader range of flames with various residence times. The main purpose of this parameter is to generalize the $\alpha$ function. For instance, the residence times for the Smooke flames are less than those for the Santoro flames, and this parameter allows for the use of the function for both of these flame configurations without making adjustments to - or retuning of the function parameters.

The detailed approach to determine the function for surface reactivity is similar to that in Veshkini et al. [11], wherein the function is determined by considering the optimal constant values of $\alpha$ for a variety of datasets, and then combining them into a single function. In this 
regard, the first step is to find an optimum constant value for $\alpha$ which predicts correct peak soot volume fraction for each flame; this value can change from flame to flame. This constant $\alpha$ is representative of the average surface reactivity of soot particles throughout a given flame. The thermal age distribution is obtained for each flame. The flames used to generate the function include NSI, NSII, IS, S, SM32, SM40, SM60, and SM80. The average surface reactivity for each flame is integrated along the pathline of maximum soot with respect to thermal age, $\int \alpha d T_{a}$, and plotted against thermal age. An exponential function, as suggested in the literature [78] [79], is fitted through this curve. This exponential function provides the average value for surface reactivity, i.e., $\alpha$, as a function of thermal age. However, in order to use the $\alpha$ function throughout the flame, it is necessary to calculate the local values for $\alpha$ in the flame. In order to find a function for the instantaneous $\alpha$ at any point in a flame, the exponential function fitted to the integrated $\alpha$, which represents an average value for surface reactivity, is differentiated and the coefficients are optimized for more accurate predictions. The proposed function, shown in Fig. 5.1, is expressed as:

$\alpha=\left(T_{a, \max } / T_{a}\right)^{2.2} \exp \left[\left(2.4 *\left(0.85-T_{a, \max } / T_{a}\right)\right]\right.$,

where $T_{a}$ is thermal age and $T_{a, \max }$ is the thermal age at the point of maximum soot, which differs depending on the flame being studied. As thermal age increases, $\alpha$ increases, peaks, and then decreases. There are competing factors contributing to the shape of the function. The increase in $\alpha$ can be attributed to an increase in active sites during the growth phase [101]. Results of detailed Monte-Carlo simulations performed by Whitesides and Frenklach [102] verified the increasing trend. The decreasing trend in $\alpha$ is a result of the carbonization that occurs by 
exposure to high temperature. Carbonization (polymerization, dehydrogenation, and bond rearrangements) in the soot particle is characterized by the $\mathrm{C} / \mathrm{H}$ ratio. Soot surface reactivity is inversely proportional to $\mathrm{C} / \mathrm{H}$ ratio. Since $\mathrm{C} / \mathrm{H}$ ratio increases with residence time, $\alpha$ decreases with $T_{a}$ as the soot continues to mature [95] [103] [104] [105]. Functional parameters depend on the predicted $\mathrm{C}_{2} \mathrm{H}_{2}$ concentrations, which despite having been well validated in [4], [111], and [115], could need recalibration if a different chemical mechanism was used.

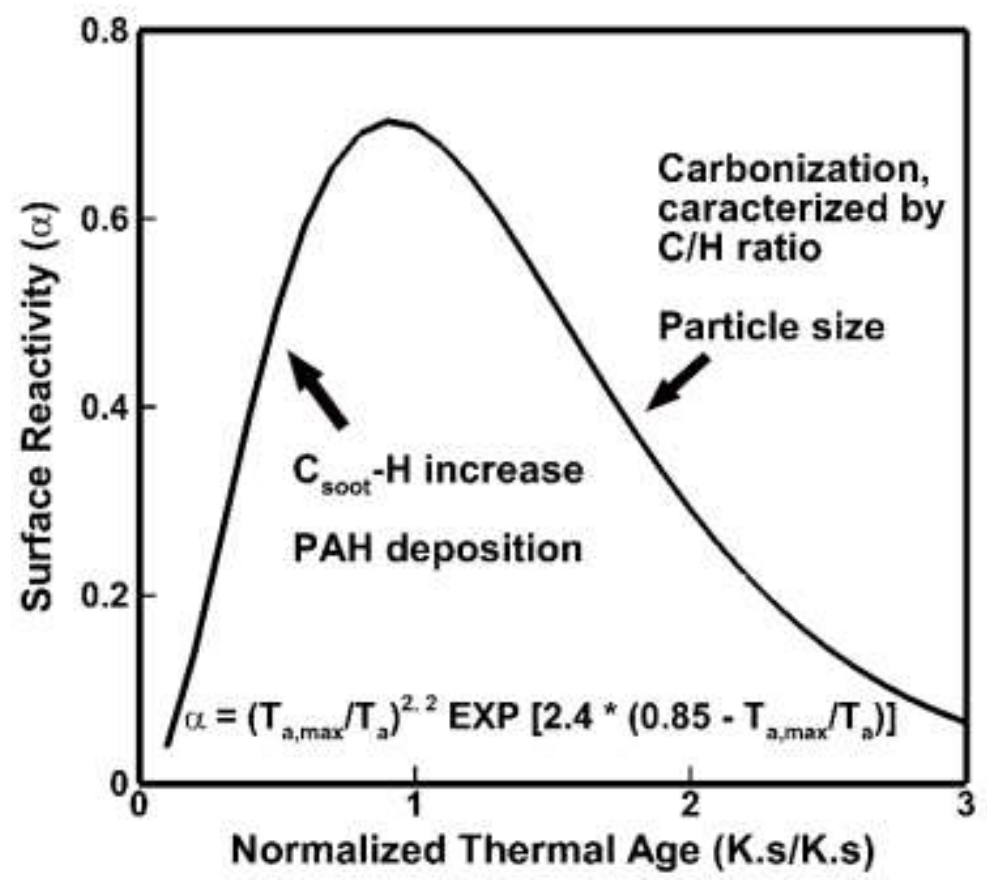

Fig. 5.1. Proposed function for soot surface reactivity to employ in both growth and oxidation regions.

This model is used to simulate soot formation for the ethylene diffusion flames studied by Santoro and coworkers [12] [13], diluted ethylene flames studied by Smooke et al. [14], and the methane/air flame studied by Lee et al. [15], listed in Table 5.2. Santoro flames have been chosen for simulations because of ethylene's moderately sooting tendencies which provide a suitable ground for studying soot and comparisons. Applying the model to simulate Smooke 
flames tests the model's capabilities to predict the effects of fuel dilution as well as flame residence time. The Smooke flames experience a relatively short residence time, which varies with dilution ratio. Lastly, simulations of methane flames are also performed to apply the model to flames with lower sooting tendencies, and test its applicability to a different fuel. Figure 5.2 shows surface reactivity determined by the proposed function (Eq. 3.3) for the NSII, S, SM32, and SM80 flames versus the height above the burner $(z)$. It can be observed how the function reflects the changes in flame residence times and flame lengths. The general shape of each of the four curves is the same. However, the NSII and S flames (Santoro flames) with longer residence times show smoother and more drawn-out surface reactivity variation.

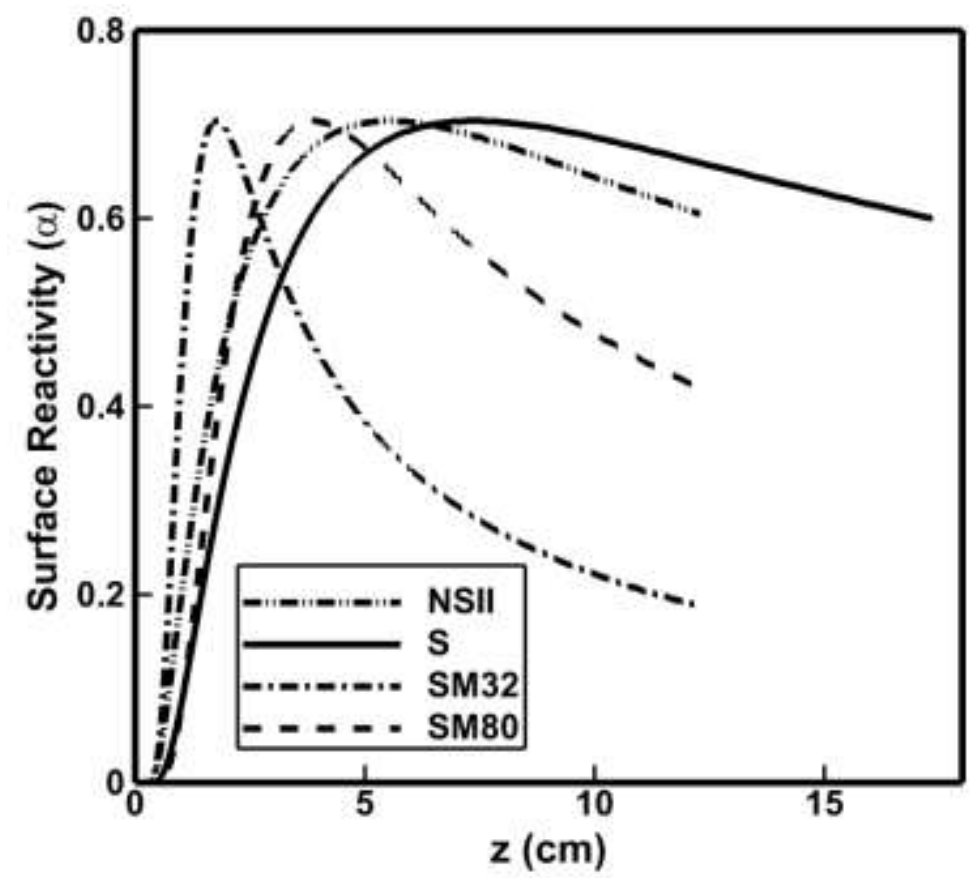

Fig. 5.2. Surface reactivity $(\alpha)$ determined by Eq. 3.3 for the NSII, S, SM32, and SM80 flames versus the height above the burner. 


\subsubsection{Modelling Santoro Flames}

The coflow laminar diffusion flames first studied by Santoro et al. [12] are simulated here. Ethylene enters the coflow burner through the central tube with an inner diameter of $11.1 \mathrm{~mm}$. Air is supplied through a coflowing annular region with an inner diameter of $102.0 \mathrm{~mm}$. Other details of these flames can be found in [12] [13]. The modelling is performed for four flames with different air and fuel flow rates, resulting in different sooting behaviour for the flames. These flames are introduced in Table 5.2 as low flow rate non-smoking (NSI), non-smoking (NSII), incipient sooting (IS), and smoking (S) flames along with fuel and air velocities. There is no soot emitted through the tip of the NSI or NSII flames. The onset of smoke emission occurs in the IS flame. Significant smoke emits from the S flame.

The study of soot formation in these flames has been the subject of many works in the literature [4] [5] [11] [12] [13] [117]. In order to validate the present model (PM), the simulation results for the NSII flame obtained using this model are compared with experimental data. As soot formation processes are highly dependent on temperature, correctly reproducing temperature in flames is a key factor in soot modelling. Therefore, the model predictions for temperature profiles at two different heights, $z=2 \mathrm{~cm}$ and $z=7 \mathrm{~cm}$, are compared with experimental results from [13] in Fig. 5.3(a). As it is observed, numerical results show good agreement with those of experiments, consistent with previous works [4]. Apart from temperature, the correct modelling of soot formation requires an accurate prediction of acetylene, which is a primary soot precursor. Figure 5.3(b) shows radial profiles of acetylene at two heights, $z=0.7 \mathrm{~cm}$ and $z=2 \mathrm{~cm}$, reproduced by the PM along with experimental results from [13]. At $z=0.7 \mathrm{~cm}$, acetylene mole fraction is slightly overpredicted by the model; however, at $z=2 \mathrm{~cm}$, the predictions show 
relatively good agreement with experimental results. Figure 5.3(c) depicts $\mathrm{OH}$ mole fraction profiles at two heights above the burner, $z=0.7 \mathrm{~cm}$ and $z=7 \mathrm{~cm}$. A slight overprediction is observed at $z=0.7 \mathrm{~cm}$, while the predictions improve at $z=7 \mathrm{~cm}$. Figure $5.3(\mathrm{~d})$ shows the radial profiles of soot volume fraction predicted by the present model and the constant- $\alpha$ model $(\alpha=$ $0.5)$, along with the experimental data at two different heights, $z=1.5 \mathrm{~cm}$ and $z=5 \mathrm{~cm}$. It is observed that both models provide sound predictions for soot volume fraction.
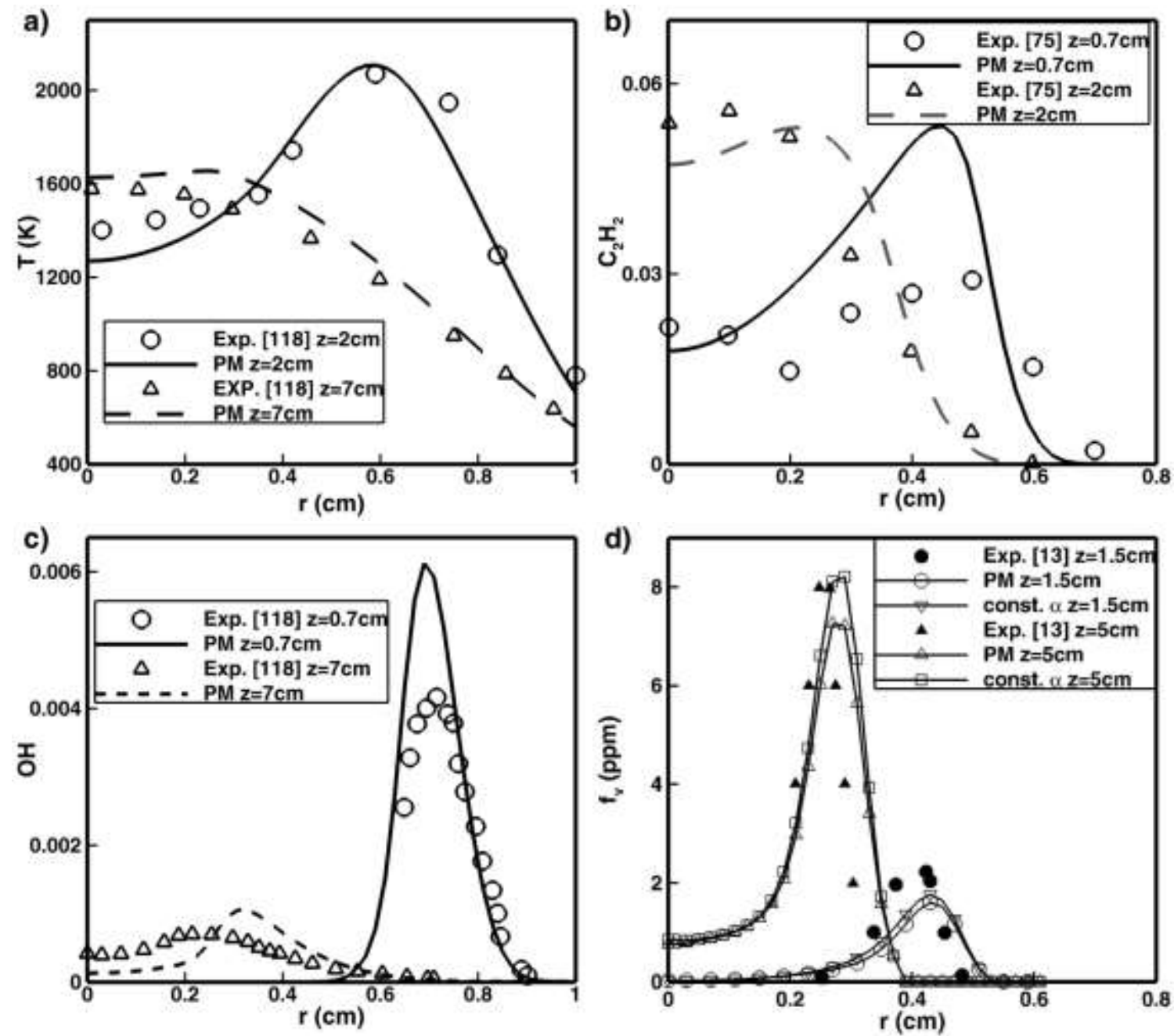

Fig. 5.3. Comparison of numerical predictions of the present model and experimental data for (a) temperature (measurements from [118]), (b) acetylene mole fraction (measurements from [75]), (c) $\mathrm{OH}$ mole fraction (measurements from [118]), and (d) soot volume fraction (measurements from [13]) at the axial heights indicated as functions of radial distance from the centerline. 
To further examine the prediction capabilities of the present model, this model along with three other models are used to simulate the NSII and S flames. Soot volume fraction and particle size are two primary characteristics of soot particles. These parameters are of particular interest in that their correct prediction requires an accurate and detailed modelling of soot formation and oxidation sub-models, and consequently shows the practicality of the model.

The simulations here are performed using four models, the constant- $\alpha$ model $(\alpha=0.5)$, the models developed by Veshkini et al. [11] (Veshkini model) and Khosousi and Dworkin [117] (Khosousi model), and the present model (PM). Table 5.3 shows how surface reactivity is either prescribed or calculated for the four models.

Table 5.3. Different models and their surface reactivity models used in the present work.

\section{Surface Growth Oxidation}

\begin{tabular}{ccc}
\hline Constant- $\alpha$ Model & $\alpha=0.5$ & $\alpha=0.5$ \\
\hline Veshkini et al. model [11] & $\alpha=6974.6 / T_{a}^{2} \exp \left(-88.06 / T_{a}\right)$ & $\alpha=0.5$ \\
\hline Khosousi and Dworkin & $\alpha=0.5$ & $\alpha=\left(T_{a, \max } / T_{a}\right)^{2} \exp \left[\left(2 *\left(1-T_{a, \max } / T_{a}\right)\right]\right.$ \\
model [117] & & \\
\hline Present Model (PM) & $\alpha=\left(T_{a, \max } / T_{a}\right)^{2.2} \exp \left[\left(2.4 *\left(0.85-T_{a, \max } / T_{a}\right)\right]\right.$
\end{tabular}

Figures 5.4 and 5.5 compare the numerical and experimental results for soot volume fraction (measurements from [13]) and primary particle size (measurements from [75]) along the pathline of maximum soot for the NSII and S flames. As it is observed from Fig. 5.4(a), all models correctly predict the peak soot volume fraction for the NSII flame. In addition, all models capture the increasing and decreasing trends for soot in the growth and oxidation regions. 
While reproducing the correct peak soot shows the model's efficiency in modelling growth processes, capturing the non-smoking nature of the flame does not guarantee that soot surface reactivity has been modelled effectively, as the non-smoking nature could be achieved due to unphysically high oxidation rates. To investigate the capability of different models in modelling soot surface reactivity in the oxidation region, one should consider modelling a smoking flame, as predicting the amount of smoke emission essentially shows if the model is working well in the oxidation zone. Figure 5.4(b) shows soot volume fraction along the pathline of maximum soot obtained using different models versus experiments for the S flame. All models predict the peak soot volume fraction correctly. The constant- $\alpha$ and Veshkini models, however, which were calibrated to soot growth only, fail to capture the smoke emission in the post-flame oxidation region. These two models implement an oxidation model which does not account for the change in soot surface reactivity effects in the oxidation region. However, the PM and Khosousi models predict the correct soot volume fraction in both growth and oxidation regions, and therefore correctly predict the amount of smoke emission from the flame. 

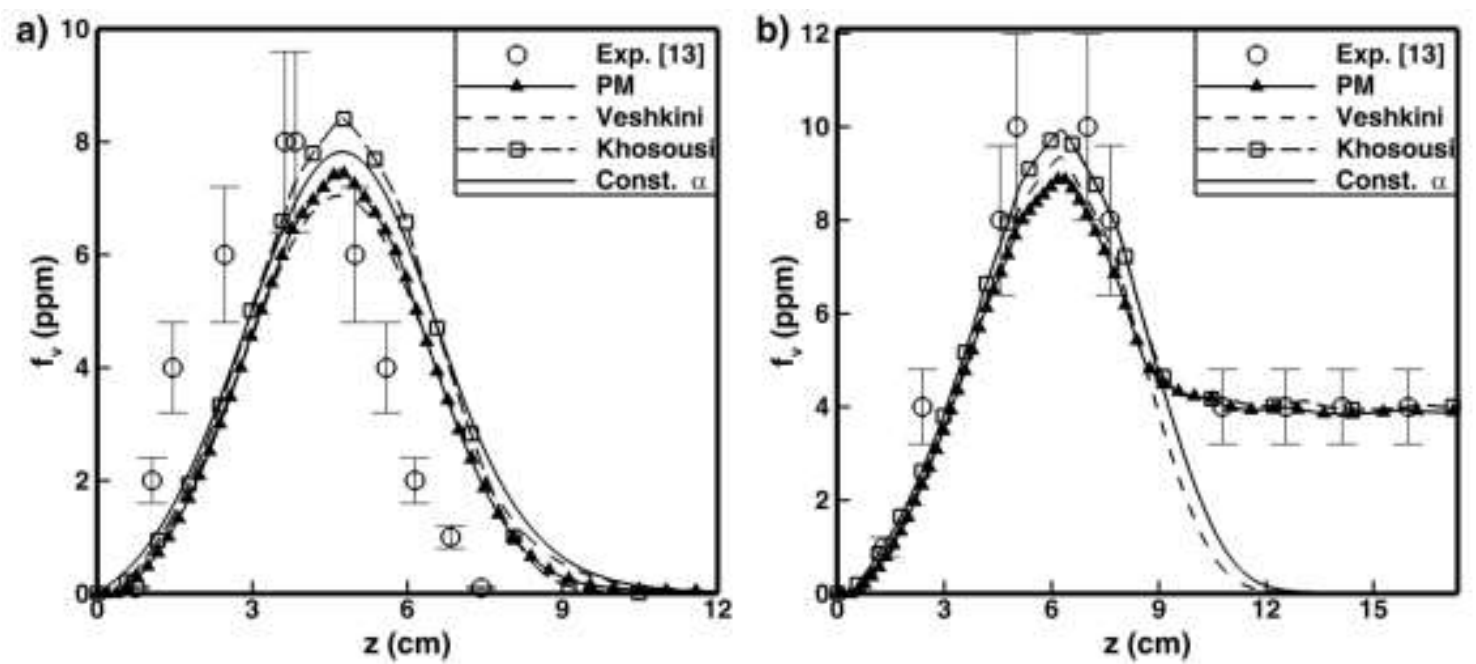

Fig. 5.4. Comparison of numerical predictions of the present model, Veshkini model [11], Khosousi model [117], and constant $-\alpha$ model for soot volume fraction along the streak line exhibiting maximum soot with the experimental results from [13] for the (a) NSII and (b) S flames.

Figure 5.5 shows primary particle size along the pathline exhibiting maximum soot for the NSII (Fig. 5.5(a)) and S (Fig. 5.5(b)) flames. It can be seen that the particle size, as with soot volume fraction, for the NSII flame is predicted correctly by all four models. The effects of soot surface reactivity in the oxidation region are insignificant for the NSII flame, which is why all models capture the correct trend of increase and then decrease in particle size while moving upward along the pathline of maximum soot. For the S flame (Fig. 5.5(b)), the constant- $\alpha$ and Veshkini models predict particle size distribution in the growth region, however, they underpredict the particle size in the oxidation region. The predictions of the PM and Khosousi models lie within the experimental uncertainty throughout the flame. These two models reproduce soot volume fraction and primary particle size very well compared to experimental results, but the PM has the advantage of employing a particle-history based surface reactivity function in the flame, and eliminating one tuning parameter. 

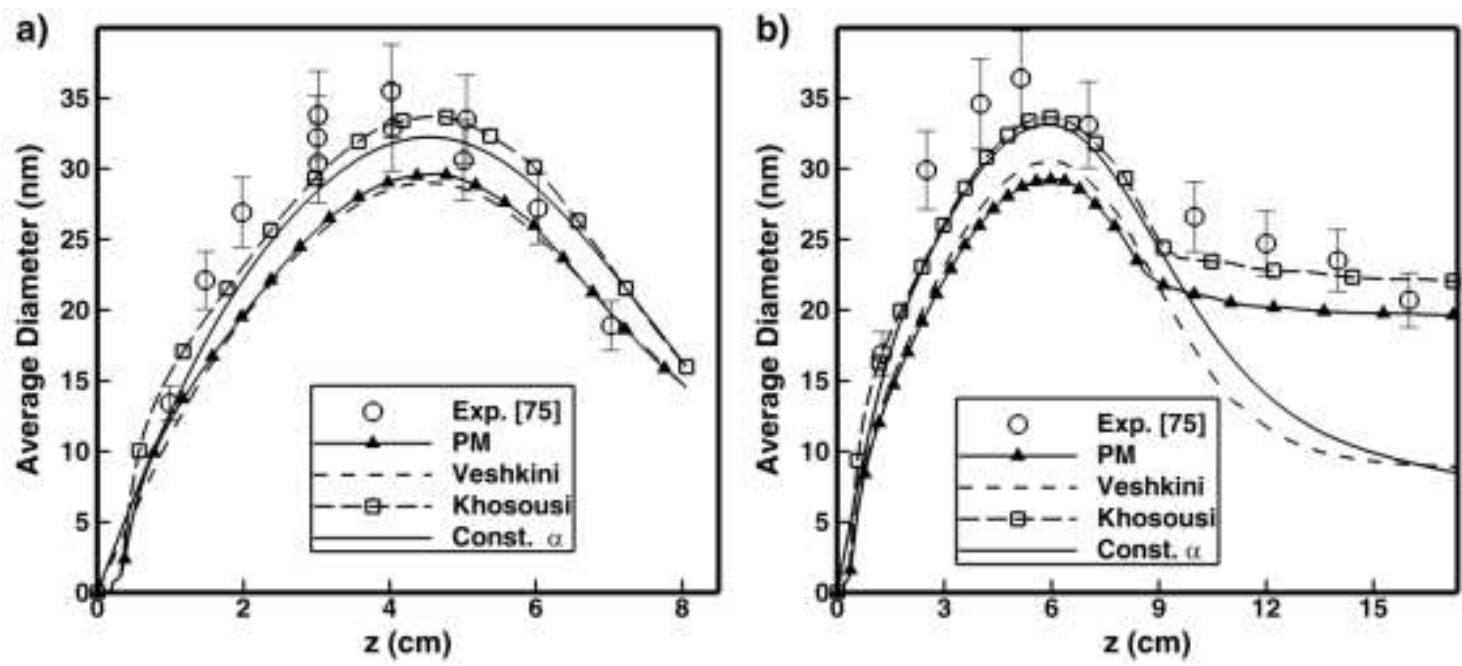

Fig. 5.5. Comparison of numerical predictions of the present model, Veshkini model [11], Khosousi model [117], and constant $\alpha$ model for primary particle size along the streak line exhibiting maximum soot, with the experimental results from [75] for the (a) NSII and (b) S flames.

In determining the temperature history, which is used to compute surface reactivity, sootcontaining fluid parcels need to be tracked within the flame. The residence time data along streak lines in the flame can be used to explain relative soot growth phenomena. Figure 5.6 shows soot volume fraction along the streak line exhibiting maximum soot for the four flames as a function of fluid parcel residence time. As it is observed, the NSI flame experiences the shortest residence time, around $0.06 \mathrm{~s}$, consequently leading to less soot formation. The NSII flame has a longer residence time, providing more time for soot formation and growth processes to generate more soot. The IS flame experiences an even longer residence time, compared with the NSI and NSII flames, which again contributes to greater soot formation. The $\mathrm{S}$ flame has very similar residence time to the IS flame, as both of their curves follow essentially the same path in the oxidation region. However, the $\mathrm{S}$ flame forms soot the fastest in the growth region, and therefore generates the most soot. The reason for the relative increases in soot concentration is that the fuel flow rate increases moving from the NSI flame to the S flame. As a result, the time required for the fuel to 
completely burn out increases, which leads to increasing residence times. In addition, the slope of the curves in the growth region decreases from the NSI to NSII to IS flames, pointing to a slowdown in soot formation, while the slope increases for the $\mathrm{S}$ flame, pointing to faster soot formation. The reason for the slower soot formation for the IS flame compared to the NSI and NSII flames is the increase of fuel flow rate while the air flow rate is kept constant; however, for the $\mathrm{S}$ flame, the air flow rate is also increased which provides additional oxidizer, leading to accelerated fuel burnout and soot formation.

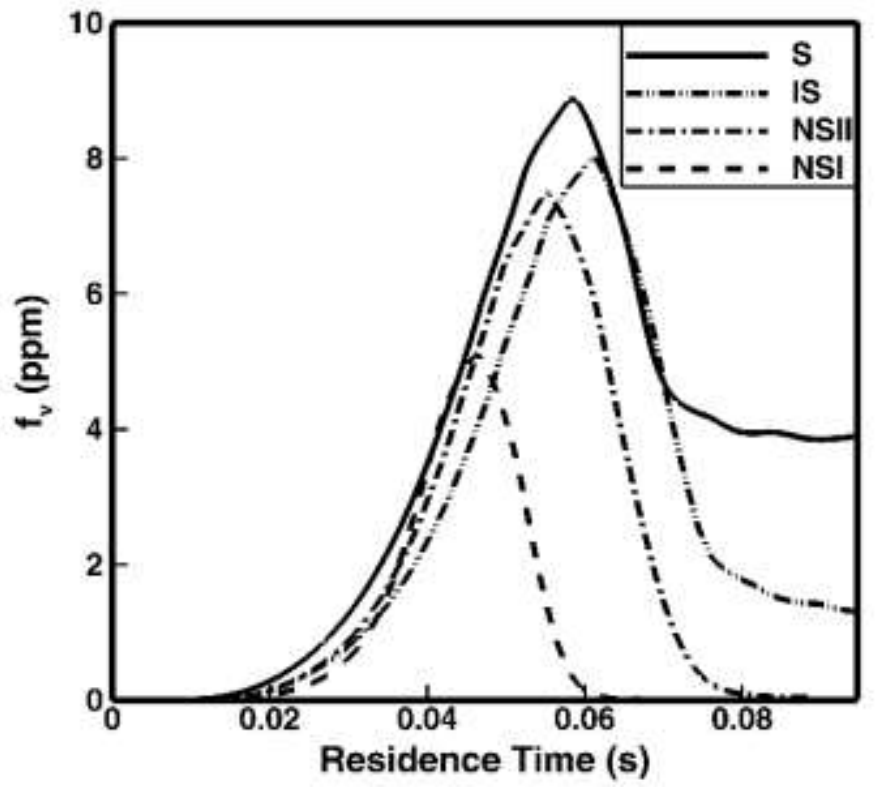

Fig. 5.6. Soot volume fraction along the pathline exhibiting maximum soot as a function of fluid parcel residence time for the NSI, NSII, IS, and S flames.

\subsubsection{Modelling Diluted Smooke Flames}

Smooke et al. [14] studied soot formation in atmospheric pressure, coflow laminar diffusion flames numerically and experimentally. In their work, the fuel, which is a mixture of ethylene and nitrogen, is supplied through the central tube with an inner diameter of $4 \mathrm{~mm}$; the oxidizer, which is air, is fed through the coflowing tube which has an inner diameter of $50 \mathrm{~mm}$. The fuel 
and oxidizer velocities are kept constant at $35 \mathrm{~cm} / \mathrm{s}$ for all fuel dilution levels. The mixture ratio of ethylene and nitrogen in the fuel stream was varied to produce four different flames, i.e. SM32 (32\% ethylene by volume in the fuel stream), SM40 (40\% ethylene by volume in the fuel stream), SM60 (60\% ethylene by volume in the fuel stream), and SM80 (80\% ethylene by volume in the fuel stream), introduced in Table 5.2. In their simulations, they accounted for soot ageing effects by implementing a cut-off for formation of primary particles that were larger than the maximum experimental values, i.e. $\sim 25 \mathrm{~nm}$. The formation of large particles seemed to slow oxidation and lead to an extended sooting region.

In order to further examine the efficiency of the present model, this model is used to simulate these four diluted ethylene flames. Diluting the fuel changes the flame length and residence time, which in turn alters temperature history profiles, which are used by the PM, as it is based on particle temperature history. Figure 5.7 shows the contours of soot volume fraction for the four flames predicted by numerical simulations using the PM (right panel) along with the corresponding experimental data (left panel) from [14], with each contour having its own contour range. Overall, the model predictions agree with experiments. 


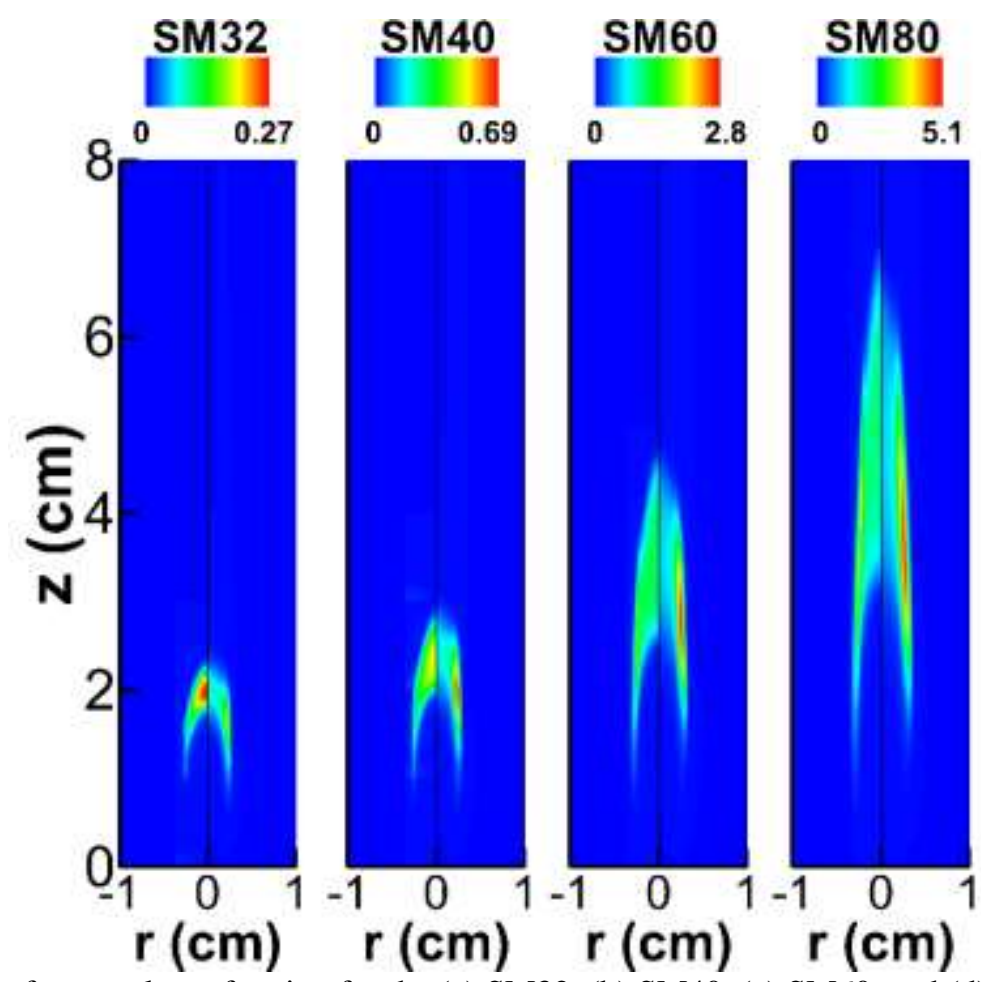

Fig. 5.7. Contours of soot volume fraction for the (a) SM32, (b) SM40, (c) SM60, and (d) SM80 flames. The predictions of the present model are shown on the right side and the experimental measurements from [14] are shown on the left side of each panel.

Both model and experiments point to the fact that peak soot increases as the fuel dilution ratio decreases. The model reproduces the values for peak soot volume fraction within the experimental uncertainty for each flame. The model slightly overpredicts peak soot volume fraction which could be due to overprediction of surface growth rates. Since flame residence time is an important factor in formation and oxidation of soot particles, it is useful to study how they are affected as fuel dilution level changes. Figure 5.8 compares soot volume fraction along the pathline exhibiting maximum soot versus the residence time for the four flames. It is observed that as fuel dilution ratio increases, the flame residence time decreases, which, as it is discussed in [14] in detail, is because the more diluted flames have less fuel content in the fuel stream which is burnt faster, causing the flame to become shorter and the residence time to 
reduce. Therefore, in the flames with lower dilution ratios, the higher residence time allows for more soot inception and growth, thus increasing soot concentration. It is also interesting to note that with an increase of residence time caused by reduced fuel dilution, the sooting region extends further downstream in the flame (Fig. 5.7), which is again attributed to the additional time available for inception and surface growth to generate more soot and therefore extend the sooting region.

Soot volume fraction is highly dependent on flame temperature as the formation/oxidation rates are strongly related to temperature. The peak temperatures for the SM32, SM40, SM60, and SM80 flames are calculated to be $2076 \mathrm{~K}, 2124 \mathrm{~K}, 2131 \mathrm{~K}$, and $2168 \mathrm{~K}$, respectively. As fuel mole fraction increases, so too does the flame peak temperature. This increase in flame temperature and the aforementioned additional residence time contribute to soot volume fraction increase as fuel mole fraction increases, i.e., fuel dilution level decreases.

The model predicts the peak soot to occur on the wings for all four flames, while the experimental data show that the peak soot, for the SM32 and SM40 flames, occurs on the flame centerline. Smooke et al. [14] attributed the occurrence of the peak soot on the centerline, for the SM32 and SM40 flames, to the high inception rates in this region. The underprediction of the peak soot on the centerline is therefore likely a result of deficiencies in the inception and PAH condensation models, or in prediction of PAH precursors, which are less sensitive, compared to those on the wings, to soot surface reactivity modelling for the ethylene flames [3] [4]. 


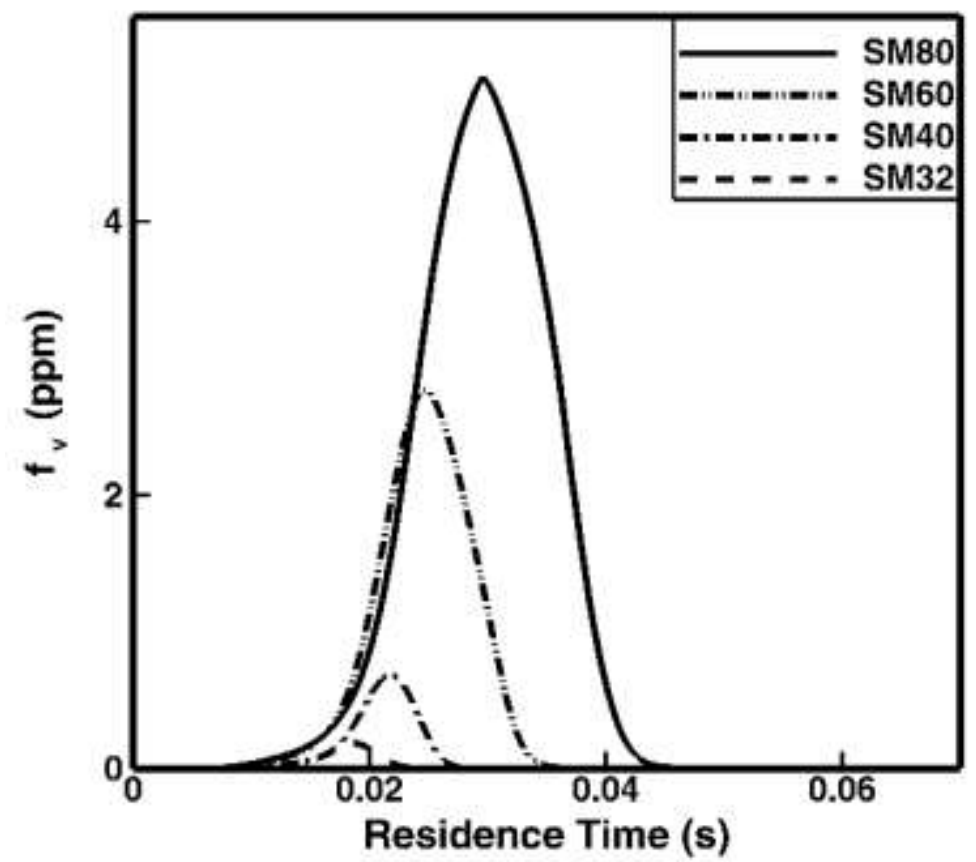

Fig. 5.8. Soot volume fraction along the pathline exhibiting maximum soot as a function of fluid parcel residence time for the SM32, SM40, SM60, and SM80 flames.

\subsubsection{Modelling Methane/Air Flame}

The numerical modelling of $\mathrm{C}_{2}$ flames has been done in many works in the literature [4] [5] [11] [12] [13] [14] [22] [77] [109] [110] [111] [117]; but soot simulations of $\mathrm{C}_{1}$ flames (i.e., methane flames) have received comparatively little attention [15] [30] [111]. The formation of soot precursors changes with different fuels. There are other substantial differences between $C_{1}$ and $\mathrm{C}_{2}$ flames in that they comprise a different radical pool and acetylene profiles, have different PAH formation pathways, and experience different residence times. These differences make modelling $\mathrm{C}_{1}$ flames more difficult using conventional models developed for $\mathrm{C}_{2}$ flames. For this reason, applying the present model to a methane/air flame, which was not used to generate the $\alpha$ function and tends to be less sooting compared to ethylene flames, would provide an ideal testing ground to determine if the model predictions deteriorate in a differing environment. 
The surface reactivity model presented in this study (PM) is used to simulate the coflow laminar methane/air diffusion flame studied by Lee et al. [15]. The fuel and oxidizer are supplied through two concentric tubes with inner diameters of $11.1 \mathrm{~mm}$ and $101.6 \mathrm{~mm}$, respectively. There are some similarities between this flame and the ethylene flame studied in section 4.1; both flames use the same burner and are of about the same luminous height. This flame has been modelled previously by Chernov et al. [30]. In their simulations, however, they used a tuned constant value for soot surface reactivity $(\alpha=0.15)$.

In the present work, the chemical mechanism used for the methane/air flame simulations is that used in [30], which was modified in [30] based on an updated literature review. In order to determine the effectiveness/ineffectiveness of the present model, the constant- $\alpha$ model is also implemented in the modelling for comparison. Numerical results for the profiles of soot volume fraction at five different heights obtained using the PM (Fig. 5.9(a) right) and the constant- $\alpha$ model (Fig. 5.9(b) right) are compared with the experimental results from Lee et al. [15] (Fig. 5.9(a) and (b) left). Both models offer good predictions compared to the experiments, correctly capturing that soot moves towards the centerline as height increases. The peak soot volume fraction predicted by the PM is about $0.53 \mathrm{ppm}$, which is about $47 \%$ higher than that measured in the experiments ( $\sim .36 \mathrm{ppm})$; while the constant- $\alpha$ model predicts the peak soot volume fraction to be $\sim 0.20 \mathrm{ppm}$, underpredicting by about $44 \%$. As for the location of peak soot, according to both models, peak soot occurs on the annular region of the flame (wings), while the experiments indicate that the peak soot is located on the flame centerline. This discrepancy is consistent with that seen in the ethylene flames. The height at which the peak soot occurs, however, is better 
predicted by the PM, $60 \mathrm{~mm}$, similar to experiments, in comparison with $70 \mathrm{~mm}$ predicted by the constant- $\alpha$ model.
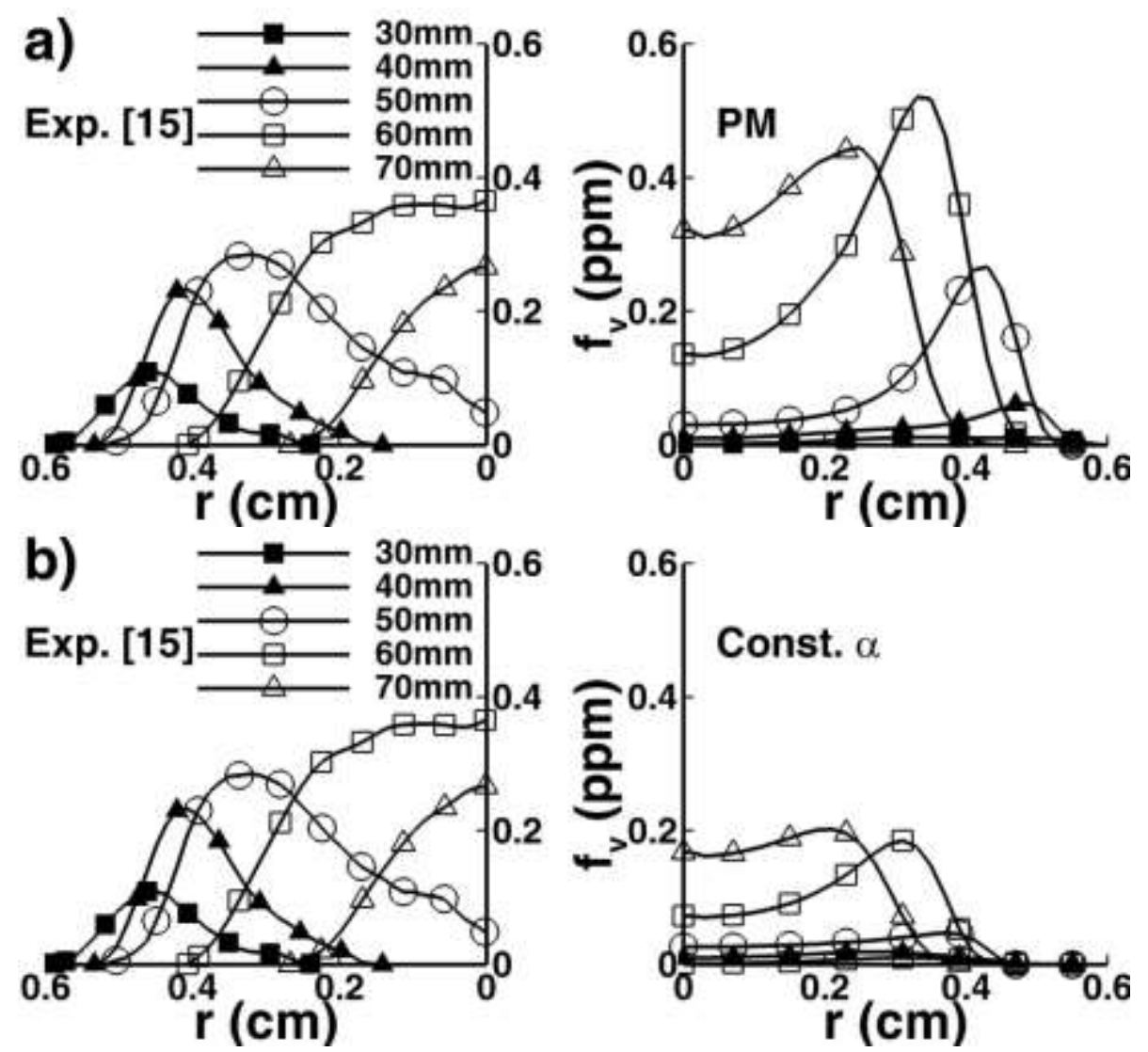

Fig. 5.9. Comparison of the profiles of soot volume fraction as a function of radial distance predicted by (a) the present model and (b) the constant- $\alpha$ model, with the experimental results from [15] for the M/A flame. The left side shows the experimental measurements and the right side shows the model predictions.

Both model predictions lie almost within experimental uncertainty. Using the PM slightly improves the results. However, given that the PM was initially developed for the ethylene/air flames and that it is applicable to both $\mathrm{C}_{1}$ and $\mathrm{C}_{2}$ flames, it offers a broader model, while replacing one tuned constant with an empirically determined function, that is held unchanged between simulations. The chemical mechanism used for the methane flame simulations is an expanded version of that used for the ethylene flames. Using a different chemical mechanism 
changes soot precursor formation pathways, which further signifies model capabilities in predicting soot with altered PAH formation pathways.

\subsubsection{Results Summary}

The newly proposed surface reactivity model has been applied to a wide range of conditions, including smoking and non-smoking flames, varying dilution levels, and ethylene and methane. In addition, peak soot concentrations in the flames studied here vary from $\sim 0.1 \mathrm{ppm}$ to $10 \mathrm{ppm}$. Table 5.4 summarizes the numerical results obtained using the present model (PM) for the nine flames. The computed peak soot volume fraction and the amount of soot emission along with the experimental data for these flames are shown. Value ranges in brackets represent the experimental uncertainty. For each case, the present model predicts peak soot volume fraction within the experimental uncertainty range, which shows that the surface reactivity of soot is accurately modelled in the growth region. More interestingly, the correct emissions behaviour of all flames is captured, including the IS flame $(\sim 1.9 \mathrm{ppm}$ emitted) and the $\mathrm{S}$ flame ( 4 ppm emitted), confirming the correct modelling of soot surface reactivity in the oxidation region. ${ }^{1}$ Therefore, the present model (PM), which utilizes a unique surface reactivity model throughout the flame and for both growth and oxidation processes, is shown to be widely applicable, without any modification between cases, to a variety of flames that include different burner geometries, fuels, smoking characteristics, dilution, and residence times.

\footnotetext{
${ }^{1}$ Note that emitted soot concentration was not reported for the IS flame, but the concentration is expected to be less than that of the $\mathrm{S}$ flame.
} 
Table 5.4. Comparison of the model predictions for the nine flames studied with experiments

\begin{tabular}{lcccc} 
Flames & $\begin{array}{c}\text { Peak Soot } \\
\text { volume fraction } \\
(\mathbf{p p m})\end{array}$ & \multicolumn{2}{c}{$\begin{array}{c}\text { Smoke Emission } \\
(\mathbf{p p m})\end{array}$} \\
\hline & Exp. & $\begin{array}{c}\text { Present } \\
\text { Model }\end{array}$ & Exp. & $\begin{array}{c}\text { Present } \\
\text { Model }\end{array}$ \\
\hline NSI $^{\mathbf{a}}$ & {$[3,6]$} & 5.1 & NS & NS \\
\hline NSII $^{\mathbf{a}}$ & {$[6,10]$} & 7.5 & NS & NS \\
\hline $\mathbf{I S}^{\mathbf{a}}$ & {$[6,13]$} & 8.0 & - & 1.9 \\
\hline $\mathbf{S}^{\mathbf{a}}$ & {$[8,13]$} & 9.0 & {$[3,5]$} & 4.0 \\
\hline $\mathbf{S M 3 2}^{\mathbf{b}}$ & {$[0.1,0.3]$} & 0.2 & $\mathrm{NS}$ & $\mathrm{NS}$ \\
\hline $\mathbf{S M 4 0}^{\mathbf{b}}$ & {$[0.3,0.6]$} & 0.6 & $\mathrm{NS}$ & $\mathrm{NS}$ \\
\hline $\mathbf{S M 6 0}$ & {$[1.1,2.1]$} & 2.5 & $\mathrm{NS}$ & $\mathrm{NS}$ \\
\hline $\mathbf{S M 8 0}^{\mathbf{b}}$ & {$[2.4,4.4]$} & 5.0 & $\mathrm{NS}$ & $\mathrm{NS}$ \\
\hline $\mathbf{M} / \mathbf{A}^{\mathbf{c}}$ & {$[0.2,0.5]$} & 0.53 & $\mathrm{NS}$ & $\mathrm{NS}$ \\
\hline
\end{tabular}

${ }^{\mathrm{a}}$ Exp. results from [13], ${ }^{\mathrm{b}}$ Exp. results from [14], ${ }^{\mathrm{c}}$ Exp. results from [15]

\subsection{Conclusions}

Surface reactivity of soot particles in a variety of laminar coflow diffusion flames was studied. Surface reactivity is found to be important in determining the soot mass yield on the wings of the coflow flames due to dominant effects of surface growth in this region. A new model was proposed to account for the effects of soot surface reactivity in both growth and oxidation regions, considering soot ageing parameters defined in the previous works [11]. The proposed model correlated the surface reactivity of soot with particle thermal age, a function of temperature and residence time. This model was used to take into account the effects of soot surface reactivity changes due to growth and was implemented in the oxidation and surface growth models in the CoFlame code. Using this approach, one tunable modelling parameter, $\alpha$, which had previously been used in both soot growth and oxidation modelling, was replaced with an empirically determined function, that is held unchanged between simulations. The model was applied to simulate nine flames with different flow conditions, fuel dilution ratios, and fuels. 
The model was successfully able to capture the correct peak soot volume fraction and soot emission in all flames. The modelling was performed without any variation in model parameters between cases. Four flames, originally studied by Santoro and coworkers [12] [13], with varying peak soot concentrations and smoke emission characteristics were simulated. The model correctly predicted peak soot concentrations and smoke emission for all four flames. Furthermore, the diluted ethylene/air flames, originally studied by Smooke et al. [14], were modelled, again without any model variation. The fuel was diluted with nitrogen at different ratios. Peak soot concentrations for these flames, which have varying residence times, were also correctly predicted. The model also captured the decreasing trend of soot concentrations as the fuel dilution levels increased. The surface reactivity model was also employed to simulate the methane/air flame studied by Lee et al. [15]. The predictions of the model for peak values and profiles of soot concentrations were also relatively well reproduced. 


\section{Chapter 6}

\section{Summary and Future Work}

\subsection{Conclusions ${ }^{2}$}

The studies presented in this thesis utilized a strong computing tool, the CoFlame code, to simulate soot formation in different laminar flames. The CoFlame code has been validated for many flames and its use provides an opportunity to investigate different soot formation processes in flames with various fuels and burner configurations. Each chapter of this thesis focused on different subjects relating to soot formation. In Chapter 3, the soot formation in vaporized ethanol/ gasoline flames was studied. This chapter also provided the intermediate processes of soot formation for laminar diffusion flames of ethanol/gasoline mixtures. In Chapters 4 and 5, soot surface reactivity in different parts of the flame and its variations with flame properties were investigated. These two chapters were outlined such that the investigation of the surface reactivity of soot in the oxidation region was presented in Chapter 4, and was complimented in Chapter 5 wherein soot surface reactivity was studied in both oxidation and growth regions. Heavy computations required parallelization of the problem. The computations were performed on the General Purpose Cluster (GPC) and the Ryerson Sandybridge (Sandy) Cluster of the SciNet Computing Consortium of Compute Canada.

\footnotetext{
${ }^{2}$ This section is adapted from Chapters 2,3 , and 4 .
} 
The detailed study of the soot formation process in ethanol/gasoline flames was conducted, given that the detailed CoFlame code provides a strong tool to investigate the intermediate steps involved in soot formation. The work presented in Chapter 3 studied the effects of adding ethanol to fuel on soot formation in gasoline/air coflow diffusion flames at atmospheric pressure. A gasoline surrogate identified in the literature was employed in the numerical modelling to replicate the No. 92 gasoline used in the experiments.

Consistent with the experimental measurements, the numerical results revealed that blending ethanol to gasoline suppresses soot formation. However, the soot formation suppression remains not very significant until the blending ratio of ethanol is more than 50\%. The E85 flame produces much less soot than the E0, E20, and E50 flames. This behaviour has also been reported in the literature. The visible flame heights and soot volume fractions were relatively well predicted in terms of the magnitude. Although the location of peak soot volume fractions was not correctly predicted in comparison to the measurements, the overall effects of ethanol addition to gasoline on soot formation reduction were captured by the numerical model. The results suggested that the gasoline surrogate model used in this study emulates the gasoline fuel relatively well in terms of sooting propensity.

The numerical predictions were leveraged for further information by tracking the pathlines of soot particles through the flames. This analysis demonstrated that the reduced soot concentrations with ethanol addition can be attributed to the dilution effects (due to the resulting aromatic content reduction in the fuel stream) as opposed to the increased oxygen content of ethanol, enhanced oxidation, or temperature changes. 
The present work further focused on advancing numerical simulations of soot formation in laminar coflow diffusion flames. The CoFlame code was used to simulate other flames. In Chapter 4, soot oxidation in a variety of laminar coflow ethylene/air diffusion flames was investigated. The oxidation by $\mathrm{O}_{2}$ was found more influential in the post-flame oxidation region and mainly responsible for the smoking behaviour of the flames, while the effect of $\mathrm{OH}$ oxidation was only significant on the peak soot volume fraction. Using a constant ageing parameter, $\alpha_{o x}$ for oxidation proved unsuccessful in predicting the smoking behaviour of the flames. A new soot oxidation model for $\mathrm{O}_{2}$ was proposed based on soot particle thermal age. The dependence of surface reactivity of soot on temperature and residence time led to a function for $\alpha_{o x}$ based on thermal age, which was implemented in the oxidation model. The model was applied to simulate eight flames with different flow conditions and fuel dilution ratios. The model was successfully able to capture the transition of the flames from non-smoking to smoking. The model also correctly reproduced peak soot volume fraction and primary particle size distributions without any variation in model parameters between cases.

Even though the work presented in Chapter 4 solved the problem of accounting for soot surface reactivity, it did not address this issue completely. The modelling of soot surface reactivity was considered only for the particles in the oxidation region and a constant surface reactivity for soot particles in the growth region was assumed. This study provided the foundation for an extension of the work to study soot surface reactivity in a more comprehensive manner, presented in Chapter 5. 
Chapter 5 focused on a more generalized study of surface reactivity of soot particles in a variety of laminar coflow diffusion flames. Surface reactivity was found to be important in determining the soot mass yield on the wings of the coflow flames due to the dominant effects of surface growth in this region. A new reconciled model was proposed to simultaneously account for the effects of soot surface reactivity in both growth and oxidation regions, considering soot ageing parameters defined in the previous works [11]. The proposed model correlated the surface reactivity of soot with particle thermal age, a function of temperature and residence time. This model was used to take into account the effects of soot surface reactivity changes due to growth and oxidation and was implemented in the oxidation and surface growth models in the CoFlame code. Using this approach, one tunable modelling parameter, $\alpha$, which had been used previously in both soot growth and oxidation modelling and often treated differently in the two regions, was eliminated from numerical simulations. The model was applied to simulate nine flames with different flow conditions, fuel dilution ratios, and fuels.

The more fundamentally sound model was successfully able to capture the correct peak soot volume fraction and soot emission in all flames. The modelling was performed without any variation in model parameters between cases. Four flames, originally studied by Santoro and coworkers [12] [13], with varying peak soot concentrations and smoke emission characteristics were simulated. The model predicted peak soot concentrations and smoke emission for all four flames relatively well. Furthermore, the diluted ethylene/air flames, originally studied by Smooke et al. [14], were modelled, again without any model variation. The fuel was diluted with nitrogen at different ratios. Peak soot concentrations for these flames, which have varying residence times, were also correctly predicted. The model also captured the decreasing trend of 
soot concentrations as the fuel dilution levels increased. The surface reactivity model was also employed to simulate the methane/air flame studied by Lee et al. [15]. The predictions of the model for peak values and profiles of soot concentrations were also relatively well. This work represented a substantial advancement in soot surface reactivity modelling in that it proposed a systemic method to model soot surface reactivity based on flame properties and it successfully implemented the model in different laminar diffusion flames.

\subsection{Future Work}

The objective of future work relating to the soot surface reactivity model should be to implement the model in different burner configurations and also premixed flames. The model development is achieved through rigorous testing and studying of different laminar diffusion flames. Another interesting topic to study could be to investigate the effectiveness of the model in predicting the concentration of major species and soot precursors. In addition, the investigation of how the model affects inception and condensation rates and also relative contributions of soot formation and oxidation processes to total soot mass yield would provide interesting insight into the causes of the change in soot characteristics of various flames. Furthermore, the possible effects of other tunable parameters including inception efficiency, condensation efficiency, and coagulation efficiency on model development could be studied.

Another interesting subject for future study would be to investigate the reasons as to why the location of peak soot volume fraction shifts to the flame centerline in diluted ethylene/air flames as dilution ratio increases, while the model fails to predict this transition. A similar trend is 
observed in gasoline/ethanol flames as ethanol content in the fuel stream increases, which is, again, not predicted by the model. The study could focus on why the current soot model fails to predict this transition and how to improve the model to capture such a shift.

One interesting topic to consider for future study would be to use different gasoline surrogates which are available in the literature to perform numerical modelling. It would also be useful to implement various blends of other oxygenated biofuels into the model. Understanding the effects of varying fuel mixture ratios is of particular interest to industry as alternative/conventional fuel mixing is becoming commonplace. The proposed techniques could be applied to ethanol/octane mixtures and provide significant insight into the way in which competing decomposition/oxidation mechanisms of mixed fuels will interact, and how they contribute to reduction of emissions. The results should be processed to find the best biofuel blend generating the least soot emissions. The study of the synergistic effect that may occur between the E0 and E20 in the ethanol/gasoline mixtures would also be of merit. 


\section{References}

[1] Environmental Health Investigation Branch, Government of California (www.ehib.org).

[2] D.R. Snelling, K.A. Thomson, G.J. Smallwood, and Ö.L. Gülder, “Two-Dimensional Imaging of Soot Volume Fraction in Laminar Diffusion Flames," Applied Optics, 38 (1999) $2478-2485$.

[3] W.J. Pitz, N.P. Cernansky, F.L. Dryer, F.N. Egolfopoulos, J.T. Farrell, D.G. Friend, and H. Pitsch, "Development of an Experimental Database and Chemical Kinetic Models for Surrogate Gasoline Fuels," SAE Technical Paper, Series 2007-01-0175.

[4] S.B. Dworkin, Q. Zhang, M.J. Thomson, N.A. Slavinskaya, and U. Riedel, “Application of an Enhanced PAH Growth Model to Soot Formation in a Laminar Coflow Ethylene/Air Diffusion Flame,” Combustion and Flame, 158 (2011) 1682-1695.

[5] N.A. Eaves, A. Veshkini, C. Riese, Q. Zhang, S.B. Dworkin, and M.J. Thomson, “A Numerical Study of High Pressure, Laminar, Sooting, Ethane-Air Coflow Diffusion Flames," Combustion and Flame, 159 (2012) 3179-3190.

[6] A. Raj, I.D.C. Prada, A.A. Amer, and S.H. Chung, "A Reaction Mechanism for Gasoline Surrogate Fuels for Large Polycyclic Aromatic Hydrocarbons," Combustion and Flame, 159 (2012) 500-515.

[7] J.C.G. Andrae, "Development of a Detailed Kinetic Model for Gasoline Surrogate Fuels," Fuel, 87 (2008) 2013-2022.

[8] S.J. Harris and A.M. Weiner, "Determination of the Rate Constant for Soot Surface Growth," Combustion Science and Technology, 32 (1983) 267-275. 
[9] S.J. Harris and A.M. Weiner, "Chemical Kinetics of Soot Particle Growth," Annual Review of Physical Chemistry, 36 (1985) 31-52.

[10] B.S. Haynes and H.G. Wagner, "The Surface Growth Phenomenon in Soot Formation," Z. Phys, Chem. N. F., 133 (1982) 201-213.

[11] A. Veshkini, S.B. Dworkin, and M.J. Thomson, “A Soot Particle Surface Reactivity Model Applied to a Wide Range of Laminar Ethylene/Air Flames," Combustion and Flame, 161 (2014) 3191-3200.

[12] R.J. Santoro, H.G. Semerjian, and R.A. Dobbins, "Soot Particle Measurements in Diffusion Flames," Combustion and Flame, 51 (1983) 203-218.

[13] R.J. Santoro, T.T. Yeh, J.J. Horvath, and H.G. Semerjian, "The Transport and Growth of Soot Particles in Laminar Diffusion Flames," Combustion Science and Technology, 53 (1987) 89-115.

[14] M.D. Smooke, M.B. Long, B.C. Connelly, M.B. Colket, and R.J. Hall, "Soot Formation in Laminar Diffusion Flames," Combustion and Flame, 143 (2005) 613-628.

[15] K.O. Lee, C.M. Megaridis, S. Zelepouga, A.V. Saveliev, L.A. Kennedy, O. Charon, and F. Ammouri, "Soot Formation Effects of Oxygen Concentration in the Oxidizer Stream of Laminar Coannular Nonpremixed Methane/Air Flames," Combustion and Flame, 121 (2000) 323-333.

[16] F. Liu, G.J. Smallwood, and Ö.L. Gülder, "Band Lumping Strategy for Radiation Heat Transfer Calculations Using a Narrowband Model," Journal of Thermophysics and Heat Transfer, 14 (2000) 278-281. 
[17] A. Veshkini, Understanding Soot Particle Growth Chemistry and Particle Sizing Using a Novel Soot Growth and Formation Model, Ph.D. Thesis, University of Toronto, Toronto, ON, 2015.

[18] Q. Zhang, Detailed Modeling of Soot Formation/Oxidation in Laminar Coflow Diffusion Flames, Ph.D. Thesis, University of Toronto, Toronto, ON, 2009.

[19] S.J. Harris and A.M. Weiner, "Soot Particle Growth in Premixed Toluene/Ethylene Flames," Combustion Science and Technology, 38 (1984) 75-84.

[20] K.G. Neoh, J.B. Howard, and A.F. Sarofim, Soot Oxidation in Flames, in Particulate Carbon: Formation during Combustion, Plenum Press, New York, 1981, p. 261.

[21] J. Appel, H. Bockhorn, and M. Frenklach, "Kinetic Modeling of Soot Formation with Detailed Chemistry and Physics: Laminar Premixed Flames of $\mathrm{C}_{2}$ Hydrocarbons," Combustion and Flame, 121 (2000) 122-136.

[22] Q. Zhang, H. Guo, F. Liu, G.J. Smallwood, and M.J. Thomson, "Modeling of Soot Aggregate Formation and Size Distribution in a Laminar Ethylene/Air Coflow Diffusion Flame with Detailed PAH Chemistry and an Advanced Sectional Aerosol Dynamics Model," Proceedings of Combustion Institute, 32 (2009) 761-768.

[23] S. V. Patankar, Numerical Heat Transfer and Fluid Flow, Hemisphere, $1^{\text {st }}$ edition, 1980.

[24] H. Böhm, H. Jander, and D. Tanke, "PAH Growth and Soot Formation in the Pyrolysis of Acetylene and Benzene at High Temperatures and Pressures: Modeling and Experiment," Proceedings of Combustion Institute, 27 (1998) 1605-1612. 
[25] H. Böhm and H. Jander, "PAH Formation in Acetylene-Benzene Pyrolysis," Physical Chemistry Chemical Physics, 1 (1999) 3775-3781.

[26] R.J. Kee, J.A. Miller, and T.H. Jefferson, Chemkin: A General Purpose, Problem Independent, Transportable, Fortran Chemical Kinetics Code Package, Report SAND80-8003, 1980.

[27] R.J. Kee, F.M. Rupley, and J.A. Miller, A Fortran Chemical Kinetics Package for the Analysis of Gas-phase Chemical Kinetics, Sandia Report SAND89-8009, 1989.

[28] R.J. Kee, J. Warnatz, and J.A. Miller, A Fortran Computer Code Package for the Evaluation of Gas-Phase Viscosities, Conductivities, and Diffusion Coefficients, Report SAND82-8209, 1983.

[29] R.J. Kee, G. Dixon-Lewis, J. Warnatz, M.E. Coltrin, and J.A. Miller, A Fortran Computer Code Package for the Evaluation of Gas-Phase Multicomponent Transport Properties, Report SAND86-8246, 1986.

[30] V. Chernov, M.J. Thomson, S.B. Dworkin, N.A. Slavinskaya, and U. Riedel, "Soot Formation with $\mathrm{C}_{1}$ and $\mathrm{C}_{2}$ Fuels Using an Improved Chemical Mechanism for PAH Growth," Combustion and Flame, 161 (2014) 592-601.

[31] International Energy Agency, http://www.iea.org.

[32] F. Zhao, M.-C. Lai, and D.L. Harrington, "Automotive Spark-Ignited Direct-Injection Gasoline Engines," Progress in Energy and Combustion Science, 25 (1999) 437-562.

[33] M.M. Maricq, "Soot Formation in Ethanol/Gasoline Fuel Blend Diffusion Flames," Combustion and Flame, 159 (2012) 170-180. 
[34] J.B. Heywood and F.R. Vilchis, "Comparison of Flame Development in a Spark-Ignition Engine Fueled with Propane and Hydrogen," Combustion Science and Technology, 38 (1984) 313-324.

[35] Ö.L. Gülder, "Correlations of Laminar Combustion Data for Alternative SI Engine Fuels," SAE Technical Paper No. 841000, (1984) 1-23.

[36] R. Lemaire, E. Therssen, and P. Desgroux, "Effect of Ethanol Addition in Gasoline and Gasoline-Surrogate on Soot Formation in Turbulent Spray Flames," Fuel, 89 (2010) 3952-3959.

[37] J. Wu, K.H. Song, T. Litzinger, S.Y. Lee, R. Santoro, M. Linevsky, M. Colket, and D. Liscinsky, "Reduction of PAH and Soot in Premixed Ethylene-Air Flames by Addition of Ethanol," Combustion and Flame, 144 (2006) 675-687.

[38] K.L. McNesby, A.W. Miziolek, T. Nguyen, F.C. Delucia, R.R. Skaggs, and T.A. Litzinger, "Experimental and Computational Studies of Oxidizer and Fuel Side Addition of Ethanol to Opposed Flow Air/Ethylene Flames," Combustion and Flame, 142 (2005) 413-427.

[39] C.S. McEnally and L.D. Pfefferele, "The Effects of Dimethyl Ether and Ethanol on Benzene and Soot Formation in Ethylene Nonpremixed Flames," Proceedings of Combustion Institute, 31 (2007) 603-610.

[40] H. Chen, S.J. Shuai, and J.X. Wang, "Study on Combustion Characteristics and PM Emission of Diesel Engines Using Ester-Ethanol-Diesel Blended Fuels," Proceedings of Combustion Institute, 31 (2007) 2981-2989.

[41] M. Lapuerta, O. Armas, and J.M. Herreros, "Emissions from a Diesel-Bioethanol Blend in an Automotive Diesel Engine," Fuel, 87 (2008) 25-31.

[42] F. Liu, X. He, X. Ma, Q. Zhang, M.J. Thomson, H. Guo, G.J. Smallwood, S. Shuai, and J. Wang, "An Experimental and Numerical Study of the Effects of Dimethyl Ether Addition to Fuel 
on Polycyclic Aromatic Hydrocarbon and Soot Formation in Laminar Coflow Ethylene/Air Diffusion Flames," Combustion and Flame, 158 (2011) 547-563.

[43] C.J. Dasch, "One-Dimensional Tomography: A Comparison of Abel, Onion-Peeling, and Filtered Backprojection Methods," Applied Optics, 31 (1992) 1146-1152.

[44] V. Chernov, Q. Zhang, M.J. Thomson, and S.B. Dworkin, "Numerical Investigation of Soot Formation Mechanisms in Partially-Premixed Ethylene-Air Co-flow Flames," Combustion and Flame, 159 (2012) 2789-2798.

[45] F. Liu, S.B. Dworkin, M.J. Thomson, and G.J. Smallwood, "Modeling DME Addition Effects to Fuel on PAH and Soot in Laminar Coflow Ethylene/Air Diffusion Flames Using Two PAH Mechanisms," Combustion Science and Technology, 184 (2012) 966-979.

[46] N.A. Eaves, M.J. Thomson, and S.B. Dworkin, "The Effect of Conjugate Heat Transfer on Soot Formation Modeling at Elevated Pressures," Combustion Science and Technology, 185 (2013) 1799-1819.

[47] M. Saffaripour, M. Kholghy, S.B. Dworkin, and M.J. Thomson, "A Numerical and Experimental Study of Soot Formation in a Laminar Coflow Diffusion Flame of a Jet A-1 Surrogate," Proceedings of Combustion Institute, 34 (2013) 1057-1065.

[48] J.-L. Consalvi and F. Liu, "Numerical Study of the Effects of Pressure on Soot Formation in Laminar Coflow $n$-Heptane/Air Diffusion Flames Between 1 and 10 atm," Proceedings of Combustion Institute, 35 (2015) 1727-1734.

[49] Ö.L. Gülder, D.R. Snelling, and R.A. Sawchuk, "Influence of Hydrogen Addition to Fuel on Temperature Field and Soot Formation in Diffusion Flames," Proceedings of Combustion Institute, 26 (1996) 2351-2358. 
[50] F. Migliorini, K.A. Thomson, and G.J. Smallwood, "Investigation of Optical Properties of Aging Soot,” Applied Physics B, 104 (2011) 273-283.

[51] J. Zerbs, K.P. Geigle, O. Lammel, J. Hader, R. Stirn, R. Hadef, and W. Meier, “The Influence of Wavelength in Extinction Measurements and Beam Steering in Laser-Induced Incandescence Measurements in Sooting Flames,” Applied Physics B, 96 (2009) 683-694.

[52] F. Liu, K.A. Thomson, and G.J. Smallwood, "Numerical Investigation of the Effect of Signal Trapping on Soot Measurements Using LII in Laminar Coflow Diffusion Flames," Applied Physics B, 96 (2009) 671-682.

[53] A.R. Coderre, K.A. Thomson, D.R. Snelling, and M.R. Johnson, "Spectrally Resolved Light Absorption Properties of Cooled Soot from a Methane Flame," Applied Physics B, 104 (2011) $175-188$.

[54] M. Frenklach and H. Wang, "Detailed Modeling of Soot Particle Nucleation and Growth," Proceedings of the Combustion Institute, 23 (1991) 1559-1566.

[55] F. Liu, H. Guo, and G.J. Smallwood, "Effects of Radiation Model on the Modeling of a Laminar Coflow Methane/Air Diffusion Flame," Combustion and Flame, 138 (2004) 136-154.

[56] C.P. Fenimore and G.W. Jones, "Oxidation of Soot by Hydroxyl Radicals," Journal of Physical Chemistry, 71 (1967) 593-597.

[57] D. Bradley, G. Dixon-Lewis, S. El-Din Habik, and E.M.J. Mushi, "Oxidation of Graphite Powder in Flame Reaction Zones," Proceedings of the Combustion Institute, 20 (1984) 931-940.

[58] A. Garo, G. Prado, and J. Lahaye, "Chemical Aspects of Soot Particles Oxidation in a Laminar Methane-Air Diffusion Flame," Combustion and Flame, 79 (1990) 226-233. 
[59] P. Roth, O. Brandt, and S. Von Gersum, "High Temperature Oxidation of Suspended Soot Particles Verified by $\mathrm{CO}$ and $\mathrm{CO}_{2}$ Measurements," Proceedings of the Combustion Institute, 23 (1990) 1485-1491.

[60] R. Puri, R.J. Santoro, and K.C. Smyth, “The Oxidation of Soot and Carbon Monoxide in Hydrocarbon Diffusion Flames," Combustion and Flame, 97 (1994) 125-144.

[61] B.M. Gauthier, D.F. Davidson, and R.K. Hanson, "Shock Tube Determination of Ignition Delay Times in Full-Blend and Surrogate Fuel Mixtures," Combustion and Flame, 139 (2004) 300-311.

[62] J.C.G. Andrae, P. Björnbom, R.F. Cracknell, and G.T. Kalghatgi, “Autoignition of Toluene Reference Fuels at High Pressures Modeled with Detailed Chemical Kinetics," Combustion and Flame, 149 (2007) 2-24.

[63] N. Morgan, A. Smallbone, A. Bhave, M. Kraft, R. Cracknell, and G. Kalghatgi, "Mapping Surrogate Gasoline Compositions into RON/MON Space,” Combustion and Flame, 157 (2010) $1122-1131$.

[64] C. Pera and V. Knop, "Methodology to Define Gasoline Surrogates Dedicated to AutoIgnition in Engines," Fuel, 96 (2012) 59-69.

[65] D.B. Lenhert, D.L. Miller, N.P. Cernansky, and K.G. Owens, "The Oxidation of A Gasoline Surrogate in the Negative Temperature Coefficient Region," Combustion and Flame, 156 (2009) 549-564.

[66] D. Witkowski, K. Kondo, G. Vishwanathan, and D. Rothamer, "Evaluation of the Sooting Properties of Real Fuels and Their Commonly Used Surrogates in a Laminar Co-Flow Diffusion Flame," Combustion and Flame, 160 (2013) 1129-1141. 
[67] C. Marchal, J. Delfau, C. Vovelle, G. Moréac, C. Mounaim-Rousselle, and F. Mauss, "Modelling of Aromatics and Soot Formation from Large Fuel Molecules," Proceedings of Combustion Institute, 32 (2009) 753-759.

[68] M.K. Kashif, P. Guibert, J. Bonnety, and G. Legros, "Sooting Tendencies of Primary Reference Fuels in Atmospheric Laminar Diffusion Flames Burning into Vitiated Air," Combustion and Flame, 161 (2014) 1575-1586.

[69] M.K. Kashif, J. Bonnety, A. Matynia, P. Da Costa, and G. Legros, "Sooting Propensities of Some Gasoline Surrogate Fuels: Combined Effects of Fuel Blending and Air Vitiation,” Combustion and Flame, 162 (2015) 1840-1847.

[70] C. McEnally and L.D. Pfefferle, "Aromatic and Linear Hydrocarbon Concentration Measurements in a Non-Premixed Flame," Combustion Science and Technology, 116-117 (1996) 183-209.

[71] F. Liu, H. Guo, G.J. Smallwood, and Ö.L. Gülder, "Effects of Gas and Soot Radiation on Soot Formation in a Coflow Laminar Ethylene Diffusion Flame,” Journal of Quantitative Spectroscopy and Radiative Transfer, 73 (2002) 409-421.

[72] M.S. Celnik, M. Sander, A. Raj, R.H. West, and M. Kraft, "Modelling Soot Formation in a Premixed Flame Using an Aromatic-Site Soot Model and an Improved Oxidation Rate," Proceedings of the Combustion Institute, 32 (2009) 639-646.

[73] F. Liu, H. Guo, G.J. Smallwood, and O.L. Gulder, "Numerical Modelling of Soot Formation and Oxidation in Laminar Coflow Non-Smoking and Smoking Ethylene Diffusion Flames," Combustion Theory and Modeling, 7 (2003) 301-315.

[74] C.M. Megaridis and R.A. Dobbins, "Soot Aerosol Dynamics in a Laminar Ethylene Diffusion Flame,” Proceedings of Combustion Institute, 22 (1988) 353-362. 
[75] C.M. Megaridis and R.A. Dobbins, "Comparison of Soot Growth and Oxidation in Smoking and Non-Smoking Ethylene Diffusion Flames," Combustion Science and Technology, 66 (1989) $1-16$.

[76] F. Liu, G.J. Smallwood, and Ö.L. Gülder, “Application of the Statistical Narrow-Band Correlated-k Method to Low-Resolution Spectral Intensity and Radiative Heat Transfer Calculations - Effects of the Quadrature Scheme," International Journal of Heat and Mass Transfer, 43 (2000) 3119-3135.

[77] H. Guo, F. Liu, G.J. Smallwood, and Ö.L. Gülder, "Numerical Study on the Influence of Hydrogen Addition on Soot Formation in a Laminar Ethylene-Air Diffusion Flame," Combustion and Flame, 145 (2006) 324-338.

[78] F. Xu, A.M. El-Leathy, C.H. Kim, and G.M. Faeth, "Soot Surface Oxidation in Hydrocarbon/Air Diffusion Flames at Atmospheric Pressure," Combustion and Flame, 132 (2003) 43-57.

[79] M. Haudiquert, A. Cessou, D. Stepowski, and A. Coppalle, "OH and Soot Concentration Measurements in a High-Temperature Laminar Diffusion Flame”, Combustion and Flame, 111 (1997) 338-349.

[80] S. von Gersum and P. Roth, "High Temperature Oxidation of Soot Particles by O Atoms and OH Radicals," Journal of Aerosol Science, 21 (1990) S31-S34.

[81] I.M. Kennedy, C. Yam, D.C. Rapp, and R.J. Santoro, "Modeling and Measurements of Soot and Species in a Laminar Diffusion Flame," Combustion and Flame, 107 (1996) 368-382.

[82] J. Nagle and R.F. Strickland-Constable, "Oxidation of Carbon between 1000-2000 C" Proceedings of the $5^{\text {th }}$ Carbon Conference, 1 (1962) 154-164. 
[83] C. Park and J.P. Appleton, "Shock-Tube Measurements of Soot Oxidation Rates," Combustion and Flame, 20 (1973) 369-379.

[84] C.Y. Lin and M.C. Lin, "Thermal Decomposition of Methyl Phenyl Ether in Shock Waves: The Kinetics of Phenoxy Radical Reactions," Paper 7 presented at the Fall Technical Meeting of the Eastern States Section of the Combustion Institute, Gaithersburg, MD, November 1987.

[85] A. Kazakov, H. Wang, and M. Frenklach, "Detailed Modeling of Soot Formation in Laminar Premixed Ethylene Flames at a Pressure of 10 Bar," Combustion and Flame, 100 (1995) $111-120$.

[86] H. Wang and M. Frenklach, "A Detailed Kinetic Modeling Study of Aromatics Formation in Laminar Premixed Acetylene and Ethylene Flames," Combustion and Flame, 110 (1997) $173-221$.

[87] A. Raj, G.R. da Silva, and S.H. Chung, "Reaction Mechanism for the Free-Edge Oxidation of Soot by $\mathrm{O}_{2}$, " Combustion and Flame, 159 (2012) 3423-3436.

[88] F. Xu, K.-C. Lin, and G.M. Faeth, "Soot Formation in Laminar Premixed Methane/Oxygen Flames at Atmospheric Pressure," Combustion and Flame, 115 (1998) 195-209.

[89] F. Xu and G.M. Faeth, "Soot Formation in Laminar Acetylene/Air Diffusion Flames at Atmospheric Pressure," Combustion and Flame, 125 (2001) 804-819.

[90] M. Balthasar and M. Frenklach, "Detailed Kinetic Modeling of Soot Aggregate Formation in Laminar Premixed Flames," Combustion and Flame, 140 (2005) 130-145.

[91] C.J. Dasch, "The Decay of Soot Surface Growth Reactivity and Its Importance in Total Soot Formation," Combustion and Flame, 61 (1985) 219-225. 
[92] K.H. Homann, "Formation of Large Molecules, Particulates and Ions in Premixed Hydrocarbon Flames; Progress and Unresolved Questions," Proceedings of Combustion Institute, 20 (1985) 857-870.

[93] I.T. Woods and B.S. Haynes, "Soot Surface Growth at Active Sites," Combustion and Flame, 85 (1991) 523-525.

[94] F. Mauss, T. Schäfer, and H. Bockhorn, "Inception and Growth of Soot Particles in Dependence on the Surrounding Gas Phase," Combustion and Flame, 99 (1994) 697-705.

[95] R.A. Dobbins, R.A. Fletcher, and H.C. Chang, "The Evolution of Soot Precursor Particles in a Diffusion Flame," Combustion and Flame, 115 (1998) 285-298.

[96] P.D. Teini , D.M.A. Karwat, and A. Atreya, "Observations of Nascent Soot: Molecular Deposition and Particle Morphology," Combustion and Flame, 158 (2011) 2045-2055.

[97] A. Faccinetto, P. Desgroux, M. Ziskind, E. Therssen, and C. Focsa, "High-Sensitivity Detection of Polycyclic Aromatic Hydrocarbons Adsorbed onto Soot Particles Using Laser Desorption/Laser Ionization/Time-of-Flight Mass Spectrometry: An Approach to Studying the Soot Inception Process in Low-Pressure Flames," Combustion and Flame, 158 (2011) 227-239.

[98] A.M. El-Leathy, F. Xu, C.H. Kim, and G.M. Faeth, "Soot Surface Growth in Laminar Hydrocarbon/Air Diffusion Flames," AIAA Journal, 41 (2003) 856-865.

[99] J. Singh, M. Balthasar, M. Kraft, and W. Wagner, "Stochastic Modeling of Soot Particle Size and Age Distributions in Laminar Premixed Flames," Proceedings of Combustion Institute, 30 (2005) 1457-1465.

[100] S.K. Friedlander, Smoke, Dust, and Haze: Fundamentals of Aerosol Dynamics, Second Edition, New York, Oxford University Press, 2000. 
[101] G. Blanquart and H. Pitsch, "Analyzing the Effects of Temperature on Soot Formation with a Joint Volume-Surface-Hydrogen Model," Combustion and Flame, 156 (2009) 1614-1626.

[102] R. Whitesides and M. Frenklach, "Detailed Kinetic Monte Carlo Simulations of GrapheneEdge Growth,” Journal of Physical Chemistry, 114 (2010) 689-703.

[103] B. S. Haynes and H.G. Wagner, "Soot Formation," Progress in Energy and Combustion Science, 7 (1981) 229-273.

[104] R.L. Vander Wal and A.J. Tomasek, "Soot Oxidation: Dependence upon Initial Nanostructure," Combustion and Flame, 134 (2003) 1-9.

[105] M. Alfè, B. Apicella, J.N. Rouzaud, A. Tregrossi, and A. Ciajolo, "The Effect of Temperature on Soot Properties in Premixed Methane Flames," Combustion and Flame, 157 (2010) 1959-1965.

[106] W. Lee and Y.D. Na, "Soot Study in Laminar Diffusion Flames at Elevated Pressure Using Two-Color Pyrometry and Abel Inversion," JSME International Journal Series B Fluids and Thermal Engineering, 43 (2000) 550-555.

[107] K.K. Kuo, Principles of Combustion, John Wiley \& Sons, Inc., Hoboken, New Jersey, 2005.

[108] S.R. Turns, An Introduction to Combustion: Concepts and Applications, McGraw-Hill, Singapore, 2000.

[109] Q. Zhang, M.J. Thomson, H. Guo, F. Liu, and G.J. Smallwood, "A Numerical Study of Soot Aggregate Formation in a Laminar Coflow Diffusion Flame," Combustion and Flame, 156 (2009) 697-705. 
[110] Q. Zhang, H. Guo, F. Liu, G.J. Smallwood, and M.J. Thomson, "Implementation of a Fixed Sectional Aerosol Dynamics Model with Soot Aggregate Formation in a Laminar Axisymmetric Coflow Methane/Air Diffusion Flame," Combustion Theory and Modeling, 12 (2008) 621-641.

[111] N.A. Slavinskaya and P. Frank, "A Modelling Study of Aromatic Soot Precursors Formation in Laminar Methane and Ethene Flames," Combustion and Flame, 156 (2009) $1705-1722$.

[112] M.E. Mueller, G. Blanquart, and H. Pitsch, "Modeling the Oxidation-Induced Fragmentation of Soot Aggregates in Laminar Flames," Proceedings of Combustion Institute, 33 (2011) 667-674.

[113] E.K.Y. Yapp, D. Chena, J. Akroyda, S. Mosbacha, M. Kraft, J. Camachoc, and H. Wang, "Numerical Simulation and Parametric Sensitivity Study of Particle Size Distributions in a Burner-Stabilised Stagnation Flame,” Combustion and Flame, 162 (2015) 2569-2581.

[114] J. Singh, R.I.A. Patterson, M. Kraft, and H. Wang, "Numerical Simulation and Sensitivity Analysis of Detailed Soot Particle Size Distribution in Laminar Premixed Ethylene Flames," Combustion and Flame, 145 (2006) 117-127.

[115] N.A. Slavinskaya, U. Riedel, S.B. Dworkin, and M.J. Thomson, "Detailed Numerical Modeling of PAH Formation and Growth in Non-Premixed Ethylene and Ethane Flames," Combustion and Flame, 159 (2012) 979-995.

[116] M. Alfe, B. Apicella, R. Barbella, J. Rouzaud, A. Tregrossi, and A. Ciajolo, "StructureProperty Relationship in Nanostructures of Young and Mature Soot in Premixed Flames," Proceedings of Combustion Institute, 32 (2009) 697-704.

[117] A. Khosousi and S.B. Dworkin, "Detailed Modelling of Soot Oxidation by $\mathrm{O}_{2}$ and $\mathrm{OH}$ in Laminar Diffusion Flames," Proceedings of Combustion Institute, 35 (2015) 1903-1910. 
[118] J.A. Cooke, One- Two-Dimensional Simulations of Diffusion Flames Using Complex Fuels and Distributed-Memory Computing Clusters, Ph.D. Thesis, Yale University, New Haven, CT, 2006. 